The impact of antibiotic exposure on the human microbiome and resistome: from laboratory to clinical studies

Kjersti Sturød

Oslo 2021

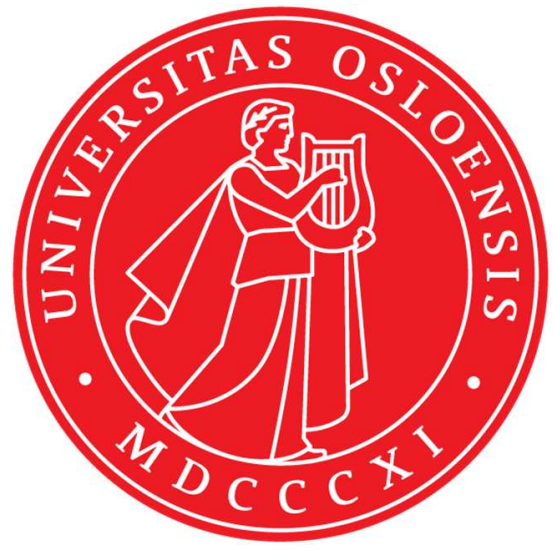

Ph.D. thesis

Institute of Oral Biology

Faculty of Dentistry

University of Oslo

Norway 
(C) Kjersti Sturød, 2021

Series of dissertations submitted to the

Faculty of Dentistry, University of Oslo

ISBN 978-82-8327-055-6

All rights reserved. No part of this publication may be

reproduced or transmitted, in any form or by any means, without permission.

Cover: Hanne Baadsgaard Utigard.

Print production: Reprosentralen, University of Oslo. 


\section{Table of Contents}

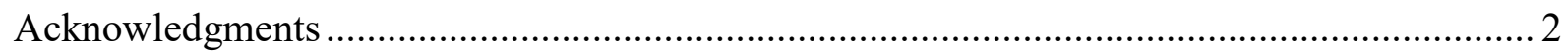

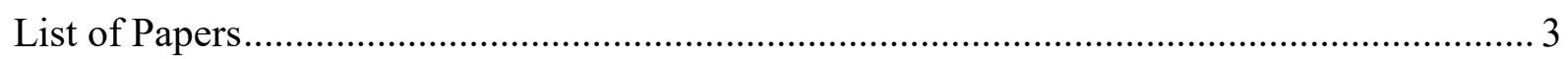

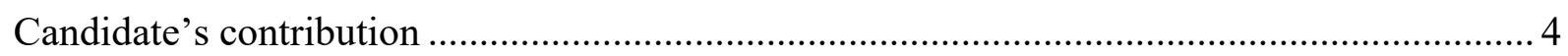

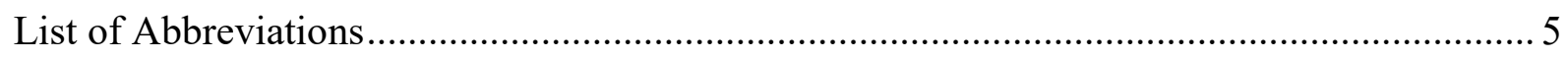

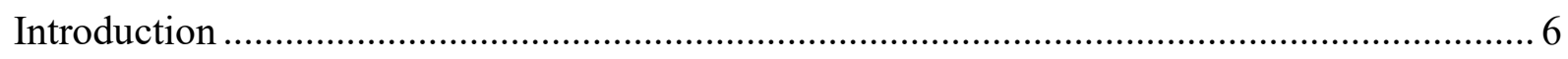

1. General Introduction to Antibiotics and Antimicrobial Resistance (AMR) ............................. 6

1.1 Historical Insight to Antibiotics and Antimicrobial Resistance ......................................... 6

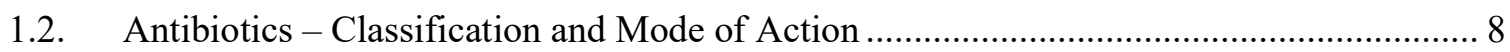

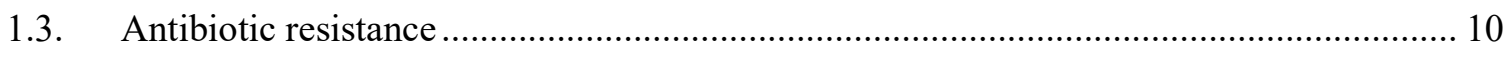

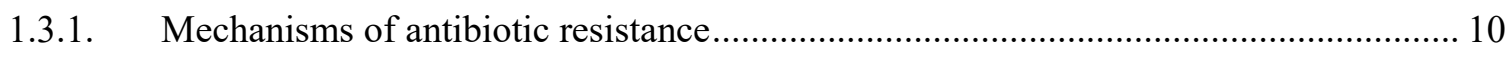

1.3.2. Emergence and Spread of Antimicrobial Resistance.................................................... 11

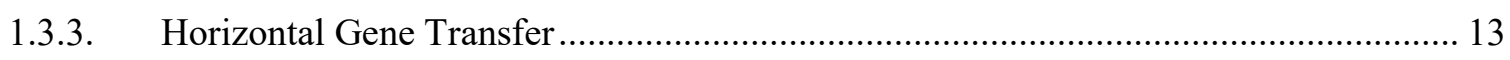

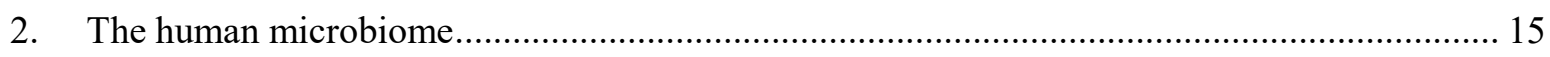

$2.1 \quad$ Development of microbiome in young children ......................................................... 15

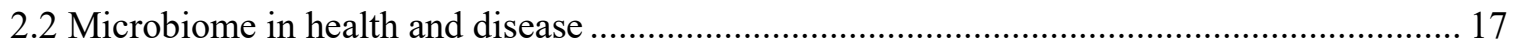

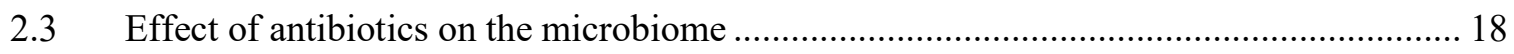

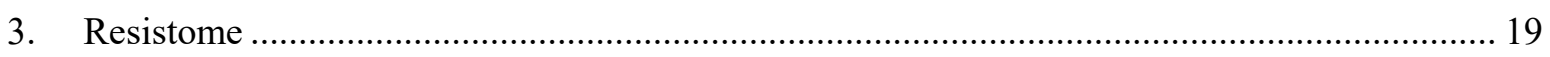

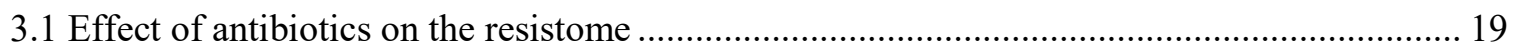

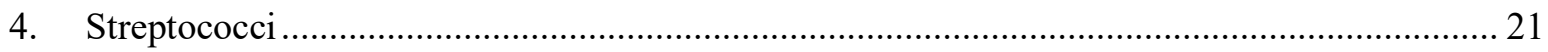

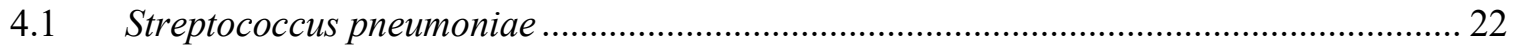

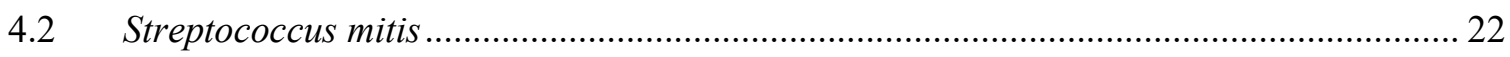

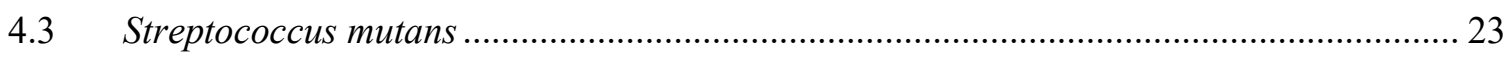

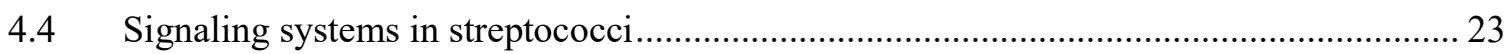

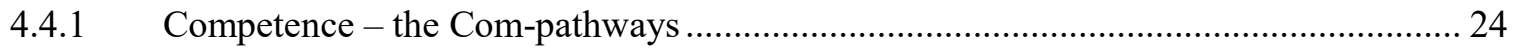

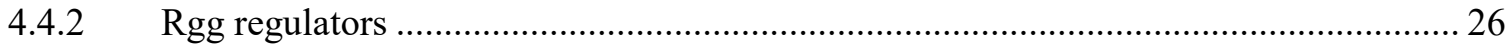

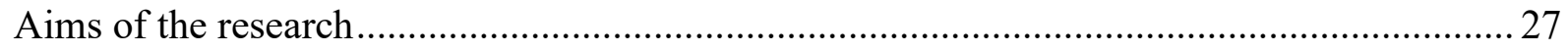

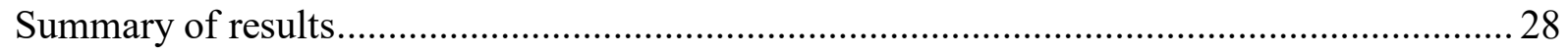

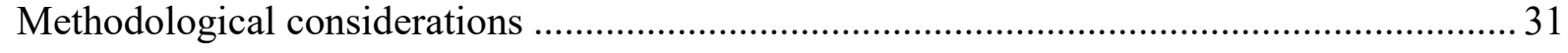

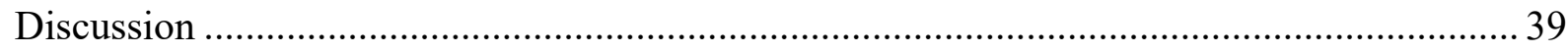

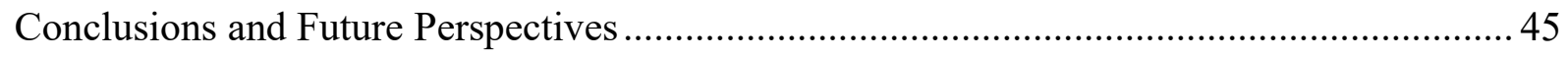

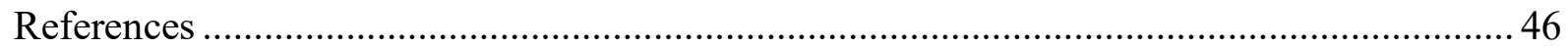





\section{Acknowledgments}

The work of this thesis was conducted at the Institute of Oral Biology, Faculty of Dentistry at the University of Oslo from 2014 to 2020 . I would like to express my gratitude to the faculty for the financial support and to the institute for giving me the opportunity to carry out my $\mathrm{PhD}$.

To my supervisor, Prof. Fernanda C. Petersen, thank you for your enthusiasm and guidance throughout this project. Thank you for sharing your knowledge and experience in the field of research, and for having such a positive attitude. I am also very grateful to my co-supervisors Ulf R. Dahle and Didrik F. Vestrheim for their feedback and valuable contributions in this project. Also, thanks to all other co-authors and collaborators for making this possible.

Special thanks to all past and present members of Prof. Petersen's research group and the former crosstalk-group. Gabriela, my fantastic office-mate for six years, thank you for sharing your knowledge and kindness. Roger, thank you for always offering your help, and for lifting the mood with your "funny" memes. Achal, thank you for a great collaboration in our metagenomic projects. Heidi, thank you for everything you do in the lab, and for all the help you have given me these years.

I am also grateful to my colleagues at IOB for scientific, and sometimes more importantly, non-scientific discussions and laughs in the hallway, at lunch, or during morning coffee. To Maren and Gro, thank you for sharing ups and downs, and just for being there!

To my friends and family (Sturøds and Holdens), thank you for your encouragement and support throughout this period. Nils (born 2016) and Sunniva (born 2019), thank you for resetting my brain every day, for all your smiles and laughter, and for putting things in perspective. Finally, and most importantly, thank you Trygve. Thank you for your love and motivation and for never giving up in trying to understand what I have been working on the last six years. 


\section{List of Papers}

I. Sturød K, Salvadori G, Junges R, Petersen FC. Antibiotics alter the window of competence for natural transformation in streptococci.

Molecular Oral Microbiology. 2018;33(5):378-387

II. Junges R, Sturød K, Salvadori G, Åmdal HA, Chen T, Petersen FC.

Characterization of a signaling system in Streptococcus mitis that mediates interspecies communication with Streptococcus pneumoniae.

Applied and Environmental Microbiology. 2019;85(2):e02297-18

III. Sturød K, Dhariwal A, Dahle UR, Vestrheim DF, Petersen FC. Impact of narrow-spectrum penicillin $\mathrm{V}$ on the oral and fecal resistome in a young child treated for otitis media.

Journal of Global Antimicrobial Resistance. 2020;20:290-297.

IV. Sturød K, Dhariwal A, Bråten LCH, Berild D, Storheim K, Zwart JA, Petersen FC. Long-term treatment with amoxicillin - impact on the oral microbiome and resistome.

In manuscript. 


\section{Candidate's contribution}

\section{Paper I}

$>$ Contributed in study design, methodology, carried out experiments, analyzed data and wrote the manuscript with input from all authors.

\section{Paper II}

Contributed in methodology, experiments and analysis concerning antibiotic exposure. In addition, discussed the results with co-authors and contributed in drafting and commenting on the final manuscript.

\section{Paper III}

Contributed in study design, methodology, applying for ethical approval, sample preparation, interpretation of the results and wrote the manuscript with input from all authors.

\section{Paper IV}

Contributed in study design, methodology, sample preparation, interpretation of the results and wrote the manuscript with input from all authors. 


\section{List of Abbreviations}

$\begin{array}{ll}\text { AMR } & \text { Antimicrobial resistance } \\ \text { ARG } & \text { Antimicrobial resistance gene } \\ \text { Com } & \text { Competence } \\ \text { CSP } & \text { Competence stimulating peptide } \\ \text { DNA } & \text { Deoxyribonucleic acid } \\ \text { ESBL } & \text { Extended spectrum beta-lactamase } \\ \text { GAS } & \text { Group A Streptococcus } \\ \text { GBS } & \text { Group B Streptococcus } \\ \text { HGT } & \text { Horizontal gene transfer } \\ \text { HMP } & \text { Human microbiome project } \\ \text { IACG } & \text { Interagency Coordination Group } \\ \text { IBD } & \text { Inflammatory bowel disease } \\ \text { ICE } & \text { Integrative and conjugative elements } \\ \text { MIC } & \text { Minimum inhibitory concentration } \\ \text { MLS } & \text { Macrolide, lincosamide and streptogramin } \\ \text { MRSA } & \text { Methicillin-resistant Staphylococcus aureus } \\ \text { NGS } & \text { Next generation sequencing } \\ \text { PCR } & \text { Polymerase chain reaction } \\ \text { QS } & \text { Quorum sensing } \\ \text { Rgg } & \text { Regulator gene of glucosyltransferase (and proteins in the same family) } \\ \text { RNA } & \text { Ribonucleic acid } \\ \text { SHP } & \text { Short hydrophobic peptide } \\ \text { SigX } & \text { Alternative sigma factor } \\ \text { TSB } & \text { Tryptic Soya Broth } \\ \text { WHO } & \text { World Health Organization } \\ \text { XIP } & \text { igXing peptide } \\ & \end{array}$




\section{Introduction}

\section{General Introduction to Antibiotics and Antimicrobial Resistance (AMR)}

1.1 Historical Insight to Antibiotics and Antimicrobial Resistance

In 1677, Antoni von Leeuwenhoek discovered some tiny organisms in his self-constructed microscope. He called them "animalcules", and this was probably the very first observation of bacteria ${ }^{1}$. At this point, there was no known connection between the observed animalcules and disease. About 200 years later, the theory of microorganisms causing disease, "The Germ Theory" gained increasing acceptance in the scientific community, much thanks to research by the famous scientists Robert Koch, Ignaz Semmelweis and Louis Pasteur ${ }^{2-5}$. Their work and the germ theory opened up for new important research questions. As the origin of some diseases now were known, would it be possible to discover a cure?

In the search to find a substance or a remedy that could treat specific infection-causing agents in the early 20th century, scientists had different approaches. The German physician Paul Ehrlich had a systematic approach where he screened several hundred compounds in his search for a curative agent. In 1909, compound number 606 (arsphenamine) was found successful in targeting Treponema pallidum, which causes syphilis ${ }^{6}$. Soon after the discovery, the drug was out on the marked under the name Salvarsan ${ }^{7}$. The same systematic approach also led the German pathologist Gerhard Domagk to the discovery of the first sulfa drug in $1932^{8}$. Other scientists, like the British physician and researcher Alexander Fleming, did a more accidentally discovery. In 1928, after returning from a summer vacation in Scotland to St. Mary's Hospital in London, Fleming realized that he had forgotten to put one of his petridishes with Staphylococcus aureus culture in the incubator before he left. On this petri-dish, a moldy colony had contaminated the bacterial culture while he was gone. When he examined the plate more closely, he observed a bacteria-free zone around the mold ${ }^{9}$. The mold was later isolated in pure culture by Fleming, and eventually identified as Penicillium notatum by the American microbiologist Charles Thom ${ }^{10}$. By the help of several other scientists, including Howard Florey and Ernst Boris Chain, penicillin evolved from a moldy agar plate in 1928 to a lifesaving drug during the beginning of the $1940 \mathrm{~s}^{11-13}$.

The discovery of penicillin by Fleming, together with the synthesis of sulfonamides in the 1930s, marked the beginning of the antibiotic era. In the following three decades, the 
discovery and synthesis of several other antibiotic classes and drugs contributed to a revolution within modern medicine. This period is often referred to as the golden era of antibiotic discovery. Since then, there has been a discovery void and only a few new compounds have been approved for clinical use after this golden era ${ }^{14}$.

For every new antibiotic discovery there has been a grey cloud hanging over it, namely the observation that soon after introduction of a new antibiotic agent, resistant bacteria have appeared ${ }^{15}$. In 1948, three years after penicillin hit the marked, resistant penicillinase producing staphylococci became a considerable problem ${ }^{16}$. To combat penicillinaseproducing bacteria, methicillin was introduced in 1959. However, less than two years later, the first reports of methicillin resistant $S$. aureus (MRSA) were published ${ }^{17,18}$. This pattern, with resistance rapidly following the introduction of new drugs, was unfortunately also the case for most other antibiotic agents introduced into the market. Interestingly, already in 1945, Fleming warned about how penicillin could change the nature of the microbe if not used correctly. In his Nobel Prize Lecture he stated: "It is not difficult to make microbes resistant to penicillin in the laboratory by exposing them to concentrations not sufficient to kill them, and the same thing has occasionally happened in the body" ${ }^{19}$.

Today, 75 years and many new discoveries later, convincing scientific evidence shows that the extensive use of antibiotics in the last century have accelerated the evolution of resistant bacteria, leaving us soon without effective treatment options towards bacterial infections ${ }^{20}$. Recent reports from the World Health Organization (WHO) and the United Nations Interagency Coordination Group (IACG) have stated that a post-antibiotic-era is a real possibility for the twenty-first century, and that there is no time to wait; "unless the world acts urgently, antimicrobial resistance will have disastrous impact within a generation." 21,22 . 


\subsection{Antibiotics - Classification and Mode of Action}

Antibiotics are defined as drugs that kill or inhibit growth of bacteria. Prior to human intervention, microorganisms have produced antibiotic molecules for millions of years ${ }^{23}$, though in concentrations much lower than those used in antibiotic therapy. The low concentrations have led to a debate about the primary function of these molecules, as it may be too low to kill competitors. Interestingly, it has been suggested that natural antibiotic molecules may function as signal molecules, having an effect on bacterial physiology ${ }^{24-27}$. Most antibiotic drugs used today are natural compounds or derivatives of compounds produced by microorganisms. Only a few antibiotic classes are completely synthetic (e.g. trimethoprim, sulfonamides and quinolones) ${ }^{28}$.

\subsubsection{Classification and Mode of Action}

Different antibiotic classes are separated by their molecular structure, and most classes contain several compounds including similar or modified versions of the initial type. Further, antibiotic drugs can be classified using several different approaches ${ }^{28}$.

Commonly, antibiotics are classified according to the range of species/groups of bacteria it affects. Narrow-spectrum antibiotics have a limited spectrum of activity that affects a specific subset of bacterial species, such as Gram-positive or Gram-negative bacteria. Broad-spectrum antibiotics have a wider range of activity, affecting both Gram-positive and Gram-negative bacteria. However, among narrow-spectrum antibiotics, some are narrower than others and among broad-spectrum antibiotics some are broader than others. Despite the common use of the terms "narrow" and "broad" spectrum activity, there is no international consensus on the definition of the two categories, and the terms are often presented differently in the literature 29-31.

A second mode of classification is based on the effect of the antibiotic drugs on the bacteria, either bacteriostatic or bactericidal. A bacteriostatic antibiotic inhibits growth while a bactericidal antibiotic aims to kill the bacteria. Notably, the definition is slightly vague as many antibiotic agents may potentially act both bactericidal and bacteriostatic depending on growth conditions and antibiotic concentrations ${ }^{32}$. 
A third way of categorizing antibiotic drugs is by their target site ${ }^{33}$. A successful antibiotic agent targets bacteria-specific structures without being toxic to the individual receiving the treatment ${ }^{34}$. The number of different antibiotic agents on the market is large, however, the number of antibiotic targets in the bacteria is limited, with three major target sites used by most of the successful antibiotic agents ${ }^{33}$. The three most used targets for antibiotic agents are the cell wall ${ }^{35}$ (e.g. beta-lactams, glycopeptides), the protein synthesis apparatus ${ }^{36}$ (e.g. aminoglycosides, macrolides and tetracycline) and the nucleic acid metabolism and repair system ${ }^{37}$ (e.g. quinolones). In addition to these three groups, there are also antibiotic agents that affect membrane integrity ${ }^{38,39}$ (polymoxins, daptomycin), and folic acid metabolism (trimethoprim, sulfonamides) ${ }^{40}$.

Antibiotic agents used in Paper I - Paper IV of this thesis are described in more detail in table $1^{28}$.

Table 1: Classifications and mechanisms of antibiotic agents included in this thesis

\begin{tabular}{|c|c|c|c|c|c|}
\hline Paper & Antibiotic & Class & Origin & Mode of action & Spectrum \\
\hline Paper I & Novobiocin & Aminocoumarin & $\begin{array}{l}\text { Natural } \\
\text { compound }\end{array}$ & $\begin{array}{l}\text { Inhibition ATP hydrolysis } \\
\text { and DNA supercoiling } \\
\text { activity (GyrB) }\end{array}$ & $\begin{array}{l}\text { Broad } \\
\text { Spectrum }\end{array}$ \\
\hline Paper I & Streptomycin & Aminoglycoside & $\begin{array}{l}\text { Natural } \\
\text { compound }\end{array}$ & $\begin{array}{l}\text { Inhibition of protein } \\
\text { synthesis by binding of } 30 \mathrm{~S} \\
\text { ribosomal unit. }\end{array}$ & $\begin{array}{l}\text { Broad } \\
\text { Spectrum }\end{array}$ \\
\hline Paper I & Tetracycline & Tetracycline & $\begin{array}{l}\text { Natural } \\
\text { compound }\end{array}$ & $\begin{array}{l}\text { Inhibition of protein } \\
\text { synthesis by binding of } 30 \mathrm{~S} \\
\text { ribosomal unit. }\end{array}$ & $\begin{array}{l}\text { Broad } \\
\text { Spectrum }\end{array}$ \\
\hline Paper I \& II & Ampicillin & $\begin{array}{l}\text { Beta-lactams } \\
\text { (Aminopenicillin) }\end{array}$ & $\begin{array}{l}\text { Semi-synthetic } \\
\text { derivative of } \\
\text { penicillin }\end{array}$ & $\begin{array}{l}\text { Inhibition of cell wall } \\
\text { biosynthesis }\end{array}$ & $\begin{array}{l}\text { Broad } \\
\text { Spectrum }\end{array}$ \\
\hline Paper I \& II & Ciprofloxacin & $\begin{array}{l}\text { Quinolone } \\
\text { (2nd generation) }\end{array}$ & Synthetic & $\begin{array}{l}\text { Interference with DNA } \\
\text { replication and } \\
\text { transcription (GyrA) }\end{array}$ & $\begin{array}{l}\text { Broad } \\
\text { Spectrum }\end{array}$ \\
\hline Paper I \& II & Erythromycin & Macrolide & $\begin{array}{l}\text { Natural } \\
\text { compound }\end{array}$ & $\begin{array}{l}\text { Inhibition of protein } \\
\text { synthesis by binding of } 50 \mathrm{~S} \\
\text { ribosomal unit. }\end{array}$ & $\begin{array}{l}\text { Narrow } \\
\text { Spectrum }\end{array}$ \\
\hline Paper II & Nisin & $\begin{array}{l}\text { Lantibiotic } \\
\text { (bacteriocin) }\end{array}$ & $\begin{array}{l}\text { Natural } \\
\text { compound }\end{array}$ & $\begin{array}{l}\text { Disruption of membrane } \\
\text { function by pore formation }\end{array}$ & $\begin{array}{l}\text { Narrow } \\
\text { Spectrum }\end{array}$ \\
\hline Paper III & Amoxicillin & $\begin{array}{l}\text { Beta-lactams } \\
\text { (Aminopenicillin) }\end{array}$ & $\begin{array}{l}\text { Semi-synthetic } \\
\text { derivative of } \\
\text { penicillin }\end{array}$ & $\begin{array}{l}\text { Inhibition of cell wall } \\
\text { biosynthesis }\end{array}$ & $\begin{array}{l}\text { Broad } \\
\text { Spectrum }\end{array}$ \\
\hline Paper IV & Penicillin V & $\begin{array}{l}\text { Beta-lactams } \\
\text { (Natural } \\
\text { Penicillin) }\end{array}$ & $\begin{array}{l}\text { Natural } \\
\text { compound }\end{array}$ & $\begin{array}{l}\text { Inhibition of cell wall } \\
\text { biosynthesis }\end{array}$ & $\begin{array}{l}\text { Narrow } \\
\text { Spectrum }\end{array}$ \\
\hline
\end{tabular}




\subsection{Antibiotic resistance}

Antibiotic resistance is defined as the survival of bacteria when exposed to antibiotic concentrations that would normally stop their growth or kill them. Similarly to antibiotic molecules, antibiotic resistance genes (ARGs) can be found in natural environments free from human intervention ${ }^{41}$. In fact, scientists have identified several ARGs from 30000 year old Beringial permafrost sediments, showing that this is a natural and ancient phenomenon ${ }^{42}$. However, the situation we are in today, with resistant bacteria leading to treatment failure, is not a natural phenomenon, but a consequence of overuse of antibiotics for a long time ${ }^{20}$. Now, the United Nations, including the WHO, states that antibiotic resistance is one of the biggest threats to global health, food security, and development today ${ }^{21,43}$.

\subsubsection{Mechanisms of antibiotic resistance}

Bacteria evolve and survive by developing strategies of resistance to avoid being killed by antimicrobial molecules. The most common strategies fall into three main categories depending on their mechanistic action, (I) - enzymatic breakdown or modifications of the antibiotic molecule, (II) - changing or protecting the target site or (III) - keeping the drug away by efflux mechanisms (extrusion) or preventing penetration into the bacteria (Figure 1)

${ }^{44}$. Resistance towards one antimicrobial class can be achieved through various strategies ${ }^{45}$, and one bacterial cell may be able to use several mechanisms to survive attacks from antibiotics ${ }^{46}$. Some mechanisms, e.g. multi-drug-efflux pumps, may affect many different classes of antibiotics ${ }^{47}$, while mechanisms such as antibiotic inactivation usually are specific to one, or a similar group of antibiotic classes ${ }^{44,48}$. 


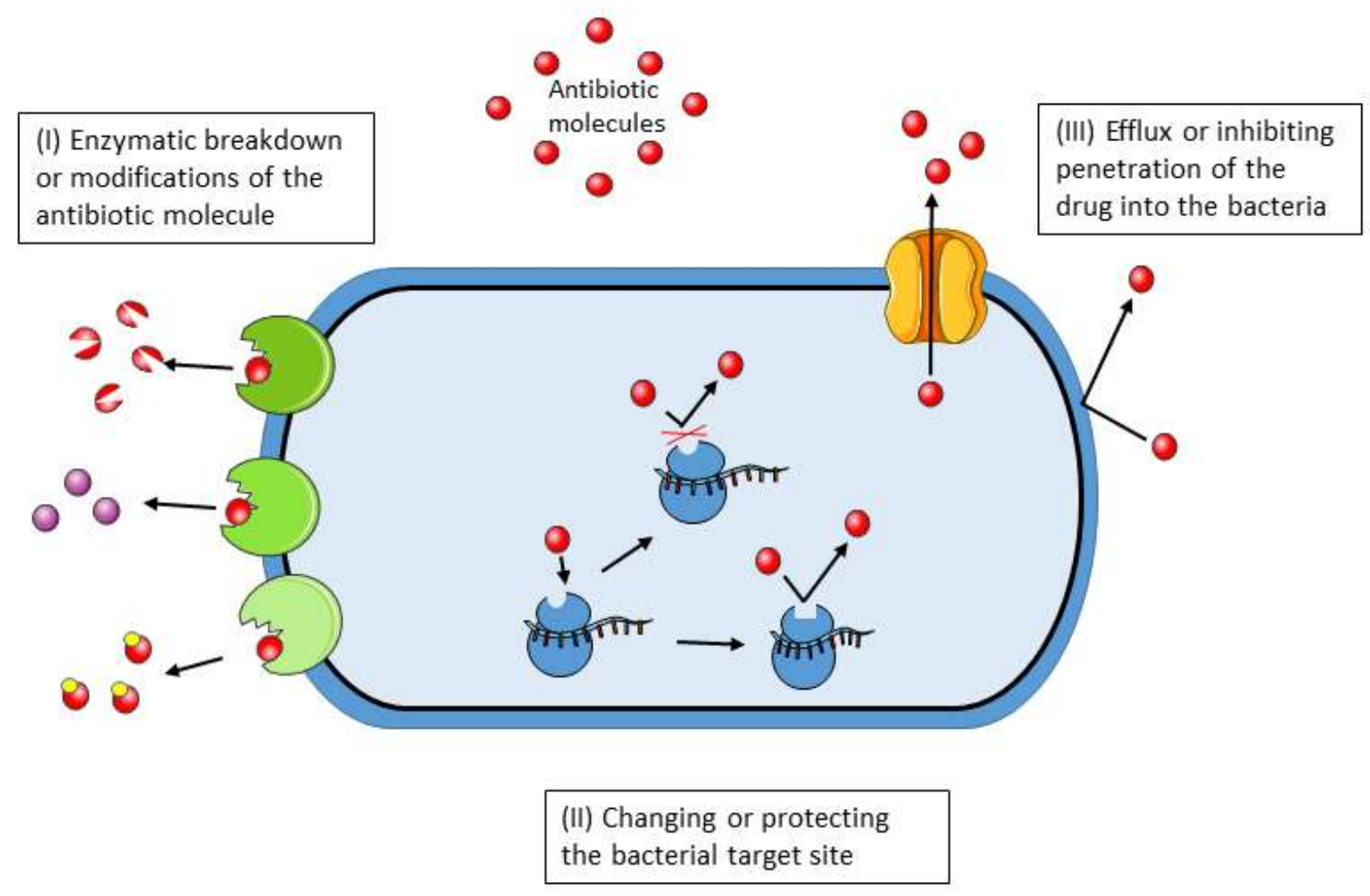

Figure 1: Antibiotic resistance strategies in bacteria.

\subsubsection{Emergence and Spread of Antimicrobial Resistance}

The accelerating emergence of antibiotic resistance observed over the last decades is an example of a Darwinian selection process, complicated by several interlinking drivers of resistance (Figure 2) ${ }^{49}$. The main driver of resistance is use of antibiotic drugs, which directly or indirectly exposes bacteria to inhibitory and subinhibitory concentrations of antibiotics ${ }^{50-}$ 54 . This exposure leads to high selection pressure, which contributes in accelerating the emergence of resistant bacteria ${ }^{20}$. Antibiotic selection pressure occurs everywhere antibiotics are present, including in humans, animals, plants, and in the environment. This has led to the development of a One Health approach in tackling the challenge of antibiotic resistance.

Bacteria can develop resistance to antibiotics in two main ways. Either by mutating existing genes or by acquiring external genetic material via horizontal gene transfer (HGT) ${ }^{49}$. Spontaneous mutations occur as a random process during DNA replication. The short generation time enables bacteria to evolve rapidly to changes in the environment such as 
antibiotic selection pressure. Mutations leading to antibiotic resistance can include mutations affecting a gene product, such as a target site protein, or it can include changes in regulation of gene expression, leading to over- or under expression of a gene ${ }^{55}$. Recently, epigenetic modifications in relation to antibiotic stress have gained increased attention, suggesting that epigenetic mechanisms may increase mutation rate and contribute in resistance development 56,57 . The ability of taking up external genetic elements by HGT is the second way bacteria acquire resistance ${ }^{58}$. Transfer of genes between bacteria contributes greatly to the challenge of antibiotic resistance we experience today ${ }^{59,60}$. The mechanisms of HGT will be described in more detail in the following section.

In addition to spread of ARGs between bacteria, the resistant bacteria itself can spread in the environment with food ${ }^{61}$ and water ${ }^{62}$, between humans and animals ${ }^{63}$, among healthcare institutions and the community ${ }^{64}$, and they can spread all over the world through travel ${ }^{65}$. All these factors contribute to the current situation with increased prevalence of resistance worldwide and make it difficult to get under control.

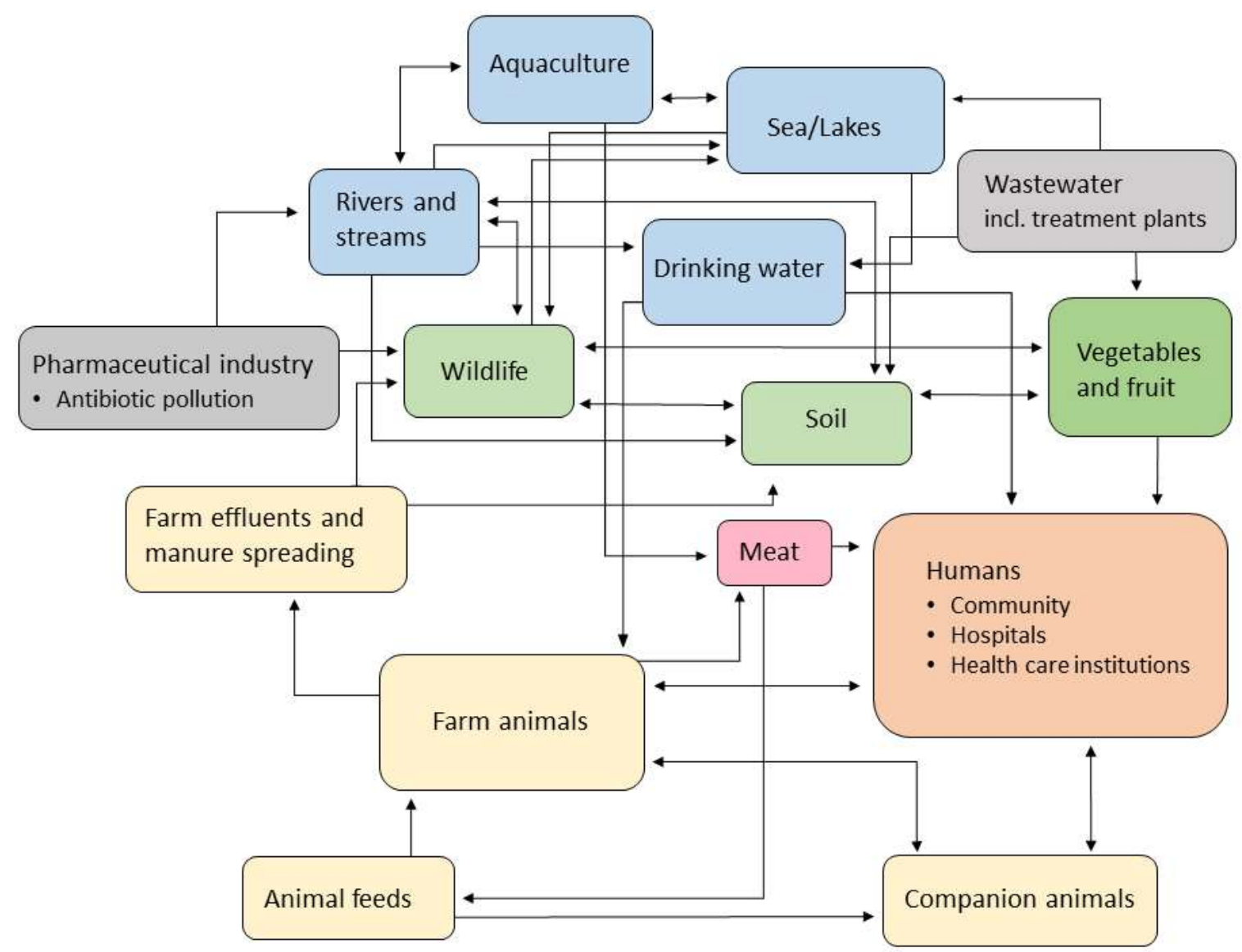

Figure 2: Interlinking network of ARG spread. The figure is based on Davies and Davies, $2010^{20}$. 


\subsubsection{Horizontal Gene Transfer}

In contrast to vertical transmission, which happens from parent to offspring, HGT is the exchange of genetic material between organisms of the same or different species ${ }^{66}$, and even between kingdoms (bacteria to yeast or plants) ${ }^{67,68}$.

In prokaryotes, HGT is involved in acquisition of new genes and functions, such as virulence genes and antibiotic resistance genes. The recent development of sequence-based genomics has highlighted the tremendous impact HGT has on genome evolution in bacteria ${ }^{69,70}$. There are three main mechanisms of genetic exchange between bacteria: Conjugation, Transduction and Transformation (Figure 3).

Conjugation is a mechanism that depends on direct contact between bacterial cells. A pilus, or a hollow tube, is formed between the two cells and provides a channel for DNA to move from the donor cell to the recipient, as described already in 1946 by Lederberg \& Tatum ${ }^{71}$. Mobile genetic elements such as plasmids and integrative and conjugative elements (ICEs) are transferred using conjugation and are also mediators of the process itself ${ }^{72,73}$.

Transduction is the transfer of DNA from one cell to another by bacteriophages ${ }^{74}$.

Bacteriophages are viruses that incorporate genes from bacteria into its own genome. Further, injecting their genomes into another bacteria where it can either exploit the cell machinery for replication followed by cell lysis (lytic life circle), or integrate into the bacterial genome and replicate as part of the host chromosome (lysogenic life cycle) ${ }^{75}$.

Transformation involves active uptake of free DNA from the bacteria's surroundings and incorporation of that DNA into its own genome. For transformation to occur, bacteria need to be in a competent state, and it requires a set of proteins for DNA uptake and the subsequent homologous recombination. The transformation machinery and its regulation varies between different bacterial genera and species. One of the most studied genera regarding natural transformation is the genus Streptococcus. Natural transformation is recognized as a major driver in streptococcal evolution. The mechanisms and regulation of streptococcal transformation are further discussed in section 4.4.1. 

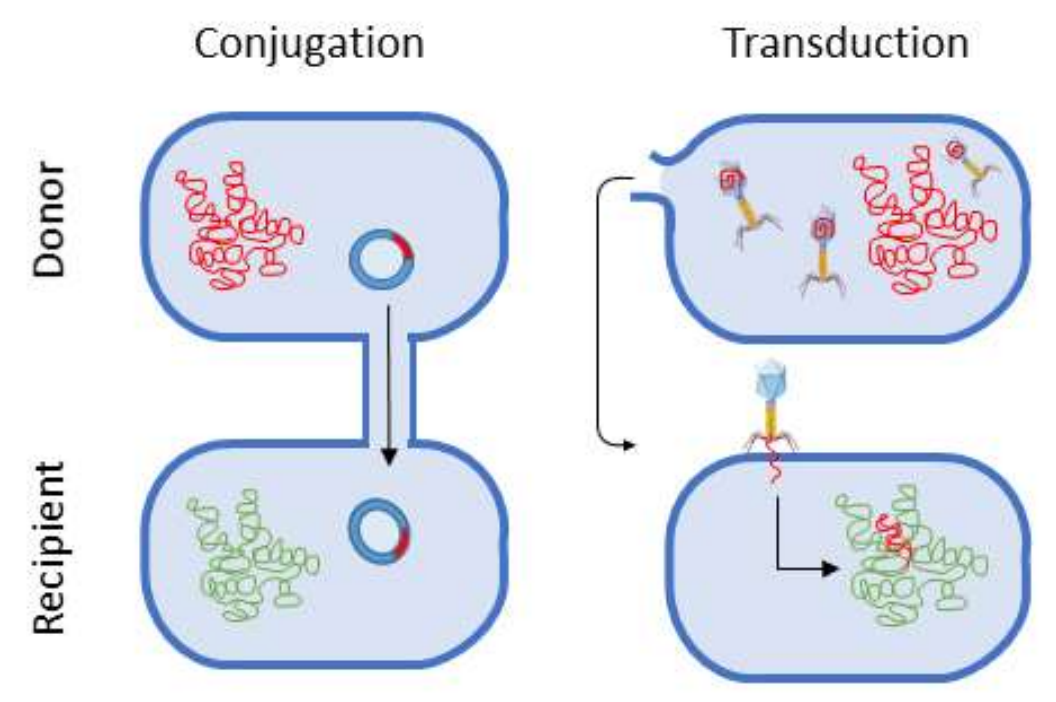

\section{Transformation}

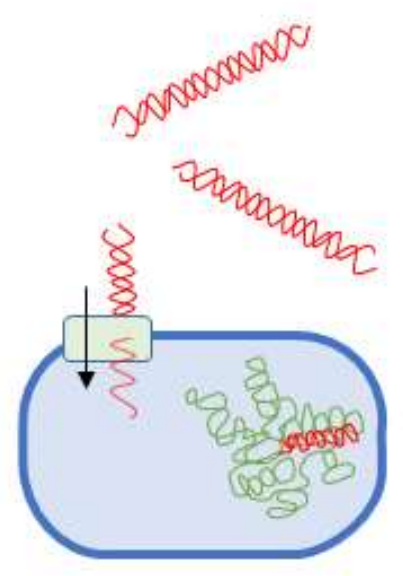

Figure 3: Transmission of DNA between bacteria via HGT. 


\section{The human microbiome}

The human body is home to more than just human cells. Microorganisms are found in and on our bodies in vast amounts ${ }^{76}$. They inhabit the skin, mouth, nose, respiratory tract, genital tract and gastrointestinal tract, where they form site-specific eco-systems ${ }^{77}$ and contribute in a range of important functions, including metabolism ${ }^{78}$, nutrition ${ }^{79}$, endocrine functions ${ }^{80}$, protection against pathogenic overgrowth ${ }^{81}$ and development and maturation of the host's immune system ${ }^{82}$. The collection of all microorganisms in our bodies is known as the human microbiome, and the microbial genes in our microbiome outnumber the genes in our human genome by about 100 to one ${ }^{83}$. The human microbiome consists of mostly bacteria, but also includes viruses, archaea and eukaryote organisms.

The terminology in this field can be confusing as there are different definitions for the term "microbiome". Some authors refer to the microbiome as the genetic content of the microorganisms in an environment, while others refer to the microbiome as the entire habitat of a niche, including the microorganisms and their genomes, and even the environmental conditions ${ }^{84}$. In this thesis, the term "microbiome" refers to the entire microbial habitat, including both the microorganisms and their genomes.

The last decades, advances in next generation sequencing technology has led to an enormous interest and research activity on the composition and functions of the microbiome. One of the first large-scale research initiatives within this field was the Human Microbiome Project (HMP), launched in 2007 and funded by the US National Institutes of Health ${ }^{85}$. The project sampled microbes from multiple sites from the mouth, nose, skin, colon and vagina. They included 300 healthy individuals, collected over 11000 samples in total, and contributed to a better understanding of the complexity of the microbial communities living in our bodies ${ }^{86}$.

\subsection{Development of microbiome in young children}

The composition of the human microbiome is influenced by the way we are born, where we are born, whom we live with, what we eat and medications we take, among several other variables ${ }^{87}$. The first major encounter a baby has with the microbial world is during birth. Depending on the mode of birth, vaginal or by cesarean section, the baby is covered with bacteria from its mother's vaginal tract (+ intestinal tract) and/or skin. This initial colonization 
will affect the pattern of further colonization and microbial development, which may have lifetime implications ${ }^{88}$. Other important factors for the development of the infant microbiome are diet (breast-feeding vs formula feeding) ${ }^{89}$, host genetics ${ }^{90}$, environment (siblings, pets), rural vs urban living, hospitalization and infrastructure ${ }^{91-93}$ and antibiotic consumption (Figure 4) ${ }^{94}$. Development and maturation of the microbiome differs between different body habitats. In the gut, there is a major shift in the microbial community around the time when solid food replaces breastmilk. From there, the gut microbiome will become more diverse until it stabilizes around 3 years of age ${ }^{95}$. By contrast, the composition of the skin microbiome is restructured during puberty due to increased levels of hormones stimulating the sebaceous glands ${ }^{96}$. In the mouth, there are constant changes due to tooth development in young children, and as recently reported, the oral microbiome is still distinct from that of their caregivers at 4 years old ${ }^{97}$.

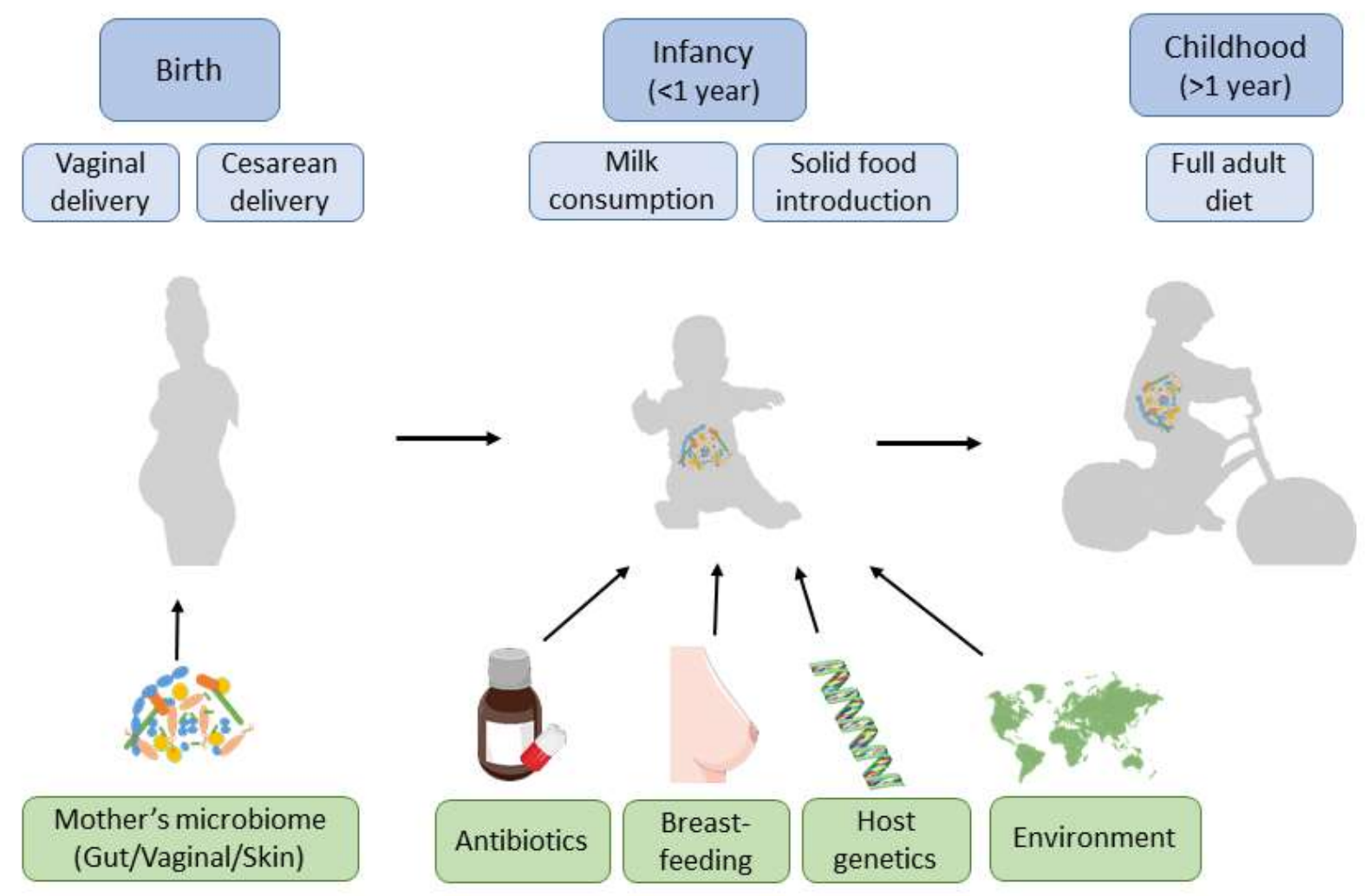

Figure 4: Microbiome development. Figure is based on Tamburini et al., 2016, Nature Medicine ${ }^{87}$. 
As mentioned in the first section, the understanding of microbes and their role in disease was recognized by famous scientists like Pasteur and Koch in the mid- $19^{\text {th }}$ century. Individual bacterial species were cultivated, isolated and then identified as causative agents of specific diseases. Later, scientists observed bacteria living in complex communities in the environment and in our bodies. Interestingly, most of these bacteria did not cause disease and were living in symbiosis with the host and are now known as commensals. Microbes within these communities interact with other microbes and their host, and this interplay has gained increased interest in the recent years ${ }^{98}$. Particularly, culture-independent 'omic'-technologies, (genomics, transcriptomics, proteomics and metabolomics) have emphasized the role of the microbiome in human health and disease ${ }^{99}$. An imbalance of the microbiome is often referred to as a dysbiosis and it has been associated with several conditions and diseases. Conditions such as inflammatory bowel disease (IBD), obesity, type 2 diabetes and colon cancer have been associated with an unhealthy gut microbiome ${ }^{100}$. Interestingly, several conditions not typically linked with the gastrointestinal-tract, such as autism and Alzheimer disease, have also been associated with the composition and functions of the intestinal microbiome ${ }^{101}$. In the mouth, the composition of the oral microbiome has been linked to diseases such as caries and periodontitis for a long time ${ }^{102}$. Further, there is also increasing evidence that systemic diseases such as vascular disease and stroke can be associated with oral dysbiosis ${ }^{103,104}$. Importantly, the mechanisms behind many microbiome-disease associations are not fully understood. The interpretation of associations between microbes and disease are challenging due to the multifactorial nature of most conditions, in addition to the individuality of the microbiome. However, the vast amount of research conducted in this field in the last decades, and the diverse functional repertoire of the microbiome, leave little doubt that there is an important connection between the human microbiome and our state of health. 
2.3 Effect of antibiotics on the microbiome

Antibiotic therapy does not only target the infective bacteria but also affects the millions of microbes in the human body. This collateral effect will have at least two main consequences; alterations in the composition of the bacterial taxonomic profile and the emergence of antibiotic resistance ${ }^{105}$. Mechanisms and examples of antibiotic effects on emergence of resistance are presented later in section 3.2. Depending on the infectious agent and the anatomic location of the infection, factors such as antimicrobial spectrum, route of administration, absorption, elimination, dose and duration of treatment are of importance when choosing the most appropriate antibiotic agent for treatment. Importantly, these factors influence the drug concentrations at both target- and off-target-sites in the body, and consequently affect the antibiotic impact on the microbiome ${ }^{106-108}$.

In 2015, Zaura et al. published a paper showing that different antibiotics affected the same ecological niche differently, and that different niches could have radically different responses to the same antibiotic agent. Treatment with clindamycin and ciprofloxacin reduced the diversity of the gut microbiome up to 4 and 12 months, respectively, while amoxicillin had no significant effect on microbiome diversity. Further, the authors reported that the salivary microbiome was far less affected by exposure to antibiotics than the fecal microbiome, irrespectively of the antibiotic used ${ }^{109}$.

Healthy adults have a relatively stable microbiome ${ }^{77}$. In general, exposure to antibiotics will have a temporary effect on the microbiome. However, some studies show long lasting effects that persist for years ${ }^{110}$. During and soon after antibiotic exposure ecological disturbances such as reduced bacterial diversity and altered microbial composition are often observed. This leads to increased risk of overgrowth of pathogens, such as Clostridium difficile in the gut, or yeast infections in the genital tract ${ }^{111,112}$. Additionally, antibiotic exposure results in changes in the functionality of the microbiome. As described in section 2.2., the microbiome has an array of important functions, which might be disturbed by antibiotic treatment ${ }^{113}$. In young children, with an immature microbiome, the consequences of antibiotic exposure are hypothesized to be of greater extent than in adults, and it is suggested that extensive use of antibiotics in a young age may be associated with conditions such as asthma, obesity and IBD ${ }^{114-116}$. Worryingly, antibiotic use is particularly high in children aged $<4$ years ${ }^{117,118}$. 
When treating an infection with antibiotics there will be a concentration gradient in the body, resulting in anatomical sites with subinhibitory concentrations of the drug ${ }^{119}$. Also, the widespread and often inappropriate use of antibiotics worldwide have resulted in frequent human antibiotic exposure from the wider environment, via food, water and animals. Antibiotic concentrations in the environment can vary, but are often in the subinhibitory range for most bacteria. Regardless of where the exposure happens, if it is via antibiotic drugs or from the environment, subinhibitory concentrations are a case of concern. It is suggested that antibiotics at subinhibitory concentrations may function as signaling molecules with consequences such as increased gene exchange, mutation rate and biofilm formation ${ }^{120}$. A study published in 2006 showed that a total of 386 genes (20\% of the genome) in $S$. pneumoniae changed their expression level due to sub-MIC concentrations of penicillin ${ }^{121}$.

\section{Resistome}

The term resistome is defined as the collection of all ARGs found in the microbiome, including intrinsic and acquired genes, and genes found in commensal and pathogenic bacteria ${ }^{122}$. Previously, ARGs found in clinically important pathogenic bacteria have been the focus of research. However, in the last 20 years, the presence of resistance in environmental bacteria and commensals have gained increased attention, particularly those in the human microbiome ${ }^{123}$. Advances in methodology, especially culture-independent methods, have revealed that ARGs in environmental and commensal bacteria may serve as a reservoir of resistance, as it can spread to more harmful species by $\mathrm{HGT}^{124}$. In fact, several clinically important resistance genes, such as many extended spectrum beta-lactamases (ESBLs) and multidrug efflux pumps are thought to have originated from environmental bacteria ${ }^{125}$. Thus, the resistance observed in clinical settings is only the "tip of the resistome-iceberg".

\subsection{Effect of antibiotics on the resistome}

As mentioned in section 1.3.2, the use of antibiotics is the main driver of emergence of ARGs, and emergence of resistance in bacteria can happen via mutations or by acquiring new genetic traits through HGT. The underlying mechanisms driving resistance emergence is partly due to 
natural selection pressure, which selects pre-existing resistant bacteria, but also because antibiotic exposure itself increases the rate of mutations and HGT.

Increased mutation rates by exposure to subinhibitory concentrations of antibiotics have been reported in several studies, and different antibiotic agents may increase mutation rate by different mechanistic approaches. Fluoroquinolones act by inhibiting enzymes involved in DNA replication, which may activate an SOS response allowing for survival and continuous replication even if there is DNA damage ${ }^{126}$. Other antibiotic agents, such as ampicillin have been reported to increase the production of reactive oxygen species, which may cause DNA lesions and lead to the accumulation of mutations ${ }^{127}$. Further, subinhibitory concentrations of antibiotics have been reported to increase the rate of HGT ${ }^{128-130}$. In 2006, Prudhomme et al. published a paper showing that aminoglycoside and fluoroquinolones as well as mitomycin $\mathrm{C}$, a DNA-damaging agent with antitumour activity, induced competence and transformation in Streptococcus pneumoniae. S. pneumoniae lacks the classical SOS-system, and Prudhomme et al. suggested that competence might function as a general stress response in $S$. pneumoniae ${ }^{128}$. Increased conjugation frequency is also reported to be associated with subinhibitory exposure of antibiotics. For instance, subinhibitory concentrations of beta-lactam antibiotics increased the conjugative transfer of a plasmid containing tetracycline resistance in S. aureus, and exposure to several types of antibiotics increased conjugation of plasmids containing ESBLs in Escherichia coli ${ }^{131,132}$. Thus, it appears that low concentrations of antibiotics may act as a stressor on the bacteria, which respond by increasing mutation rate and gene exchange to maximize their chance of survival.

Antibiotic treatment promote resistance in both target and off-target microbes. This will increase the gene pool of resistance mechanisms in the community, and also promote resistance in bystanding opportunistic pathogens, which might be a source of future infections 119. 


\section{Streptococci}

The Streptococcus genus represents a wide variety of pathogenic and commensal bacteria, colonizing both humans and animals. Streptococci belong to the phylum Firmicutes, are Gram-positive, have a coccoid or spherical shape, are facultative anaerobes and occur in pairs or chains, thus the name (streptos = chain, coccus =berries). Traditionally, streptococci were classified based on their ability to hemolyze erythrocytes in blood agar medium and on their cell wall polysaccharide composition (Lancefield grouping, A-G) ${ }^{133}$. However, not all streptococcal species, including most oral streptococci and $S$. pneumoniae, could be assigned to a Lancefield group. Improved DNA sequencing methods have introduced a new and more accurate approach in classification of streptococci based on 16S rRNA sequence phylogeny. The most recent classification have separated streptococci into eight major groups: Mitis, Sanguinis, Anginosus, Salivarius, Downei, Mutans, Pyogenic, and Bovis ${ }^{134}$. Bacteria within the genus Streptococcus are responsible for a high burden of morbidity and mortality worldwide. Among the most clinically important species are Streptococcus pyogenes and Streptococcus agalactiae belonging to the Pyogenic group, S. pneumoniae belonging to the Mitis group and Streptococcus mutans belonging to the Mutans group. S. pyogenes (often referred to as Group A Streptococcus - GAS) can cause a wide variety of acute infections, such as pharyngitis and necrotizing skin infections ${ }^{135}$, while $S$. agalactiae (often referred to as Group B Streptococcus - GBS) is known to cause severe infections in newborns ${ }^{136}$. $S$. pneumoniae is an opportunistic bacterium with a high pathogenic potential, while $S$. mutans is associated with dental caries.

Although some streptococci may cause infections, most streptococci that colonize our bodies show a nonvirulent behavior. Streptococci are among the most dominating genus in the oral cavity and naso-pharynx, however, they can also be a part of the normal microbiome in the gut and vaginal tract ${ }^{137}$. Most oral streptococci are harmless, and seldom cause disease. In fact, they are most likely beneficial in keeping the microbiome balanced, and by protecting against more pathogenic bacteria ${ }^{138}$. Interestingly, previous reports have shown that oral commensals, such as Streptococcus oralis, Streptococcus salivarius and Streptococcus mitis, may protect against recurrent ear infections (otitis media) in otitis-prone children and $S$. pneumoniae lung infections in mice ${ }^{139,140}$. Hence, streptococci are a very diverse group of bacteria, involved in both health and disease. Streptococcal species used in laboratory experiments of this thesis are described in more detail in the next sections. 


\subsection{Streptococcus pneumoniae}

As mentioned above, $S$. pneumoniae is one of the most clinically important species within the genus Streptococcus. It is often referred to as pneumococcus, and it can cause severe infections such as pneumonia, meningitis and sepsis ${ }^{141}$. However, it is also a common inhabitant of the upper respiratory tract in humans (especially in young children), being part of the normal human microbiome. This two-faced behavior is what makes this species especially interesting regarding virulence factors, signaling systems and other regulation mechanisms $^{142}$.

The polysaccharide capsule is a critical virulence factor. So far, over 90 different serotypes have been described based on differences in polysaccharide structure, and some of them seem to cause invasive disease more frequently than others ${ }^{143,144}$. High variability between $S$. pneumoniae strains may be attributed to the ability of natural genetic transformation ${ }^{60} . S$. pneumoniae reaches its competent state by recognizing one of two dominating competence stimulating pheromones (CSPs) within this species, leading to the uptake of external DNA. This will be further described in section 4.4. The ability to acquire new genetic traits through natural transformation makes both vaccine prophylaxis and antibiotic treatment challenging. Thus, pneumococcal diseases are still a major global health concern today.

Historically, S. pneumoniae has not only been an important cause of disease, it has also played a significant role in the research field of microbiology. In 1928, Frederick Griffith proposed the "transforming principle" by showing that information could somehow be transferred between different strains of bacteria using mice and encapsulated (Smooth) and unencapsulated (Rough) strains of S. pneumoniae ${ }^{145}$. Further, in 1944, Oswald Avery identified DNA as the substance of this 'transforming principle' ${ }^{146}$, leading to the later discovery of the DNA structure.

\subsection{Streptococcus mitis}

S. mitis is one of the first bacteria to colonize the human mouth after birth, and it remains in virtually all adults as a part of the oral microbiome throughout life ${ }^{137,147}$. It is usually harmless with a low pathogenic potential, despite being closely related to the more pathogenic S. pneumoniae. In 2014, Kilian et al. reported that S. mitis and S. pneumoniae probably have 
evolved from a common ancestor and that $S$. mitis may have lost its virulence genes and adapted to a more mutualistic lifestyle ${ }^{148}$. In immunocompromised patients however, such as those with neutropenia, $S$. mitis is associated with septicemia ${ }^{149}$. The close relationship between $S$. mitis and $S$. pneumoniae, in addition to other species within the mitis group, has made taxonomic and phylogenetic characterization difficult. Still, even with methods such as 16s rRNA gene sequencing, correct identification remains a challenge as several species share $>99 \%$ sequence homology ${ }^{150}$. Interestingly, interspecies gene transfer has been observed between $S$. mitis and $S$. pneumoniae. Thus $S$. mitis may function as a reservoir of antibiotic resistance genes for $S$. pneumoniae ${ }^{151}$.

\subsection{Streptococcus mutans}

S. mutans is commonly found in the oral cavity and is known as an important etiologic agent in dental caries ${ }^{152}$. It colonizes the mouth of young children, usually around the time of tooth eruption, and is well adapted to a life in biofilm such as dental plaque. ${ }^{153,154}$ In addition to the high cariogenic properties, it can also cause non-oral infections such as bacteremia and endocarditis ${ }^{155}$.

\subsection{Signaling systems in streptococci}

Bacteria use signaling systems for intra- and inter-species communication. By interacting with others and building social networks, bacteria can accomplish functions beyond what they can achieve as individuals. Over 50 years ago, two research groups independently discovered two different cell-cell-communication systems. Nealson et al. discovered that the luciferase enzyme in Vibrio fisheri was induced at a specific cell density ${ }^{156}$, while Tomasz et al. reported the discovery of a hormone-like cell product controlling competence in $S$. pneumoniae ${ }^{157}$. The phenomenon these two groups described is today known as Quorum sensing (QS). QS is defined as the regulation of gene expression in response to cellpopulation density by secretion and detection of signaling molecules. Signaling systems and signaling molecules vary between different bacteria. In general, Gram-negative bacteria use acylated homoserine lactones in their communication, while Gram-positive bacteria use oligopeptides, known as pheromones, as signaling molecules. Numerous important biological 
functions are regulated by QS in both Gram-negative and Gram-positive bacteria, such as virulence, competence, conjugation, motility, antibiotic production (lantibiotics, bacteriocins) and biofilm formation ${ }^{158}$.

In streptococci, several QS pathways have been described, and in the next sections, two of these signaling systems will be described in more detail.

\subsubsection{Competence - the Com-pathways}

Competence is a temporary state in streptococci during which genes allowing for natural transformation and fratricide are upregulated in response to quorum-sensing signals. The induction of competence varies between the different groups of streptococci. In streptococci from the Mitis group (e.g. S. pneumoniae and S. mitis) and Anginosus group, the QS signaling system ComABCDE is activated by the accumulation of CSP in the extracellular environment 159 . When a threshold concentration is reached, CSP binds to and autophosphorylates the membrane-bound receptor ComD, which in turn transfers a phosphoryl group to the response regulator ComE ${ }^{160}$. This is considered as the early phase of competence. ComE stimulates transcription of the so-called early genes, by binding to their promoter region ${ }^{161}$. Among the early genes activated is $\operatorname{com} C$ and $\operatorname{com} A B$, which encode the pre-CSP and a transporting system for the processing and export of CSP out of the cell. Hence, the early activation of competence functions as a positive feedback loop, stimulating further activation of the system 162. The phosphorylated-ComE also initiates the expression of $\operatorname{sig} X$ and $\operatorname{com} W$. The alternative sigma factor SigX is the master regulator of competence responsible for the link between the early and late responses, while ComW participates in SigX stabilization and activation ${ }^{163}$. In the late phase of competence, several genes, such as genes responsible for transformation, production of bacteriocins, and a cell lysis mechanism known as fratricide, are upregulated (Figure 5) ${ }^{164}$. Overall, a recent report on competence and gene regulation reveals that ComE and ComX directly control $4 \%$ of all annotated genes in S. pneumoniae, and $17 \%$ of all genes is affected, either directly or indirectly by competence regulators ${ }^{165}$.

Members of the Pyogenic, Salivarius and Bovis group have a different system for activation of their competence system. In these groups of streptococci a new quorum sensing system has been identified named ComRS, using XIP (sig $X$ inducing peptide) as the stimulating signal $^{166,167}$. XIP is imported into the cell where it binds to ComR, a transcriptional regulator 
belonging to the Rgg family (revisited in the next section), and initiates $\operatorname{sig} X$ transcription, followed by upregulation of specific genes ${ }^{168}$. In the Mutans group, both these systems, ComABCDE and ComRS, have been identified, and competence may be directly induced by XIP, or indirectly by CSP via XIP in two different signaling pathways ${ }^{169}$.

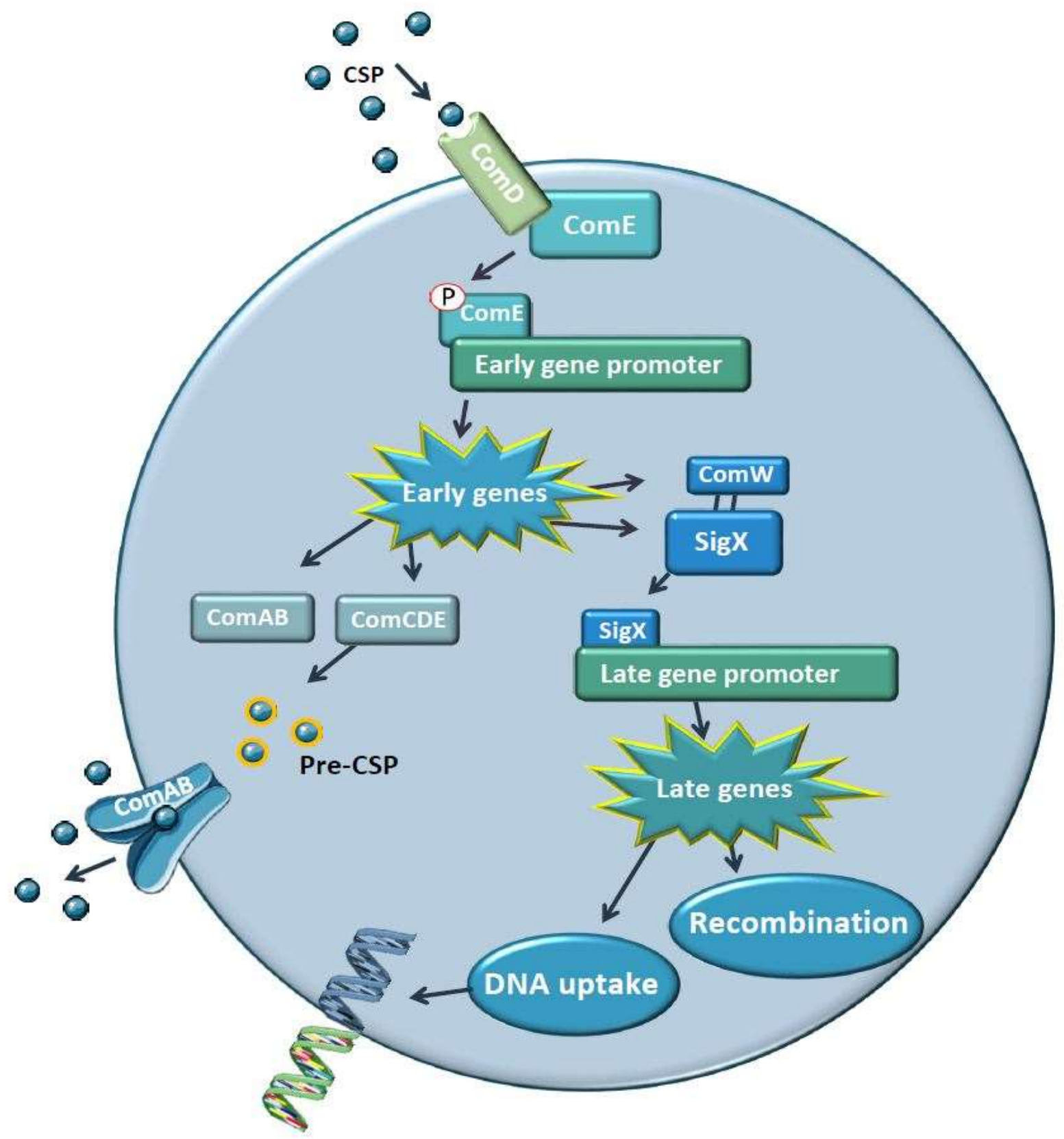

Figure 5: Model system of the competence circuit in S. pneumoniae. 


\subsubsection{Rgg regulators}

Rgg (Regulator gene of glucosyltransferase) proteins are transcriptional regulators, first described in Streptococcus gordonii as a positive regulator of glucosyltransferase expression, hence the name ${ }^{170}$. Later, several genes with sequence homology to the original Rgg regulator were detected in other bacteria, regulating transcription of genes with different physiological functions. Nonetheless, the name 'Rgg' was expanded to the whole family of proteins. Initially, the Rgg regulators were believed to be stand-alone regulators. However, in 2007, a small hydrophobic peptide (SHP) was found to be interacting with the Rgg regulator, and a new pheromone system was discovered ${ }^{171}$. Later, genome-wide surveys have shown that this pheromone system is present in most streptococci, regulating functions such as biofilm formation, bacteriocin production and virulence ${ }^{172-174}$. As described in the previous section, ComR is a transcriptional regulator belonging to the Rgg family, found in streptococci belonging to the Pyogenic, Salivarius, Bovis and Mutans group. ComR initiates $\operatorname{sig} X$ transcription, which activates the late phase of competence. 


\section{Aims of the research}

General aim:

- The main goal of this work was to explore the impact of antibiotics on the human microbiome and resistome, and mechanisms related to spread of resistance.

Specific aims:

- To study the effect of antibiotic stress on quorum sensing systems leading to increased virulence in S. pneumoniae. (Paper I and II)

- To investigate the impact of antibiotics on competence and concurrent transformation in $S$. pneumoniae, $S$. mitis and $S$. mutans, which are all common residents in the human oral and respiratory microbiome. (Paper I)

- To explore the consequence of a 5-day course of narrow-spectrum antibiotics (Penicillin V) on the oral and fecal microbiome and resistome of a young child. (Paper III)

- To study the impact of long-term amoxicillin therapy on the human oral microbiome and resistome. (Paper IV) 


\section{Summary of results}

\section{Paper I}

\section{Antibiotics Alter the Window of Competence for Natural Transformation in}

\section{Streptococci.}

The effect of subinhibitory concentrations of six different antibiotic agents on the signaling system that leads to competence and transformation in $S$. pneumoniae was investigated. The impact on competence was determined by the level of $\operatorname{sig} X$ expression using a luciferase reporter, and these results were then correlated with transformation kinetics. The results showed that ciprofloxacin, novobiocin, erythromycin and tetracycline enhanced $\operatorname{sig} X$ expression, while ampicillin and streptomycin had an inhibitory effect. When comparing it to transformability, the induction of $\operatorname{sig} X$ expression by ciprofloxacin and novobiocin correlated with increased and prolonged transformability. The prolonged effect of ciprofloxacin on competence and transformation was also observed in the streptococcal relatives $S$. mitis and $S$. mutans. In contrast, tetracycline and erythromycin had either an inhibitory or an insignificant effect on transformation, whereas streptomycin and ampicillin inhibited transformation. Thus, the results show that antibiotics may vary in their effects on competence, ranging from inhibitory to stimulatory effects, and that responses affecting transcription of $\operatorname{sig} X$ do not always correlate with transformability.

\section{Paper II}

\section{Characterization of a Signaling System in Streptococcus mitis That Mediates Interspecies} Communication with Streptococcus pneumoniae

In paper II, the effect of subinhibitory concentrations of antibiotic agents was investigated in the Rgg/SHP signaling system. Here, this newly described signaling system was identified for the first time in S. mitis and shown to be able to cross-communicate with $S$. pneumoniae. The Rgg regulator of this system presented high similarity to a transcriptional repressor in $S$. pyogenes; however, with the employment of genetic mutagenesis and luciferase assays, it was shown that this Rgg regulator functioned as a transcriptional activator in S. mitis. Transcriptome analysis showed that two downstream genes, in addition to the pheromone gene $s h p$, were strongly upregulated in response to the synthetic SHP, a core characteristic of 
the Rgg/SHP QS system. Closer analysis of these genes revealed that they were a part of a putative lantibiotic gene cluster found in a conjugative element locus in several members of the mitis group. However, when compared to the full gene cluster present in representative strains of $S$. pneumoniae, $S$. mitis lacked the full set of genes, potentially resulting in a futile cycle of autoinduction. To assess if the activation of these genes would affect viability under antibiotic stress, a growth assay was performed with $S$. mitis overexpressing the target cluster and with an rgg knockout mutant, but no effect on growth was observed. The SHP sequence in S. mitis differed with only one residue from other previously described streptococcal SHPs, and was functional in promoting cross-species communication with $S$. pneumoniae. This was shown by increased surface polysaccharide synthesis in $S$. pneumoniae when exposed to the native SHP from S. mitis. In conclusion, the Rgg/SHP system in S. mitis regulates its own shp expression and promotes cross-species-communication with $S$. pneumoniae, activating a potentially virulent phenotype with increased surface polysaccharide expression. Although a futile cycle of autoinduction would have the potential to affect $S$. mitis growth in response to antibiotics, no such effect was observed.

\section{Paper III}

\section{Impact of Narrow Spectrum Penicillin V on the Oral and Fecal Resistome in a Young Child Treated for Acute Otitis Media}

Antibiotics affect not only the causative infectious agents, but have the potential to disturb the entire human microbiome. Narrow-spectrum antibiotics like phenoxymethylpenicillin (penicillin $\mathrm{V}$ ) are believed to have less off-target effects on the microbiome than alternatives with a broader spectrum. However, little is known about the impact of penicillin $\mathrm{V}$ on the microbiome and resistome. In this study we collected oral and fecal samples from a one-year old child before (day 0 ) and after (day 5 and day 30) receiving a 5-days course of penicillin $\mathrm{V}$ against acute otitis media. The samples were sequenced using deep shotgun metagenomic sequencing. Sequencing data was analyzed to determine taxonomic profiling, using Kraken and Bracken software, and resistance profiling, using KMA in combination with the ResFinder database. Our results showed that there was a remarkable difference in how antibiotics affected the oral microbiome in contrast to the fecal microbiome. In the oral sample, the taxonomic profile was relatively stable in the three time points. In contrast, the taxonomic alterations observed in the fecal samples were prominent, especially at day 5 . In 
the oral samples, 11 ARGs, belonging to four different classes, were identified at day 0 . At day 5, the abundance of some ARGs was increased, some remained unchanged, while others disappeared. At day 30, most oral ARGs had returned to baseline levels, or lower. In the fecal samples, we observed seven ARGs at baseline and five at day 5, with only one gene observed at day 5 being present at baseline. At day 30, the number of ARGs increased to 21 ARGs from seven different classes. In conclusion, Penicillin V had a remarkable impact on the fecal microbiome and resistome indicating that even narrow-spectrum antibiotics may have important consequences in selecting for a more resistant microbiome.

\section{Paper IV}

\section{Long-term treatment with amoxicillin - impact on the oral microbiome and resistome}

Although the most common duration of an antibiotic treatment does not exceed 14 days, for some conditions, such as recurrent urinary tract infections, severe acne and chronic respiratory diseases, longer treatments are often indicated. In Paper IV, we explored the consequences of prolonged antibiotic exposure on the oral microbiome and resistome using deep shotgun metagenomic sequencing. Saliva samples were collected from seven patients receiving a 100 days amoxicillin treatment as part of a multicenter clinical trial on chronic back pain. Samples were collected before treatment started (baseline), last day of treatment (100 days) and 9 months post antibiotic exposure ( 1 year). Over 600 different bacterial species were identified in the samples, confirming the large diversity of the oral microbial community. We observed that exposure to long-term antibiotics was associated with decrease in salivary microbiome diversity from baseline to 100 days. However, the diversity returned to levels similar to baseline after one year. Further, antibiotic resistance genes were found in all saliva samples, and most patients showed an increase in abundance of beta-lactam resistance genes, Macrolide/Lincosamid/Streptogramin (MLS) and multidrug resistance genes, from baseline to end of treatment. However, the highest number of ARGs were observed at the 1-year time point. These results indicate that long-term amoxicillin treatment may not markedly shift the overall oral microbiome composition, but it may be associated with a larger reservoir of ARGs in the oral cavity. 


\section{Methodological considerations}

In this section, methodological considerations in Paper I-Paper IV will be deliberated. Due to similarities of methodological choices and challenges in Paper I and Paper II, and in Paper III and Paper IV, this section will be divided in two main parts. The first part will discuss the choices of bacterial strains, growth media and other factors influencing signaling and transformation in streptococci, important in Paper I and II. The second part will discuss the challenges and considerations of using metagenomic sequencing in clinical research, as used in Paper III and IV.

\section{Paper I and II}

\section{Strains and growth conditions in streptococcal competence and transformation}

S. pneumoniae and its ability of natural transformation have been studied for almost a century. When Griffith described how unencapsulated (rough) harmless bacteria switched to encapsulated (smooth) harmful bacteria and proposed the transforming principle in 1928, he demonstrated the importance of investigating specific bacterial strains. His virulent and smooth variant was a serotype 2 strain, today known as D39. Since then, the D39 strain has been a leading model of natural transformation in streptococci, and most studies in this field have used either the original D39 strain, or one of its many derivatives such as R36, R36A, R6 or Rx-1. The R-derivatives have lost its capsule, and generally have a much higher transformability than the original strain. In Paper I, we used D39 (NCTC 7466), and not one of its derivatives, to mimic the clinical setting as much as possible. To show that the impact on competence was not strain-specific in S. pneumoniae we also included TIGR4, which is also a widely studied strain. TIGR4 was first isolated in a patient in Kongsvinger, Norway, and it has been used in several studies assessing virulence in $S$. pneumoniae ${ }^{175,176}$. The strains of S. mitis (CCUG 31611) and S. mutans (UA159) were chosen in paper I as the function and genome sequence of these strains are previously well characterized. In paper II, the $S$. mitis type strain (CCUG 31611) was chosen also on the background of homology with the $\mathrm{Rgg} / \mathrm{SHP}$ system in S. pneumoniae. 
When studying competence and transformation in streptococci, using the appropriate growth medium is of great importance. Previous protocols for streptococcal transformation have suggested the use of rich media, such as Todd Hewitt Broth (THB) and Tryptic Soy Broth (TSB). However, most studies investigating transformation in $S$. pneumoniae have used semidefined media such as CAT-medium or C-medium supplemented with yeast extract $(\mathrm{C}+\mathrm{Y})$. In 2011, Stevens et al. found that C+Y-medium with increased concentration of yeast extract and bovine serum albumin supported spontaneous competence in $S$. pneumoniae ${ }^{130}$. This modified $\mathrm{C}+\mathrm{Y}$-medium was called $\mathrm{C}+\mathrm{Y}_{\mathrm{YB}}$, and in 2016, colleagues from our lab published an article showing significantly higher sig $X$-expression in $S$. mitis cultures grown in $\mathrm{C}+\mathrm{Y}_{\mathrm{YB}}$ than in $\mathrm{C}+\mathrm{Y}$ or $\mathrm{TSB}^{177}$.

In Paper I, several rounds of testing, including both rich media and semi-defined media, concluded that semi-defined media were superior in supporting competence gene expression and transformation in D39. In Paper II, both a rich medium, TSB, and a semi-defined medium, $\mathrm{C}+\mathrm{Y}$, were included in the analyses. The rationale behind this was that the $\mathrm{Rgg} / \mathrm{SHP}$ system in $S$. mitis was a new discovery, thus, it was unknown if peptide and nutrient content in the growth media affected the activation or function of the system.

In Paper II, two genes were upregulated by the Rgg/SHP system in S. mitis. These genes were annotated as an $\mathrm{ABC}$ transporter, and it showed some sequence homology with a lantibiotic transporter system in other bacteria. However, closer analysis revealed that these genes were a part of a larger gene locus in other streptococci, indicating that in S. mitis the system might not be functional. Hence, a growth assay was conducted to assess if the activation of this $\mathrm{Rgg/SHP}$ system could affect growth in response to antibiotics stress. In this assay, a rich media was used as this generally promotes bacterial growth and is usually used in minimum inhibitory concentration (MIC)-studies.

\section{Choice of antibiotics}

Antibiotics used to treat or prevent infections in the body have the potential to disturb the entire human microbiome. Therefore, not only antibiotics used to treat streptococcal infections were included in these studies. Antibiotic agents included in Paper I and II belong to different antibiotic classes, and consequently, impose different antibiotic stress on the bacteria. In paper II, we included Nisin as one of the antibiotic agents. Nisin is a bacteriocin with antibacterial activity produced by Lactococcus lactis, often referred to as lantibiotics ${ }^{178}$. 
Due to the possible association between the two upregulated genes and a lantibiotic gene cluster found in other members of the mitis group, we sought to investigate if Nisin affected growth in this bacteria.

\section{Gene expression and transformation assays}

In paper I, we investigated the impact of antibiotics on competence in $S$. pneumoniae by measuring $\operatorname{sig} X$ gene expression, often referred to as the master regulator of competence. Initially in this project, we tested two different methods for investigating gene expression, namely Real Time PCR based on RNA extraction with cDNA synthesis (unpublished results) and Luciferase Reporter Assays. Both methods showed an increase in $\operatorname{sig} X$ expression as a result of antibiotic exposure. However, with the luciferase reporter assay we were able to use more variables (different agents, concentrations) with continuous readings during the entire window of competence. A limitation of reporter assays is the possibility of accumulation of signal over time in comparison with Real Time PCR, which shows a snapshot of the situation at one time point. However, the bacterial luciferase enzyme has a relatively rapid turnover which reduce accumulation of the signal measured ${ }^{179}$. In addition, it is a high throughput and cost effective method. Thus, the luciferase reporter assay was the preferred method in the further investigations. The Luciferase reporter assay is a commonly used method to study gene expression at the transcriptional level, and it has been employed in several studies investigating competence ${ }^{128,130}$.

Although stimulation of competence by antibiotic stress has previously been reported, for most studies, actual transformation was not included as an end point. As antibiotics have the potential to affect competence in different ways, and in different stages of the competence circuit, we wanted to test if gene expression results correlated with transformation efficiency. Previous studies investigating the impact of antibiotics on competence and transformation in S. pneumoniae have generally used growth conditions that suppress spontaneous competence. We sought to investigate how antibiotics affected an already competent bacterial culture, and therefore grew the bacteria in permissive conditions for spontaneous competence.

Several laboratory conditions influence transformation efficiency, including the concentration and size of homologous donor DNA (PCR-product), $\mathrm{pH}$ of the culture medium, CSP concentration and the optimal bacterial density in the starting culture. Studies recently performed in our and cooperating laboratories have optimized a variety of conditions for 
streptococcal transformation, thus, the transformation assays performed in Paper I followed the already established protocols ${ }^{177,180}$.

\section{Paper III - Paper IV}

\section{Investigating the microbiome}

Next-generation sequencing (NGS) has revolutionized the field of microbiology, with the human microbiome project in 2007 as an important milestone ${ }^{181}$. The introduction of NGS has rapidly extended our understanding of the composition and function of bacterial populations in various environments. However, the many opportunities using NGS are not without challenges.

There are two main approaches when investigating the composition of the microbiome, $16 \mathrm{~s}$ rRNA gene sequencing and shotgun metagenomic sequencing. 16S rRNA is a gene universally present in all prokaryotes. It consists of highly conserved nucleotide sequences containing phylogenetic information. Thus, this gene has been used in microbial classification for several years ${ }^{182}$. The most important advantages of this method are low costs, and reduced workload compared to shotgun metagenomic sequencing. However, there are several disadvantages to this method, such as the need for PCR-amplification, copy-number variations of the $16 \mathrm{~S}$ rRNA gene, no functional information and limited taxonomic resolution. The second method used to investigate the microbiome is shotgun metagenomic sequencing, an untargeted approach, sequencing DNA from all cell types in an entire community ${ }^{183}$. It can provide detailed information on taxonomic composition in addition to functional information such as virulence genes and ARGs. Shotgun metagenomic sequencing requires complex analyses by skilled bioinformaticians, which are both costly and time consuming. Nonetheless, with the benefits of metagenomic sequencing, especially the possibility of investigating the resistome, we decided to use shotgun metagenomic sequencing in Paper III and IV. 


\section{Shotgun Metagenomic Sequencing}

Shotgun Metagenomic studies involve several steps, (i) collection and storage of samples, (ii) DNA extraction, (iii) library preparation and sequencing, (iv) preprocessing of the reads and (v) sequence analysis. In each step, the choice of protocol may influence the end result, and this is a major challenge in the reproducibility of metagenomic research, as standardized protocols are lacking ${ }^{184}$.

(i) Collection and storage of samples:

Choice of protocol for collection and preservation of samples can affect the quality of DNA and the reliability of the metagenomic data ${ }^{185}$. In our projects, we tested several methods for collection of oral samples, including different swabs, sponges, drooling and spitting, and we tested storage with and without preservatives. Because of the young age of the child participating in Paper III, a swab was used to collect the oral sample, as this was the most practical alternative. A detailed instruction of how to swab the different areas of the mouth was followed to assure comparability between samples from different time points. Oral samples in Paper III were directly put on ice, and DNA was extracted within 2 hours. Fecal samples were collected in sterile containers without preservatives, and immediately frozen. In Paper IV, saliva was collected by spitting into a sterile container without any preservatives, and directly frozen at $-80^{\circ} \mathrm{C}$. It is important to be aware that different collection and storage methods can affect the results, and in some circumstances, the effect of different protocols can be larger than the effects of the biological variables ${ }^{186}$.

(ii) DNA extraction:

DNA extraction methods can significantly alter the results of sequence data, as reported in several studies ${ }^{187}$. Extraction methods usually rely on chemical lysis, mechanical lysis or a combination of both, with each method affecting important factors such as DNA amount, purity, molecular weight and degradation differently. In the oral samples used in Paper III and IV, after much testing, we ended up using MasterPure Gram Positive DNA Purification Kit from Epicentre, as recommended by HOMINGS (Human Oral Microbe Identification using Next Generation Sequencing) at the Forsyth Institute. DNA from fecal samples (Paper III) was extracted using PowerLyzer ${ }^{\mathrm{TM}}$ PowerSoil ${ }^{\circledR}$ DNA Isolation Kit from MoBio, as also used in the HMP ${ }^{188}$. 
(iii) Library preparation and Sequencing:

The process of library construction generally includes fragmentation and tagmentation, or introduction of adapter sequences to the fragmented DNA. Several kits for library construction are available, and they use different fragmentation methods, such as enzymatic fragmentation, sonification or fragmentation and tagmentation by transposomes. As with previous steps in the metagenomic workflow, the choice of library preparation method may influence the result of sequence data ${ }^{189}$. In our projects, the choice of library preparation and sequencing platforms were done in collaboration with the Norwegian Sequencing Center, which recommended the most suitable protocol for our samples. Sample preparations in paper III were done using the TruSeq DNA PCR-free kit and sequenced on Illumina HiSeq2500, while library preparations of samples in Paper IV were done using Nextera Flex and sequenced on the Illumina 3000 platform.

(iv) Preprocessing of the reads

Preprocessing of sequence reads includes removing adapter sequences, low quality reads and host DNA. There are several preprocessing strategies available. In our metagenomics projects, we used the Trimmomatic tool, as this is a commonly used and efficient preprocessing tool, optimized for Illumina NGS data ${ }^{190}$. Contamination with host-DNA is a significant challenge in human samples, especially in oral samples. Data from the HMP shows that fecal samples usually have low levels of human DNA contamination $(<10 \%)$. In contrast, over $90 \%$ of the sequenced DNA aligns to the human genome in oral samples ${ }^{191}$. Commercial kits that remove host DNA from metagenomic DNA samples are available, and were tested in the beginning of the project for Paper III. Unfortunately, the amount and quality of the remaining prokaryotic DNA after host DNA removal was not good enough to continue with sequencing. Therefore, we sequenced all DNA in the sample and removed host-DNA by aligning sequencing reads to a human reference genome, using BowTie2 ${ }^{192}$.

(v) Sequence analysis:

Organizing and analyzing the sequence data is the last part of the shotgun sequencing pipeline. Several approaches and tools are available for analyzing sequence data, and the choice of methods may impact the end results ${ }^{193}$. There are two main approaches when analyzing metagenomic data, read-based or assembly-based analysis. In assembly-based approaches, the reads are assembled by overlapping regions into longer sequences called 
contigs. Further, contigs are grouped into genomes, and then analyzed either by comparing the assembled sequences with available databases, or by de novo assembly. One of the advantages of assembly-based analyses is the possibility of identifying new genes and species. However, the complex and difficult task to assemble short reads from many different species in one sample, often resulting in misassembles, remains a problem. To combat the issue with missassemblies, it is possible to combine long-reads using for instance Nanopore technology to facilitate correct assembly with the accuracy of short reads from the Illumina platforms, but this increases the costs considerably. In read-based approaches, short reads are directly analyzed by mapping reads to existing databases, thus, analyses are considerably less time and labor demanding but does not provide information on new genes and species. Notably, readbased approaches are more accurate in samples from previously well characterized environments with updated databases, than if the samples originated from a poorly characterized habitat ${ }^{194}$.

The aim of the study, together with costs and technological limitations, should ultimately determine which method to use. In Paper III and IV, we sought to investigate the impact of antibiotics on taxonomic composition and the resistome of the previously well characterized human microbiome. Several large and updated databases were available for both taxonomy and ARGs. Hence, being both time saving and less labor demanding, read-based approaches were used in these studies.

Taxonomic classification in Paper III was done with the Kraken program. Kraken is a fast and accurate program mapping k-mers to a library of genomes and assigning it to the lowest common ancestor ${ }^{195}$. Because many reads are similar in closely related species, there will be an underestimation of certain species with this method, and many reads will be assigned only at genus level or higher. To overcome this limitation in Kraken, the Bracken program was used to increase the species-level identification. In paper IV, an updated version of MetaPhlAn, which was used by the HMP, was used for taxonomic classification. MetaPhlAn2 uses a marker gene approach, with approximately 1 million clade-specific marker genes, to assign the reads into appropriate taxonomic groups ${ }^{196}$. This approach is faster than most other methods because the reference database only consists of a subset of the genomes found in other databases. For ARG profiling, different approaches were used in the two studies. In Paper III we used the ResFinder 2.1 database, which was a widely used database containing over 2000 ARGs at the time of analyses for Paper III ${ }^{197}$. However, the field of metagenomics and AMR are quickly evolving, and when analyzing the resistome for Paper IV, we utilized 
the novel DeepARG approach with an updated database, which has proved to be more accurate than previous methods ${ }^{198}$.

Choosing the most appropriate method for analyzing metagenomic samples is challenging. However, unlike the first steps of the shotgun sequencing pipeline, the choice of methods in this last step can be re-assessed using other methods. This almost endless potential for further investigations makes shotgun metagenomic sequencing a valuable resource in microbiome research. 


\section{Discussion}

The rapid emergence of antibiotic resistance worldwide is an evolutionary response to antibiotic exposure. During antibiotic treatment, the entire bacterial community is exposed, not only the target pathogen of treatment ${ }^{49}$. High concentrations of antibiotics will kill or inhibit growth of target and off-target susceptible bacteria. Further, increasing evidence shows that also subinhibitory concentrations have a broad range of physiological effects in bacteria exposed to antibiotics ${ }^{120}$. Microbial communities, like those found in humans, are particularly subjected to the effect of subinhibitory concentrations as a result of antibiotic therapies ${ }^{199}$. In the work of this thesis, the overall goal was to evaluate the way individual bacteria and complex microbiomes respond to antibiotic stress. The initial aim was to investigate the impact of subinhibitory concentrations of antibiotics on gene expression and transformation in a well described QS system in S. pneumoniae (Paper I), and further, if the presence of the newly discovered Rgg/SHP system in S. mitis affected its viability when exposed to antibiotics in the laboratory (Paper II). Next, the aim was to investigate how antibiotics affect clinical microbial communities. We explored this by analyzing the microbiome and resistome in the mouth and gut of a young child during and after penicillin V treatment (Paper III), and finally, we investigated the impact of long-term amoxicillin treatment on the salivary microbiome and resistome in adults (Paper IV).

Microbes communicate with each other by using QS systems. Such systems enable bacteria to modulate their collective behavior in response to different environmental cues. Competence, a classical QS system, is well described in streptococci, and it regulates bacterial behavior such as natural transformation. During the activated competent state, several genes including those involved in DNA uptake and recombination are upregulated. This enables the bacteria to incorporate external DNA into their own genome. The benefits of DNA uptake by competent cells are not fully understood and traditionally there have been three main hypotheses for the evolutionary function of competence and transformation; (1) uptake of DNA as nutrient, (2) uptake of DNA to repair damaged regions of the chromosome, or (3) to favor genetic exchange. Although competence regulates the expression of a variety of genes and functions, only a small portion of these are involved in transformation ${ }^{200}$. In 2006, Claverys et al. suggested a theory that the broad effects of competence, not only transformation, may act as a general stress response in S. pneumoniae ${ }^{201}$. Engelmoer and Rozen strengthened this theory in 2011, when they showed that for some types of stress, transformation is not essential for cells 
to benefit from the induction of competence ${ }^{202}$. Another, more recently described QS system in streptococci is the $\mathrm{Rgg} / \mathrm{SHP}$ system. Rgg regulators are transcriptional regulators shown to control a variety of functions in different bacterial species, including pathways that indirectly regulate the competence system in several streptococcal species ${ }^{203}$.

Several studies have reported that antibiotic exposure may affect the regulation of QS systems, and that QS systems may in turn affect how the bacteria tolerate antibiotic stress. This highlights the complexity of antibiotic microbial interactions, and the possibility that antibiotics may function as signaling molecules in subinhibitory concentrations. It also explains how antibiotic exposure can result in substantial transcriptional changes in bacteria. In Paper I, we investigated if antibiotics affected the competence system by measuring gene expression of $\operatorname{sig} X$ and the subsequent transformation efficiency in S. pneumoniae. In accordance with previous studies, fluoroquinolone antibiotics enhanced gene expression of $\operatorname{sig} X$ and led to increased transformation efficiency ${ }^{129}$. Interestingly, the aminoglycoside Streptomycin, reduced gene expression and transformation in our study but activated competence in a study by Prudhomme et al. in $2006^{128}$. An important difference between these two studies was the laboratory conditions under which the experiments were performed. Prudhomme et al. grew $S$. pneumoniae in non-permissive conditions for spontaneous competence, while our experiments were performed in permissive conditions. The effect of permissive vs. non-permissive conditions was also reported by Stevens et al. in 2011, which observed a competence-inducing effect of aminoglycosides only under non-permissive conditions $^{130}$.

Another interesting finding in Paper I was the effect of tetracycline on competence and transformation. Tetracycline strongly increased gene expression of $\operatorname{sig} X$ in our experiments. However, the transformation efficiency was lower than in the control samples. According to previous literature, tetracycline has been shown to reduce decoding errors in translation, thus resulting in less stress and reduced activation of competence ${ }^{130}$. This is in line with our results showing reduced transformation efficiency upon exposure to tetracycline. However, the increase in $\operatorname{sig} X$ expression due to tetracycline exposure was unexpected. A possible reason for this observation might be that tetracycline affects mechanisms downstream of SigX in the competence cascade. (Paper I). Ampicillin reduced both the $\operatorname{sig} X$ gene expression and the transformability of $S$. pneumoniae in this study, which is in accordance with previous findings performed in non-permissive conditions ${ }^{128,204}$. Noteworthy, non-permissive conditions as used in most previous studies, are unsuitable for examining reduced competence 
activity. By using permissive conditions, we were able to address this limitation. The overall findings in Paper I indicated that antibiotic agents affected competence and transformation in S. pneumoniae in different ways, depending on the specific mechanism of the agent. This might be of clinical relevance when choosing antibiotic agent in treating disease.

Other QS systems, besides competence, are also known to regulate a variety of cellular processes which can affect antibiotic susceptibility, such as biofilm formation, extracellular polysaccharide synthesis, lantibiotic production, and efflux mechanisms ${ }^{205}$. In Paper II we characterized a new signaling system in S. mitis and showed how it promoted cross-species communication. Moreover, we examined if the Rgg/SHP system affected the susceptibility towards antibiotics by using a mutant strain without the rgg gene. Our hypothesis was based on the findings that this new system seemed to trigger a futile cycle, as indicated by the transcriptome analyses, and that the up-regulated locus resembled those leading to protective responses towards bacteriocins in other streptococcal species ${ }^{206}$. No difference in MIC was observed in this $S$. mitis strain with or without $r g g$, indicating that the system did not initiate any mechanisms beneficial for survival under antibiotic exposure, at least under these experimental conditions.

In addition to the individual response of single strains to antibiotics, antibiotic stress can lead to functional and compositional disturbances in the microbiome, having consequences such as ARG enrichment and overgrowth of pathogenic bacteria. To begin investigating the connection between narrow-spectrum antibiotics and the impact on the microbiome and resistome, we started with a clinical case of a young child receiving penicillin $\mathrm{V}$ for treatment of acute otitis media, as described in Paper III. Despite only including one patient, the lack of knowledge on effects by narrow-spectrum penicillin on the microbiome, and the novel deep sequencing strategy performed in this study, made it scientifically relevant to publish the results. Globally, the use of narrow-spectrum penicillin is low. However, in Scandinavia it is the most used antibiotic drugs ${ }^{207,208}$. Because of the narrow-spectrum, it is assumed that the collateral effect on the microbiome is lower compared with broad-spectrum antibiotics. However, there is not much evidence to support this assumption, and knowledge on the impact of penicillin $\mathrm{V}$ on the microbiome and resistome is limited. We decided to investigate the microbial communities in the oral and gut of this child. Previous studies have reported that the oral microbiome is more resilient to antibiotic perturbations than the gut microbiome ${ }^{109}$, and this was also evident in this project. The mechanisms behind the resilience in the oral microbiome are still unknown. However, with the constant shifts in the oral environment 
(temperature, nutrients, $\mathrm{pH}$, oral hygiene procedures etc.) it is suggested that bacteria in the oral cavity have evolved to cope better with stress, and as a result, are more resilient towards other influences such as antibiotics ${ }^{209}$. In addition, antibiotics taken orally will disturb the gut for longer time and with a higher concentration than the rest of the body, influencing the level of antibiotic effect ${ }^{210,211}$.

Paper IV focused on the investigation of the effect of amoxicillin, a beta-lactam antibiotic with broad-spectrum activity, on the oral microbiome and resistome in adult participants. Patients in this study were participants in a multicenter clinical trial, which evaluated the effect and possible side effects of a three months long treatment with amoxicillin on chronic low back pain with type 1 or 2 Modic changes ${ }^{212}$. Long-term-treatment of antibiotics has been indicated for patients with Modic changes, and is also commonly used in several other conditions such as recurrent urinary tract infections, severe acne and chronic respiratory infections. However, there is to date limited knowledge on the off-target effects long-term antibiotic treatments have on the microbiome and resistome. As observed in Paper III, the overall changes in the oral microbiome were limited, indicating that the oral microbiome indeed exhibits an overall resilience towards antibiotics.

As expected, the baseline microbiomes in paper III and IV varied. In Paper III, an oral swab was used to collect the sample, while Paper IV used unstimulated saliva. In addition, the subject studied in Paper III was a one year old child with an immature microbiome, while in Paper IV, all participants included were adults. Despite such differences, microbial diversity decreased at the end of treatment in both studies. Interestingly, the average diversity at the last follow up sample was higher compared to the initial baseline samples in both studies, with the largest increase observed in the child in Paper III. These results showed that the oral microbiome recovered quite quickly following antibiotic treatment, which is line with another study investigating the effect of amoxicillin ${ }^{109}$. However, other studies, often associated with the use of broad-spectrum antibiotics, show alterations in microbial diversity for a long period after antibiotic treatment ${ }^{110,213}$. The abundance of Proteobacteria increased in the follow-up samples at the end of treatment in both Paper III and IV, most likely due to increase in abundance of the genera Neisseria and Haemophilus. These genera include important respiratory pathogens and naturally transforming species that are capable of intra and interspecies DNA-exchange ${ }^{66}$. This is of great importance since the oral microbiome, because of its proximity to the nasopharynx, may act as a reservoir of respiratory pathogens and ARGs 214. 
In the oral samples of paper III, an increase in abundance of some ARGs was observed after treatment, but no new ARGs appeared, and the abundance was generally back to baseline values after one month. Most patients in Paper IV had an increase in abundance of ARGs related to beta-lactam resistance, MLS resistance and multidrug resistance between baseline and end of treatment. Further, the increase of ARGs observed at the end of treatment was still observed at the follow-up sample 9 months post antibiotic exposure. The number of ARGs increased from an average of 33 at baseline, to 38 after 1 year. These results might imply that a longer treatment period requires a longer recreation time for the oral microbiome to stabilize. However, it is important to highlight that amoxicillin used in Paper IV is a broadspectrum beta-lactam, which might have a larger effect on the resistome than Penicillin V used in Paper III.

In vast contrast to the oral samples in Paper III, antibiotics had an extensive influence on the fecal samples. The composition of the microbiome changed completely from phylum to species level, and it did not fully recover after one month. After Penicillin V treatment the fecal microbiome went from being dominated by the health associated genus Bifidobacterium to the potentially pathogenic genera Escherichia, Klebsiella and Enterococcus. The reduction in Bifidobacterium and concurrent increase in Enterobacteriacea supports previous observations of the effect of broad-spectrum beta-lactam antibiotics, however, the considerable changes observed following treatment with the narrow-spectrum beta-lactam penicillin V were unexpected. At the last time point, 21 ARGs were observed in the fecal sample, which is threefold the amount in the baseline sample. An obvious limitation of this study is the fact that only one patient is included. However, the sequencing depth is a strength, allowing for higher accuracy when analyzing the results. These results indicate that narrowspectrum penicillin may have a large impact on the microbiome and resistome in young children, and also highlights the importance of future studies to focus on narrow spectrum antibiotics.

Currently, it is not possible to directly assign the observed ARGs to the bacterial host with read based metagenomic sequencing approach, which is a limitation of this methodology. When looking at the resistome at the last follow up sample in paper III, it is possible that mutations and HGT played a role, as well as the dysbiosis leading to a large taxonomic shift, with newly appeared taxa containing new resistance genes. Interestingly, only one out of the 21 ARGs identified in the fecal sample at the last time point, conferred resistance toward beta-lactam antibiotics, which might indicate that the increase of ARGs at day 30 was most 
likely due to new species colonizing the gut after penicillin $\mathrm{V}$ treatment opened up for recolonization. 


\section{Conclusions and Future Perspectives}

The findings in this thesis have demonstrated that subinhibitory concentrations of antibiotics affected competence and transformation in S. pneumoniae. Further, this observed effect was dependent on the antibiotic agent. In S. mitis, the newly discovered Rgg/SHP signaling system was able to cross-communicate with $S$. pneumoniae. However, despite the indication of a futile cycle and a possible involvement of immunity mechanisms towards bacteriocins, the presence of this signaling system in $S$. mitis did not affect growth rate during exposure to subinhibitory concentrations of antibiotics. These results also indicated that a short-term treatment with narrow-spectrum Penicillin V altered the fecal microbiome, while the oral microbiome was relatively resilient towards antibiotic disturbances. The resilience of the oral microbiome was observed even after long-term treatment ( 3 months) with amoxicillin. Both short-term treatment with a narrow-spectrum beta lactam antibiotic and long-term treatment with a beta lactam of broader spectrum affected the resistome.

For a long time, research in the field of AMR has mainly focused on pathogens and how the pharmaceutical industry can win the battle against the forever evolving bacteria. Today, the focus has switched from "how we can win this battle", to "how we can slow down the emergence and spread of resistance" so we can still be in the battle. In order to do that, a deeper understanding of how antibiotics function and how it influences the bacteria (and its hosts) is fundamental. In this context, the microbiome represents an important target and tool. Hopefully, the findings in this work may contribute with a piece of information in this massive puzzle, to help manage the global threat of AMR. 


\section{References}

1. Leeuwenhoek AV. Observations, communicated to the publisher by Mr. Antony van Leewenhoeck, in a dutch letter of the 9th Octob. 1676. here English'd: concerning little animals by him observed in rain-well-sea-and snow water; as also in water wherein pepper had lain infused. Philosophical Transactions of the Royal Society of London.

1677;12(133):821-831.

2. Berche P. Louis Pasteur, from crystals of life to vaccination. Clinical Microbiology and Infection. 2012;18:1-6.

3. Carter KC. Ignaz Semmelweis, Carl Mayrhofer, and the rise of germ theory. Medical History. 1985;29(1):33-53.

4. Koch R. Die aetiologie der tuberkulose. 2010.

5. Pasteur L. Mémoire sur la fermentation appelée lactique (Extrait par l'auteur). Molecular Medicine. 1995;1(6):599.

6. Bosch F, Rosich L. The contributions of Paul Ehrlich to pharmacology: a tribute on the occasion of the centenary of his Nobel Prize. Pharmacology. 2008;82(3):171-179.

7. Williams KJ. The introduction of 'chemotherapy' using arsphenamine - the first magic bullet. J $R$ Soc Med. 2009;102(8):343-348.

8. Domagk G. Ein beitrag zur chemotherapie der bakteriellen infektionen. DMW-Deutsche Medizinische Wochenschrift. 1935;61(07):250-253.

9. Fleming A. On the antibacterial action of cultures of a penicillium, with special reference to their use in the isolation of $B$. influenzae. British journal of experimental pathology. 1929;10(3):226.

10. Raper KB, Alexander DF, Coghill RD. Penicillin: II. Natural Variation and Penicillin Production in Penicillium notatum and Allied Species. Journal of bacteriology. 1944;48(6):639-659.

11. Abraham EP, Chain E, Fletcher CM, et al. Further observations on penicillin. The Lancet. 1941;238(6155):177-189.

12. Chain E, Florey HW, Gardner AD, et al. Penicillin as a chemotherapeutic agent. The lancet. 1940;236(6104):226-228.

13. Richards AN. Production of penicillin in the United States (1941-1946). Nature. 1964;201(4918):441-445.

14. Brown ED, Wright GD. Antibacterial drug discovery in the resistance era. Nature. 2016;529(7586):336-343.

15. Ventola CL. The antibiotic resistance crisis: part 1: causes and threats. $P$ t. 2015;40(4):277283.

16. Barber M, Rozwadowska-Dowzenko M. Infection by penicillin-resistant staphylococci. Lancet (London, England). 1948;2(6530):641-644.

17. Barber M. Methicillin-resistant staphylococci. Journal of clinical pathology. 1961;14(4):385.

18. Jevons MP. “Celbenin"-resistant staphylococci. British medical journal. 1961;1(5219):124.

19. Fleming A. Nobel Lecture, December 11, 1945. https://www.nobelprize.org/prizes/medicine/1945/fleming/lecture/. Accessed 2020.08.31.

20. Davies J, Davies D. Origins and evolution of antibiotic resistance. Microbiology and molecular biology reviews : MMBR. 2010;74(3):417-433.

21. IACG. No time to wait: Securing the future from drug resistant infections. https://www.who.int/docs/default-source/documents/no-time-to-wait-securing-the-futurefrom-drug-resistant-infections-en.pdf?sfvrsn $=5 \mathrm{~b} 424 \mathrm{~d} 7 \quad 6$. Published 2019. Accessed 01.10.2020.

22. WHO. Antimicrobial resistance: global report on surveillance. World Health Organization; 2014.

23. Waglechner N, McArthur AG, Wright GD. Phylogenetic reconciliation reveals the natural history of glycopeptide antibiotic biosynthesis and resistance. Nature microbiology. 2019;4(11):1862-1871. 
24. Martinez JL. The role of natural environments in the evolution of resistance traits in pathogenic bacteria. Proceedings Biological sciences. 2009;276(1667):2521-2530.

25. Davies J. Are antibiotics naturally antibiotics? J Ind Microbiol Biotechnol. 2006;33(7):496-499.

26. Fajardo A, Martínez JL. Antibiotics as signals that trigger specific bacterial responses. Current opinion in microbiology. 2008;11(2):161-167.

27. Goh E-B, Yim G, Tsui W, McClure J, Surette MG, Davies J. Transcriptional modulation of bacterial gene expression by subinhibitory concentrations of antibiotics. Proceedings of the National Academy of Sciences. 2002;99(26):17025-17030.

28. Fair RJ, Tor Y. Antibiotics and bacterial resistance in the 21st century. Perspectives in medicinal chemistry. 2014;6:PMC. S14459.

29. Moehring RW, Ashley ED, Davis AE, et al. Development of an electronic definition for deescalation of antibiotics in hospitalized patients. Clinical infectious diseases : an official publication of the Infectious Diseases Society of America. 2020.

30. Årdal C, Blix HS, Plahte J, Røttingen JA. An antibiotic's journey from marketing authorization to use, Norway. Bull World Health Organ. 2017;95(3):220-226.

31. Gerber JS, Ross RK, Bryan M, et al. Association of broad-vs narrow-spectrum antibiotics with treatment failure, adverse events, and quality of life in children with acute respiratory tract infections. Jama. 2017;318(23):2325-2336.

32. Pankey GA, Sabath LD. Clinical Relevance of Bacteriostatic versus Bactericidal Mechanisms of Action in the Treatment of Gram-Positive Bacterial Infections. Clinical Infectious Diseases. 2004;38(6):864-870.

33. Kapoor G, Saigal S, Elongavan A. Action and resistance mechanisms of antibiotics: A guide for clinicians. J Anaesthesiol Clin Pharmacol. 2017;33(3):300-305.

34. Silver LL. Appropriate Targets for Antibacterial Drugs. Cold Spring Harb Perspect Med. 2016;6(12).

35. Koch AL. Bacterial wall as target for attack: past, present, and future research. Clinical microbiology reviews. 2003;16(4):673-687.

36. Wilson DN. Ribosome-targeting antibiotics and mechanisms of bacterial resistance. Nature reviews Microbiology. 2014;12(1):35-48.

37. Collin F, Karkare S, Maxwell A. Exploiting bacterial DNA gyrase as a drug target: current state and perspectives. Applied microbiology and biotechnology. 2011;92(3):479-497.

38. Dixon RA, Chopra I. Polymyxin B and polymyxin B nonapeptide alter cytoplasmic membrane permeability in Escherichia coli. The Journal of antimicrobial chemotherapy. 1986;18(5):557563.

39. Vaara M. Agents that increase the permeability of the outer membrane. Microbiology and Molecular Biology Reviews. 1992;56(3):395-411.

40. Bermingham A, Derrick JP. The folic acid biosynthesis pathway in bacteria: evaluation of potential for antibacterial drug discovery. Bioessays. 2002;24(7):637-648.

41. Hall BG, Barlow M. Evolution of the serine $\beta$-lactamases: past, present and future. Drug Resistance Updates. 2004;7(2):111-123.

42. D'Costa VM, King CE, Kalan L, et al. Antibiotic resistance is ancient. Nature. 2011;477(7365):457-461.

43. WHO. Antibiotic resistance. https://www.who.int/en/news-room/factsheets/detail/antibiotic-resistance. Accessed 04.09.2020.

44. Walsh C. Molecular mechanisms that confer antibacterial drug resistance. Nature. 2000;406(6797):775-781.

45. Hooper DC, Jacoby GA. Mechanisms of drug resistance: quinolone resistance. Ann N Y Acad Sci. 2015;1354(1):12-31.

46. Wang $\mathrm{H}, \mathrm{Wang} \mathrm{J}, \mathrm{Yu} \mathrm{P}$, et al. Identification of antibiotic resistance genes in the multidrugresistant Acinetobacter baumannii strain, MDR-SHH02, using whole-genome sequencing. Int J Mol Med. 2017;39(2):364-372. 
47. Okusu $H, M a D$, Nikaido $H$. AcrAB efflux pump plays a major role in the antibiotic resistance phenotype of Escherichia coli multiple-antibiotic-resistance (Mar) mutants. Journal of bacteriology. 1996;178(1):306-308.

48. Abraham EP, Chain E. An Enzyme from Bacteria able to Destroy Penicillin. Nature. 1940;146(3713):837-837.

49. Holmes AH, Moore LS, Sundsfjord A, et al. Understanding the mechanisms and drivers of antimicrobial resistance. The Lancet. 2016;387(10014):176-187.

50. Graveland H, Wagenaar JA, Heesterbeek H, Mevius D, Van Duijkeren E, Heederik D. Methicillin resistant Staphylococcus aureus ST398 in veal calf farming: human MRSA carriage related with animal antimicrobial usage and farm hygiene. PloS one. 2010;5(6):e10990.

51. Levy SB, FitzGerald GB, Macone AB. Changes in Intestinal Flora of Farm Personnel after Introduction of a Tetracycline-Supplemented Feed on a Farm. New England Journal of Medicine. 1976;295(11):583-588.

52. Liu Y-Y, Wang Y, Walsh TR, et al. Emergence of plasmid-mediated colistin resistance mechanism MCR-1 in animals and human beings in China: a microbiological and molecular biological study. The Lancet infectious diseases. 2016;16(2):161-168.

53. ECDC/EFSA/EMA. Second joint report on the integrated analysis of the consumption of antimicrobial agents and occurrence of antimicrobial resistance in bacteria from humans and food-producing animals: Joint Interagency Antimicrobial Consumption and Resistance Analysis (JIACRA) Report. EFSA Journal. 2017;15(7):e04872.

54. Gullberg E, Cao S, Berg OG, et al. Selection of resistant bacteria at very low antibiotic concentrations. PLoS pathogens. 2011;7(7):e1002158.

55. Martinez J, Baquero F. Mutation frequencies and antibiotic resistance. Antimicrobial agents and chemotherapy. 2000;44(7):1771-1777.

56. Cohen NR, Ross CA, Jain S, et al. A role for the bacterial GATC methylome in antibiotic stress survival. Nature genetics. 2016;48(5):581-586.

57. Ghosh D, Veeraraghavan B, Elangovan R, Vivekanandan P. Antibiotic Resistance and Epigenetics: More to It than Meets the Eye. Antimicrobial agents and chemotherapy. 2020;64(2).

58. Von Wintersdorff CJ, Penders J, Van Niekerk JM, et al. Dissemination of antimicrobial resistance in microbial ecosystems through horizontal gene transfer. Frontiers in microbiology. 2016;7:173.

59. Woerther PL, Burdet C, Chachaty E, Andremont A. Trends in human fecal carriage of extended-spectrum beta-lactamases in the community: toward the globalization of CTX-M. Clinical microbiology reviews. 2013;26(4):744-758.

60. Chaguza C, Cornick JE, Everett DB. Mechanisms and impact of genetic recombination in the evolution of Streptococcus pneumoniae. Computational and structural biotechnology journal. 2015;13:241-247.

61. Slettemeås JS, Urdahl A-M, Mo SS, et al. Imported food and feed as contributors to the introduction of plasmid-mediated colistin-resistant Enterobacteriaceae to a 'low prevalence' country. Journal of Antimicrobial Chemotherapy. 2017;72(9):2675-2677.

62. Nnadozie CF, Odume ON. Freshwater environments as reservoirs of antibiotic resistant bacteria and their role in the dissemination of antibiotic resistance genes. Environ Pollut. 2019;254(Pt B):113067.

63. Guardabassi L, Schwarz S, Lloyd DH. Pet animals as reservoirs of antimicrobial-resistant bacteria: Review. Journal of Antimicrobial Chemotherapy. 2004;54(2):321-332.

64. Oteo J, Navarro C, Cercenado E, et al. Spread of Escherichia coli strains with high-level cefotaxime and ceftazidime resistance between the community, long-term care facilities, and hospital institutions. Journal of clinical microbiology. 2006;44(7):2359-2366.

65. Ostholm-Balkhed A, Tärnberg M, Nilsson M, Nilsson LE, Hanberger H, Hällgren A. Travelassociated faecal colonization with ESBL-producing Enterobacteriaceae: incidence and risk factors. The Journal of antimicrobial chemotherapy. 2013;68(9):2144-2153. 
66. Kroll JS, Wilks KE, Farrant JL, Langford PR. Natural genetic exchange between Haemophilus and Neisseria: intergeneric transfer of chromosomal genes between major human pathogens. Proceedings of the National Academy of Sciences of the United States of America. 1998;95(21):12381-12385.

67. Fitzpatrick DA, Logue ME, Butler G. Evidence of recent interkingdom horizontal gene transfer between bacteria and Candida parapsilosis. BMC evolutionary biology. 2008;8(1):181.

68. Peng Y, Cai J, Wang W, Su B. Multiple inter-kingdom horizontal gene transfers in the evolution of the phosphoenolpyruvate carboxylase gene family. PloS one. 2012;7(12):e51159.

69. Chewapreecha C, Harris SR, Croucher NJ, et al. Dense genomic sampling identifies highways of pneumococcal recombination. Nature genetics. 2014;46(3):305-309.

70. Dagan T, Artzy-Randrup Y, Martin W. Modular networks and cumulative impact of lateral transfer in prokaryote genome evolution. Proceedings of the National Academy of Sciences. 2008;105(29):10039-10044.

71. Lederberg J, Tatum EL. Gene Recombination in Escherichia Coli. Nature. 1946;158(4016):558558.

72. Wozniak RAF, Waldor MK. Integrative and conjugative elements: mosaic mobile genetic elements enabling dynamic lateral gene flow. Nature Reviews Microbiology. 2010;8(8):552563.

73. Smillie C, Garcillán-Barcia MP, Francia MV, Rocha EP, de la Cruz F. Mobility of plasmids. Microbiology and Molecular Biology Reviews. 2010;74(3):434-452.

74. Zinder ND, Lederberg J. Genetic exchange in Salmonella. Journal of bacteriology. 1952;64(5):679.

75. Penadés JR, Chen J, Quiles-Puchalt N, Carpena N, Novick RP. Bacteriophage-mediated spread of bacterial virulence genes. Current opinion in microbiology. 2015;23:171-178.

76. Sender R, Fuchs S, Milo R. Revised estimates for the number of human and bacteria cells in the body. PLoS biology. 2016;14(8):e1002533.

77. Costello EK, Lauber CL, Hamady M, Fierer N, Gordon JI, Knight R. Bacterial community variation in human body habitats across space and time. Science (New York, NY). 2009;326(5960):1694-1697.

78. Martin AM, Sun EW, Rogers GB, Keating DJ. The Influence of the Gut Microbiome on Host Metabolism Through the Regulation of Gut Hormone Release. Frontiers in Physiology. 2019;10(428).

79. Magnúsdóttir S, Ravcheev D, de Crécy-Lagard V, Thiele I. Systematic genome assessment of B-vitamin biosynthesis suggests co-operation among gut microbes. Frontiers in Genetics. 2015;6(148).

80. Neuman H, Debelius JW, Knight R, Koren O. Microbial endocrinology: the interplay between the microbiota and the endocrine system. FEMS microbiology reviews. 2015;39(4):509-521.

81. Kamada N, Chen GY, Inohara N, Núñez G. Control of pathogens and pathobionts by the gut microbiota. Nature immunology. 2013;14(7):685-690.

82. Gensollen T, Iyer SS, Kasper DL, Blumberg RS. How colonization by microbiota in early life shapes the immune system. Science (New York, NY). 2016;352(6285):539-544.

83. Gilbert JA, Blaser MJ, Caporaso JG, Jansson JK, Lynch SV, Knight R. Current understanding of the human microbiome. Nat Med. 2018;24(4):392-400.

84. Berg G, Rybakova D, Fischer D, et al. Microbiome definition re-visited: old concepts and new challenges. Microbiome. 2020;8(1):1-22.

85. Peterson J, Garges S, Giovanni M, et al. The NIH human microbiome project. Genome research. 2009;19(12):2317-2323.

86. NIH Human Microbiome Project. https://www.hmpdacc.org/hmp/overview/. Accessed 08.09.2020.

87. Tamburini S, Shen N, Wu HC, Clemente JC. The microbiome in early life: implications for health outcomes. Nature medicine. 2016;22(7):713-722. 
88. Dominguez-Bello MG, Costello EK, Contreras $\mathrm{M}$, et al. Delivery mode shapes the acquisition and structure of the initial microbiota across multiple body habitats in newborns.

Proceedings of the National Academy of Sciences of the United States of America. 2010;107(26):11971-11975.

89. Ho NT, Li F, Lee-Sarwar KA, et al. Meta-analysis of effects of exclusive breastfeeding on infant gut microbiota across populations. Nature communications. 2018;9(1):4169.

90. Knights D, Silverberg MS, Weersma RK, et al. Complex host genetics influence the microbiome in inflammatory bowel disease. Genome Med. 2014;6(12):107.

91. Ownby DR, Johnson CC, Peterson EL. Exposure to dogs and cats in the first year of life and risk of allergic sensitization at 6 to 7 years of age. Jama. 2002;288(8):963-972.

92. Brooks B, Firek BA, Miller CS, et al. Microbes in the neonatal intensive care unit resemble those found in the gut of premature infants. Microbiome. 2014;2(1):1.

93. Smits SA, Leach J, Sonnenburg ED, et al. Seasonal cycling in the gut microbiome of the Hadza hunter-gatherers of Tanzania. Science (New York, NY). 2017;357(6353):802-806.

94. Gibson MK, Crofts TS, Dantas G. Antibiotics and the developing infant gut microbiota and resistome. Current opinion in microbiology. 2015;27:51-56.

95. Yatsunenko T, Rey FE, Manary MJ, et al. Human gut microbiome viewed across age and geography. Nature. 2012;486(7402):222-227.

96. Byrd AL, Belkaid Y, Segre JA. The human skin microbiome. Nature Reviews Microbiology. 2018;16(3):143-155.

97. Kahharova D, Brandt B, Buijs $M$, et al. Maturation of the oral microbiome in caries-free toddlers: a longitudinal study. Journal of dental research. 2020;99(2):159-167.

98. Dethlefsen L, McFall-Ngai M, Relman DA. An ecological and evolutionary perspective on human-microbe mutualism and disease. Nature. 2007;449(7164):811-818.

99. Young VB. The role of the microbiome in human health and disease: an introduction for clinicians. BMJ (Clinical research ed). 2017;356:j831.

100. Lynch SV, Pedersen O. The Human Intestinal Microbiome in Health and Disease. N Engl J Med. 2016;375(24):2369-2379.

101. Dinan TG, Cryan JF. Gut instincts: microbiota as a key regulator of brain development, ageing and neurodegeneration. J Physiol. 2017;595(2):489-503.

102. Marsh PD. Are dental diseases examples of ecological catastrophes? Microbiology (Reading). 2003;149(Pt 2):279-294.

103. Kebschull A, Demmer R, Papapanou P. "Gum bug, leave my heart alone!"-epidemiologic and mechanistic evidence linking periodontal infections and atherosclerosis. Journal of dental research. 2010;89(9):879-902.

104. Grau AJ, Becher $\mathrm{H}$, Ziegler CM, et al. Periodontal disease as a risk factor for ischemic stroke. Stroke. 2004;35(2):496-501.

105. Looft T, Allen HK. Collateral effects of antibiotics on mammalian gut microbiomes. Gut microbes. 2012;3(5):463-467.

106. Zimmermann $\mathrm{P}$, Curtis $\mathrm{N}$. The effect of antibiotics on the composition of the intestinal microbiota - a systematic review. J Infect. 2019;79(6):471-489.

107. Ianiro G, Tilg H, Gasbarrini A. Antibiotics as deep modulators of gut microbiota: between good and evil. Gut. 2016;65(11):1906-1915.

108. Craig WA. Pharmacokinetic/pharmacodynamic parameters: rationale for antibacterial dosing of mice and men. Clinical infectious diseases. 1998;26(1):1-10.

109. Zaura E, Brandt BW, Teixeira de Mattos MJ, et al. Same Exposure but Two Radically Different Responses to Antibiotics: Resilience of the Salivary Microbiome versus Long-Term Microbial Shifts in Feces. mBio. 2015;6(6):e01693-01615.

110. Jernberg C, Löfmark S, Edlund C, Jansson JK. Long-term ecological impacts of antibiotic administration on the human intestinal microbiota. The ISME journal. 2007;1(1):56-66. 
111. Spinillo A, Capuzzo E, Acciano S, De Santolo A, Zara F. Effect of antibiotic use on the prevalence of symptomatic vulvovaginal candidiasis. Am J Obstet Gynecol. 1999;180(1 Pt 1):14-17.

112. Pépin J, Saheb N, Coulombe MA, et al. Emergence of fluoroquinolones as the predominant risk factor for Clostridium difficile-associated diarrhea: a cohort study during an epidemic in Quebec. Clinical infectious diseases : an official publication of the Infectious Diseases Society of America. 2005;41(9):1254-1260.

113. Scott NA, Andrusaite A, Andersen P, et al. Antibiotics induce sustained dysregulation of intestinal T cell immunity by perturbing macrophage homeostasis. Science translational medicine. 2018;10(464).

114. Marra F, Marra CA, Richardson K, et al. Antibiotic use in children is associated with increased risk of asthma. Pediatrics. 2009;123(3):1003-1010.

115. Azad M, Bridgman S, Becker A, Kozyrskyj A. Infant antibiotic exposure and the development of childhood overweight and central adiposity. International journal of obesity. 2014;38(10):1290-1298.

116. Shaw SY, Blanchard JF, Bernstein CN. Association between the use of antibiotics in the first year of life and pediatric inflammatory bowel disease. American Journal of Gastroenterology. 2010;105(12):2687-2692.

117. Holstiege J, Schink T, Molokhia M, et al. Systemic antibiotic prescribing to paediatric outpatients in 5 European countries: a population-based cohort study. BMC pediatrics. 2014;14:174.

118. Størdal K, Mårild K, Blix HS. [Use of antibiotics in children during the period 2005 - 16]. Tidsskr Nor Legeforen. 2017;137(18).

119. Morley VJ, Woods RJ, Read AF. Bystander Selection for Antimicrobial Resistance: Implications for Patient Health. Trends in microbiology. 2019;27(10):864-877.

120. Andersson DI, Hughes D. Microbiological effects of sublethal levels of antibiotics. Nature reviews Microbiology. 2014;12(7):465-478.

121. Rogers PD, Liu TT, Barker KS, et al. Gene expression profiling of the response of Streptococcus pneumoniae to penicillin. The Journal of antimicrobial chemotherapy. 2007;59(4):616-626.

122. Wright GD. The antibiotic resistome: the nexus of chemical and genetic diversity. Nature reviews Microbiology. 2007;5(3):175-186.

123. D'Costa VM, McGrann KM, Hughes DW, Wright GD. Sampling the antibiotic resistome. Science (New York, NY). 2006;311(5759):374-377.

124. Hu Y, Gao GF, Zhu B. The antibiotic resistome: gene flow in environments, animals and human beings. Frontiers of medicine. 2017;11(2):161-168.

125. Lupo A, Coyne S, Berendonk TU. Origin and evolution of antibiotic resistance: the common mechanisms of emergence and spread in water bodies. Frontiers in microbiology. 2012;3:18.

126. Ysern P, Clerch B, Castańo M, Gibert I, Barbé J, Llagostera M. Induction of SOS genes in Escherichia coli and mutagenesis in Salmonella typhimurium by fluoroquinolones. Mutagenesis. 1990;5(1):63-66.

127. Kohanski MA, DePristo MA, Collins JJ. Sublethal antibiotic treatment leads to multidrug resistance via radical-induced mutagenesis. Molecular cell. 2010;37(3):311-320.

128. Prudhomme M, Attaiech L, Sanchez G, Martin B, Claverys JP. Antibiotic stress induces genetic transformability in the human pathogen Streptococcus pneumoniae. Science (New York, NY). 2006;313(5783):89-92.

129. Slager J, Kjos M, Attaiech L, Veening JW. Antibiotic-induced replication stress triggers bacterial competence by increasing gene dosage near the origin. Cell. 2014;157(2):395-406.

130. Stevens KE, Chang D, Zwack EE, Sebert ME. Competence in Streptococcus pneumoniae is regulated by the rate of ribosomal decoding errors. mBio. 2011;2(5).

131. Barr V, Barr K, Millar MR, Lacey RW. Beta-lactam antibiotics increase the frequency of plasmid transfer in Staphylococcus aureus. The Journal of antimicrobial chemotherapy. 1986;17(4):409-413. 
132. Liu G, Bogaj K, Bortolaia V, Olsen JE, Thomsen LE. Antibiotic-Induced, Increased Conjugative Transfer Is Common to Diverse Naturally Occurring ESBL Plasmids in Escherichia coli. Frontiers in microbiology. 2019;10:2119.

133. Lancefield RC. A SEROLOGICAL DIFFERENTIATION OF HUMAN AND OTHER GROUPS OF HEMOLYTIC STREPTOCOCCI. J EXP Med. 1933;57(4):571-595.

134. Richards VP, Palmer SR, Pavinski Bitar PD, et al. Phylogenomics and the dynamic genome evolution of the genus Streptococcus. Genome Biol Evol. 2014;6(4):741-753.

135. Carapetis JR, Steer AC, Mulholland EK, Weber M. The global burden of group A streptococcal diseases. The Lancet infectious diseases. 2005;5(11):685-694.

136. Seale AC, Bianchi-Jassir F, Russell NJ, et al. Estimates of the burden of group B streptococcal disease worldwide for pregnant women, stillbirths, and children. Clinical infectious diseases. 2017;65(suppl_2):S200-S219.

137. HMP Consortium. Structure, function and diversity of the healthy human microbiome. Nature. 2012;486(7402):207-214.

138. Abranches J, Zeng L, Kajfasz JK, et al. Biology of Oral Streptococci. Microbiology spectrum. 2018;6(5).

139. La Mantia I, Varricchio A, Ciprandi G. Bacteriotherapy with Streptococcus salivarius 24SMB and Streptococcus oralis 89a nasal spray for preventing recurrent acute otitis media in children: a real-life clinical experience. Int J Gen Med. 2017;10:171-175.

140. Shekhar S, Khan R, Schenck K, Petersen FC. Intranasal immunization with the commensal Streptococcus mitis confers protective immunity against pneumococcal lung infection. Applied and environmental microbiology. 2019;85(6).

141. O'Brien KL, Wolfson LJ, Watt JP, et al. Burden of disease caused by Streptococcus pneumoniae in children younger than 5 years: global estimates. Lancet (London, England). 2009;374(9693):893-902.

142. Weiser JN. The pneumococcus: why a commensal misbehaves. Journal of molecular medicine (Berlin, Germany). 2010;88(2):97-102.

143. Bentley SD, Aanensen DM, Mavroidi A, et al. Genetic analysis of the capsular biosynthetic locus from all 90 pneumococcal serotypes. PLoS Genet. 2006;2(3):e31.

144. Balsells E, Dagan R, Yildirim I, et al. The relative invasive disease potential of Streptococcus pneumoniae among children after PCV introduction: A systematic review and meta-analysis. J Infect. 2018;77(5):368-378.

145. Griffith F. The significance of pneumococcal types. Epidemiology \& Infection. 1928;27(2):113159.

146. Avery OT, MacLeod CM, McCarty M. Studies on the chemical nature of the substance inducing transformation of pneumococcal types: induction of transformation by a desoxyribonucleic acid fraction isolated from pneumococcus type III. The Journal of experimental medicine. 1944;79(2):137-158.

147. Pearce $C$, Bowden GH, Evans M, et al. Identification of pioneer viridans streptococci in the oral cavity of human neonates. Journal of medical microbiology. 1995;42(1):67-72.

148. Kilian M, Riley DR, Jensen A, Bruggemann H, Tettelin H. Parallel evolution of Streptococcus pneumoniae and Streptococcus mitis to pathogenic and mutualistic lifestyles. $m$ Bio. 2014;5(4):e01490-01414.

149. Tunkel AR, Sepkowitz KA. Infections caused by viridans streptococci in patients with neutropenia. Clinical infectious diseases : an official publication of the Infectious Diseases Society of America. 2002;34(11):1524-1529.

150. Kawamura Y, Hou XG, Sultana F, Miura H, Ezaki T. Determination of 16S rRNA sequences of Streptococcus mitis and Streptococcus gordonii and phylogenetic relationships among members of the genus Streptococcus. International journal of systematic bacteriology. 1995;45(2):406-408. 
151. Jensen A, Valdorsson O, Frimodt-Moller N, Hollingshead S, Kilian M. Commensal streptococci serve as a reservoir for beta-lactam resistance genes in Streptococcus pneumoniae.

Antimicrobial agents and chemotherapy. 2015;59(6):3529-3540.

152. Loesche WJ, Rowan J, Straffon LH, Loos PJ. Association of Streptococcus mutants with human dental decay. Infection and immunity. 1975;11(6):1252-1260.

153. Hamada S, Slade HD. Biology, immunology, and cariogenicity of Streptococcus mutans. Microbiol Rev. 1980;44(2):331-384.

154. Wan AK, Seow WK, Purdie DM, Bird PS, Walsh L, Tudehope DI. A longitudinal study of Streptococcus mutans colonization in infants after tooth eruption. Journal of dental research. 2003;82(7):504-508.

155. Nakano K, Ooshima T. Serotype classification of Streptococcus mutans and its detection outside the oral cavity. Future microbiology. 2009;4(7):891-902.

156. Nealson KH, Platt T, Hastings JW. Cellular control of the synthesis and activity of the bacterial luminescent system. Journal of bacteriology. 1970;104(1):313-322.

157. Tomasz A. Control of the competent state in Pneumococcus by a hormone-like cell product: an example for a new type of regulatory mechanism in bacteria. Nature. 1965;208(5006):155-159.

158. Miller MB, Bassler BL. Quorum sensing in bacteria. Annual Reviews in Microbiology. 2001;55(1):165-199.

159. Håvarstein LS, Coomaraswamy G, Morrison DA. An unmodified heptadecapeptide pheromone induces competence for genetic transformation in Streptococcus pneumoniae. Proceedings of the National Academy of Sciences of the United States of America. 1995;92(24):11140-11144.

160. Pestova EV, Håvarstein LS, Morrison DA. Regulation of competence for genetic transformation in Streptococcus pneumoniae by an auto-induced peptide pheromone and a two-component regulatory system. Molecular microbiology. 1996;21(4):853-862.

161. Ween O, Gaustad P, Håvarstein LS. Identification of DNA binding sites for ComE, a key regulator of natural competence in Streptococcus pneumoniae. Molecular microbiology. 1999;33(4):817-827.

162. Straume D, Stamsas GA, Håvarstein LS. Natural transformation and genome evolution in Streptococcus pneumoniae. Infection, genetics and evolution : journal of molecular epidemiology and evolutionary genetics in infectious diseases. 2015;33:371-380.

163. Sung CK, Morrison DA. Two distinct functions of ComW in stabilization and activation of the alternative sigma factor ComX in Streptococcus pneumoniae. Journal of bacteriology. 2005;187(9):3052-3061.

164. Shanker E, Federle MJ. Quorum Sensing Regulation of Competence and Bacteriocins in Streptococcus pneumoniae and mutans. Genes (Basel). 2017;8(1).

165. Slager J, Aprianto R, Veening JW. Refining the Pneumococcal Competence Regulon by RNA Sequencing. Journal of bacteriology. 2019;201(13).

166. Håvarstein LS. Increasing competence in the genus Streptococcus. Molecular microbiology. 2010;78(3):541-544.

167. Khan R, Rukke HV, Ricomini Filho AP, et al. Extracellular identification of a processed type II ComR/ComS pheromone of Streptococcus mutans. Journal of bacteriology. 2012;194(15):3781-3788.

168. Fontaine L, Boutry $\mathrm{C}$, de Frahan $\mathrm{MH}$, et al. A novel pheromone quorum-sensing system controls the development of natural competence in Streptococcus thermophilus and Streptococcus salivarius. Journal of bacteriology. 2010;192(5):1444-1454.

169. Mashburn-Warren L, Morrison DA, Federle MJ. A novel double-tryptophan peptide pheromone controls competence in Streptococcus spp. via an Rgg regulator. Molecular microbiology. 2010;78(3):589-606. 
170. Sulavik MC, Tardif G, Clewell DB. Identification of a gene, rgg, which regulates expression of glucosyltransferase and influences the Spp phenotype of Streptococcus gordonii Challis. Journal of bacteriology. 1992;174(11):3577-3586.

171. Ibrahim M, Guillot A, Wessner F, et al. Control of the transcription of a short gene encoding a cyclic peptide in Streptococcus thermophilus: a new quorum-sensing system? Journal of bacteriology. 2007;189(24):8844-8854.

172. Chang JC, LaSarre B, Jimenez JC, Aggarwal C, Federle MJ. Two group A streptococcal peptide pheromones act through opposing Rgg regulators to control biofilm development. PLOS pathogens. 2011;7(8):e1002190.

173. Junges R, Salvadori G, Shekhar S, et al. A Quorum-Sensing System That Regulates Streptococcus pneumoniae Biofilm Formation and Surface Polysaccharide Production. mSphere. 2017;2(5).

174. Zutkis AA, Anbalagan S, Chaussee MS, Dmitriev AV. Inactivation of the Rgg2 transcriptional regulator ablates the virulence of Streptococcus pyogenes. PloS one. 2014;9(12):e114784.

175. Tettelin H, Nelson KE, Paulsen IT, et al. Complete genome sequence of a virulent isolate of Streptococcus pneumoniae. Science (New York, NY). 2001;293(5529):498-506.

176. Aaberge IS, Eng J, Lermark G, Løvik M. Virulence of Streptococcus pneumoniae in mice: a standardized method for preparation and frozen storage of the experimental bacterial inoculum. Microbial pathogenesis. 1995;18(2):141-152.

177. Salvadori G, Junges R, Morrison DA, Petersen FC. Overcoming the Barrier of Low Efficiency during Genetic Transformation of Streptococcus mitis. Frontiers in microbiology. 2016;7:1009.

178. Hurst A. Nisin. In: Advances in applied microbiology. Vol 27. Elsevier; 1981:85-123.

179. Waidmann MS, Bleichrodt FS, Laslo T, Riedel CU. Bacterial luciferase reporters: the Swiss army knife of molecular biology. Bioeng Bugs. 2011;2(1):8-16.

180. Chen JD, Morrison DA. Modulation of competence for genetic transformation in Streptococcus pneumoniae. Journal of general microbiology. 1987;133(7):1959-1967.

181. Turnbaugh PJ, Ley RE, Hamady M, Fraser-Liggett CM, Knight R, Gordon JI. The human microbiome project. Nature. 2007;449(7164):804-810.

182. Janda JM, Abbott SL. 16S rRNA gene sequencing for bacterial identification in the diagnostic laboratory: pluses, perils, and pitfalls. Journal of clinical microbiology. 2007;45(9):2761-2764.

183. Bragg L, Tyson GW. Metagenomics using next-generation sequencing. Methods in molecular biology (Clifton, NJ). 2014;1096:183-201.

184. Quince C, Walker AW, Simpson JT, Loman NJ, Segata N. Shotgun metagenomics, from sampling to analysis. Nature biotechnology. 2017;35(9):833-844.

185. Choo JM, Leong LE, Rogers GB. Sample storage conditions significantly influence faecal microbiome profiles. Scientific reports. 2015;5:16350.

186. Lozupone CA, Stombaugh J, Gonzalez A, et al. Meta-analyses of studies of the human microbiota. Genome research. 2013;23(10):1704-1714.

187. Sui HY, Weil AA, Nuwagira E, et al. Impact of DNA Extraction Method on Variation in Human and Built Environment Microbial Community and Functional Profiles Assessed by Shotgun Metagenomics Sequencing. Frontiers in microbiology. 2020;11:953.

188. HMP. Manual of Procedures for Human Microbiome Project. https://www.hmpdacc.org/hmp/doc/HMP MOP Version12 0 072910.pdf. Published 2010. Accessed 01.10.2020.

189. Jones MB, Highlander SK, Anderson EL, et al. Library preparation methodology can influence genomic and functional predictions in human microbiome research. Proceedings of the National Academy of Sciences. 2015;112(45):14024-14029.

190. Bolger AM, Lohse M, Usadel B. Trimmomatic: a flexible trimmer for Illumina sequence data. Bioinformatics (Oxford, England). 2014;30(15):2114-2120.

191. Marotz CA, Sanders JG, Zuniga C, Zaramela LS, Knight R, Zengler K. Improving saliva shotgun metagenomics by chemical host DNA depletion. Microbiome. 2018;6(1):42. 
192. Langmead B, Salzberg SL. Fast gapped-read alignment with Bowtie 2. Nature methods. 2012;9(4):357.

193. McIntyre AB, Ounit R, Afshinnekoo $E$, et al. Comprehensive benchmarking and ensemble approaches for metagenomic classifiers. Genome biology. 2017;18(1):182.

194. Knight R, Vrbanac A, Taylor BC, et al. Best practices for analysing microbiomes. Nature Reviews Microbiology. 2018;16(7):410-422.

195. Wood DE, Salzberg SL. Kraken: ultrafast metagenomic sequence classification using exact alignments. Genome biology. 2014;15(3):R46.

196. Truong DT, Franzosa EA, Tickle TL, et al. MetaPhIAn2 for enhanced metagenomic taxonomic profiling. Nature methods. 2015;12(10):902-903.

197. Zankari E, Hasman $\mathrm{H}$, Cosentino $\mathrm{S}$, et al. Identification of acquired antimicrobial resistance genes. Journal of antimicrobial chemotherapy. 2012;67(11):2640-2644.

198. Arango-Argoty G, Garner E, Pruden A, Heath LS, Vikesland P, Zhang L. DeepARG: a deep learning approach for predicting antibiotic resistance genes from metagenomic data. Microbiome. 2018;6(1):23.

199. Soriano F, Rodriguez-Cerrato V. Pharmacodynamic and kinetic basis for the selection of pneumococcal resistance in the upper respiratory tract. The Journal of antimicrobial chemotherapy. 2002;50 Suppl S2:51-58.

200. Peterson SN, Sung CK, Cline R, et al. Identification of competence pheromone responsive genes in Streptococcus pneumoniae by use of DNA microarrays. Molecular microbiology. 2004;51(4):1051-1070.

201. Claverys JP, Prudhomme M, Martin B. Induction of competence regulons as a general response to stress in gram-positive bacteria. Annual review of microbiology. 2006;60:451475.

202. Engelmoer DJ, Rozen DE. Competence increases survival during stress in Streptococcus pneumoniae. Evolution; international journal of organic evolution. 2011;65(12):3475-3485.

203. Cook LC, Federle MJ. Peptide pheromone signaling in Streptococcus and Enterococcus. FEMS microbiology reviews. 2014;38(3):473-492.

204. Domenech A, Slager J, Veening JW. Antibiotic-Induced Cell Chaining Triggers Pneumococcal Competence by Reshaping Quorum Sensing to Autocrine-Like Signaling. Cell reports. 2018;25(9):2390-2400.e2393.

205. Zhao X, Yu Z, Ding T. Quorum-Sensing Regulation of Antimicrobial Resistance in Bacteria. Microorganisms. 2020;8(3).

206. Croucher NJ, Walker D, Romero P, et al. Role of conjugative elements in the evolution of the multidrug-resistant pandemic clone Streptococcus pneumoniae Spain23F ST81. Journal of bacteriology. 2009;191(5):1480-1489.

207. Goossens H, Ferech M, Vander Stichele R, Elseviers M. Outpatient antibiotic use in Europe and association with resistance: a cross-national database study. Lancet (London, England). 2005;365(9459):579-587.

208. ECDC. Most frequently used antimicrobial agents in acute care hospitals in EU/EEA, all indications, all specialties. ECDC PPS 2011-2012 Web site.

https://www.ecdc.europa.eu/en/healthcare-associated-infections-acute-carehospitals/database/antimicrobial-use-indication-specialty/agents. Published 2013. Accessed 07.09.2020.

209. Rosier B, Marsh P, Mira A. Resilience of the oral microbiota in health: mechanisms that prevent dysbiosis. Journal of dental research. 2018;97(4):371-380.

210. Edlund C, Sjöstedt S, Nord CE. Comparative effects of levofloxacin and ofloxacin on the normal oral and intestinal microflora. Scandinavian journal of infectious diseases. 1997;29(4):383-386.

211. Steinbakk M, Lingaas E, Carlstedt-Duke B, et al. Faecal concentration of ten antibiotics and influence on some microflora-associated characteristics (MACs). Microbial ecology in health and disease. 1992;5(5):269-276. 
212. Storheim K, Espeland A, Grovle L, et al. Antibiotic treatment In patients with chronic low back pain and Modic changes (the AIM study): study protocol for a randomised controlled trial. Trials. 2017;18(1):596.

213. Palleja A, Mikkelsen KH, Forslund SK, et al. Recovery of gut microbiota of healthy adults following antibiotic exposure. Nature microbiology. 2018;3(11):1255-1265.

214. Yamasaki K, Kawanami T, Yatera K, et al. Significance of anaerobes and oral bacteria in community-acquired pneumonia. PloS one. 2013;8(5):e63103. 

I 



\title{
Antibiotics alter the window of competence for natural transformation in streptococci
}

\author{
\begin{tabular}{l|l|l|l|l} 
K. Sturød | G. Salvadori | R. Junges | F.C. Petersen (1) &
\end{tabular}
}

Department of Oral Biology, Faculty of Dentistry, University of Oslo, Oslo, Norway

Correspondence: Fernanda Cristina Petersen, Postboks 1052, Blindern, 0316, Department of Oral Biology, Faculty of Dentistry, University of Oslo, Oslo, Norway (f.c.petersen@odont.uio.no).

\begin{abstract}
Summary
Streptococcus pneumoniae transformation occurs within a short competence window, during which the alternative sigma factor $\mathrm{X}(\mathrm{SigX})$ is activated to orchestrate the expression of genes allowing extracellular DNA uptake and recombination. Importantly, antibiotic stress promotes transcriptional changes that may affect more than $20 \%$ of the S. pneumoniae genome, including competence genes. These can be activated or repressed, depending on the antibiotic agent. For most antibiotics, however, it remains unknown whether transcriptional effects on competence translate into altered transformability. Here we investigate the effect of antibiotic subinhibitory concentrations on sigX expression using a luciferase reporter, and correlate for the first time with transformation kinetics. Induction of sigX expression by ciprofloxacin and novobiocin correlated with increased and prolonged transformability in S. pneumoniae. The prolonged effect of ciprofloxacin on competence and transformation was also observed in the streptococcal relatives Streptococcus mitis and Streptococcus mutans. In contrast, tetracycline and erythromycin, which induced S. pneumoniae sigX expression, had either an inhibitory or a nonsignificant effect on transformation, whereas streptomycin and the $\beta$-lactam ampicillin, inhibited both sig $X$ expression and transformation. Thus, the results show that antibiotics may vary in their effects on competence, ranging from inhibitory to stimulatory effects, and that responses affecting transcription of $\operatorname{sig} X$ do not always correlate with the transformation outcomes. Antibiotics that increase or decrease transformation are of particular clinical relevance, as they may alter the ability of S.pneumoniae to escape vaccines and antibiotics.
\end{abstract}

\section{KEYWORDS}

antibiotics, competence, natural transformation, quorum sensing, Streptococcus

\section{1 | INTRODUCTION}

Antibiotics are one of the most important pillars in modern medicine since they were introduced nearly eight decades ago. ${ }^{1}$ However, their effectiveness is now threatened by the alarming spread of antibiotic-resistant bacteria. ${ }^{2}$ Among the most important mechanisms for rapid spread of resistance are those involved in horizontal gene transfer, including conjugation, transduction and natural transformation. ${ }^{3}$ Interestingly, for all three mechanisms there are examples of antibiotics that at subinhibitory concentrations stimulate DNA transfer. ${ }^{4-6}$ Such antibiotic effects contrast with the traditional view that antibiotics are specific in affecting particular target sites within the bacteria. ${ }^{7}$ Antibiotic stress affects the expression of a variety of genes, activating not only behaviours involved in DNA transfer, ${ }^{6,8}$ but also mutation frequencies, ${ }^{9,10}$ biofilm formation, ${ }^{11}$ and virulence. ${ }^{12,13}$ 
Streptococcus pneumoniae is a common inhabitant of the nasopharynx and it is responsible for a significant global burden of morbidity and mortality. S. pneumoniae can cause serious diseases such as pneumonia, meningitis and bacteremia. ${ }^{14-16}$ The genomic plasticity of S. pneumoniae is remarkable, and reflects its ability to develop competence. ${ }^{17}$ Competence is a physiological state during which genes allowing for killing of siblings, DNA uptake and recombination are upregulated in response to quorum-sensing signals. ${ }^{18,19}$ In S. pneumoniae, the competent state is activated by the accumulation of a competence signalling peptide (CSP) in the extracellular environment. ${ }^{20}$ When the threshold concentration is reached, CSP binds to and autophosphorylates the membrane-bound receptor ComD, which in turn transfers a phosphoryl group to the response regulator ComE. ${ }^{21}$ ComE stimulates transcription of the so-called early genes, by binding to their promoter region. Among the early genes activated is com $C$, which encodes the pre-CSP and comAB. Com $A B$ encodes a transporting system for the processing and export of CSP out of the cell. The promoter for the alternative sigma factor sigX is also recognized by phosphorylated-ComE. SigX is the master regulator of competence responsible for the link between the early and late responses. Transcription of the genes responsible for fratricide, DNA uptake and recombination, are all under the control of SigX. ${ }^{21-23}$ Natural transformation is considered the most important mechanism for the spread of resistance genes and emergence of vaccine escape variants in S. pneumoniae. ${ }^{18}$

Upper airway and ear infections by S. pneumoniae are some of the major reasons for antibiotic prescription in young children. ${ }^{24}$ Importantly, subinhibitory concentrations of several antibiotics activate the expression of competence genes in S. pneumoniae ${ }^{6,25,26}$ including the protein synthesis inhibitors kanamycin and streptomycin, ${ }^{6,25,26}$ as well as fluoroquinolones, including norfloxacin, levofloxacin and moxifloxacin. ${ }^{6}$ Although such effects are generally interpreted as indicative of an increased ability for transformation, assessment of antibiotic effects on transformation has only been reported for streptomycin and norfloxacin at a single time-point during growth, and for two DNA damaging agents: mitomycin and 6-( $p$-hydroxyphenylazol)uracil. ${ }^{6,25}$ Another constraint of current studies is that the correlation between the expression of competence genes and transformation has only been assessed under conditions that repress natural competence, hence precluding the identification of antibiotic effects that may inhibit transformation. Hence, there is currently limited knowledge regarding the actual effects of antibiotics on S. pneumoniae transformability.

Given the fact that antibiotics may regulate as much as $20 \%$ of the genes in S. pneumoniae genome, ${ }^{27}$ and that a recent report shows disrupted coordination between transcriptional and phenotypic responses to antibiotics, ${ }^{28}$ it is possible that altered expression of competence genes will not result in a corresponding effect on transformation. Of note, the machinery required for transformation is complex, and requires, among other mechanisms, a proper assembly of surface proteins that participate in the formation of pili and membrane pores for DNA import, and of several proteins that enable recombination of the income DNA within the genome. ${ }^{29}$ In this study, subinhibitory concentrations of six different antibiotic agents were investigated for their effects on sigX expression using a luciferase reporter, and correlated for the first time with detailed kinetic data on transformation. The results revealed that antibiotics may vary in their effects on competence, ranging from inhibitory to stimulatory effects, and that responses affecting transcription of sigX do not always correlate with kinetic changes in transformability.

\section{2 | MATERIALS AND METHODS}

\section{1 | Bacterial strains and media}

All bacterial strains used in this study are described in Table 1. Bacterial stocks were stored at $-80^{\circ} \mathrm{C}$ in tryptic soy broth (SoybeanCasein Digest medium, Bacto ${ }^{\mathrm{TM}}$ ) supplemented with $30 \%$ glycerol. Blood agar base (Oxoid, Basingstoke, UK) supplemented with 5\% defibrinated sheep blood (Oxoid) was used for plating. Selective plates were supplemented with either kanamycin $\left(500 \mu \mathrm{g} \mathrm{mL}^{-1}\right)$ or erythromycin $\left(10 \mu \mathrm{g} \mathrm{mL}^{-1}\right)$. Luciferase reporter and transformation assays were performed in casitone-yeast medium $(\mathrm{C}+\mathrm{Y})$ or modified casitone-yeast medium $\left(\mathrm{C}+\mathrm{Y}_{\mathrm{YB}}\right)$.

\section{2 | Synthetic peptide and antibiotics}

The sequence of the synthetic CSPs used in this study is listed in Table 1. Stock solutions were prepared by resuspending CSP-1 and CSP-Streptococcus mitis in distilled water to a concentration of $0.5 \mathrm{~mm}$ and $10 \mathrm{~mm}$, respectively, and storing it at $-20^{\circ} \mathrm{C}$. For each experiment, antibiotics were diluted into correct concentrations in $\mathrm{C}+\mathrm{Y}$ or $\mathrm{C}+\mathrm{Y}_{\mathrm{YB}}$. Antibiotic stocks were prepared in distilled water (erythromycin was prepared in ethanol, ciprofloxacin in $0.1 \mathrm{M} \mathrm{HCl}$ ) and stored at $-20^{\circ} \mathrm{C}$ at the following concentrations: ampicillin (50 mg mL ${ }^{-1}$ ), ciprofloxacin (25 $\left.\mathrm{mg} \mathrm{mL}^{-1}\right)$, erythromycin $\left(20 \mathrm{mg} \mathrm{mL}^{-1}\right.$ ), kanamycin (100 $\left.\mathrm{mg} \mathrm{mL}^{-1}\right)$, novobiocin $\left(2.5 \mathrm{mg} \mathrm{mL}^{-1}\right)$, streptomycin (25 mg mL $\mathrm{mb}^{-1}$ ), tetracycline (12.5 $\mathrm{mg} \mathrm{mL}^{-1}$ ).

\section{3 | Construction of mutants}

For construction of SPO20 (comC-luciferase reporter) and SP032 (Idhluciferase reporter), the primer pairs FP423/FP424 and FP516/FP517, respectively, were used to amplify the specific promoter regions from S. pneumoniae TIGR4 (ATCC BAA334). The amplicon was further ligated to the pFW5-luc plasmid $\left(\mathrm{Spec}^{\mathrm{R}}\right)$ and cloned into Escherichia coli as previously described. ${ }^{30}$ Plasmids with the correct insert were then purified and transformed into the TIGR4 strain. SP045 ( $\Delta$ shp0939 $)^{31}$ was constructed using a polymerase chain reaction (PCR) mutagenesis strategy. ${ }^{32}$ Briefly, fragments in the upstream and downstream region of shp0939 were amplified with primer pairs FP952/FP953 and FP954/FP955, respectively. A third fragment containing a kanamycin resistance cassette was amplified from plasmid pR410. The PCR fragments were then purified (QIAquick PCR purification kit), restriction sites were digested with Ascl and Fsel enzymes (New England Biolabs, Ipswich, MA), and the fragments were ligated with T4 DNA ligase 
TABLE 1 Strains, primers and synthetic pheromones used in this study

\begin{tabular}{|c|c|c|}
\hline Strains & Description & Source or references \\
\hline NCTC 7466 & Streptococcus pneumoniae D39 & NCTC \\
\hline АТСС ВААЗ34 & S. pneumoniae TIGR4 & ATCC \\
\hline SP047 & D39 but $\mathrm{p}_{\text {sigx }}$-luc: $\mathrm{Spt}^{\mathrm{R}}$, DNA from SP039 & This study \\
\hline SP020 & BAA334, but $p_{\text {comc }}$-luc: $S p t^{R}$ & This study \\
\hline SP039 & BAA334 but $\mathrm{p}_{\text {sigx }} x^{-l u c:}$ Spt ${ }^{R,}$ DNA from MI055 & This study \\
\hline SP032 & BAA334, but $\mathrm{p}_{\text {ldh }}$-luc; $\mathrm{Spt}^{\mathrm{R}}$ & This study \\
\hline MI055 & CCUG 31611, $\mathrm{p}_{\text {sigx }}-\mathrm{luc}_{\mathrm{U}} \mathrm{Spt}^{\mathrm{R}}$ & Salvadori et al. ${ }^{a}$ \\
\hline SM068 & UA159, $P_{\text {sigx }}-{ }^{-l u c:} \mathrm{Spt}^{\mathrm{R}}$ & Khan et al. ${ }^{\mathrm{b}}$ \\
\hline SP045 & D39, $\Delta$ shp0939, $\mathrm{Kan}^{\mathrm{R}}$ & This study \\
\hline M1009 & CCUG 31611, $\Delta s r t A$, Ery $^{R}$ & Salvadori et al. ${ }^{a}$ \\
\hline SM045 & UA159, but $\Delta \operatorname{dexA}, \mathrm{Kan}^{\mathrm{R}}$ & Morrison et al. ${ }^{c}$ \\
\hline Primers for PCR amplicons (donor DNA) & Sequence $\left(5^{\prime}\right.$ to $\left.3^{\prime}\right)$ & Description \\
\hline FP906 & ATTCACCCCAAAAAGTGCTG & \multirow{2}{*}{$\begin{array}{r}\text { Streptococcus mutans: aRJO2 } \\
\left(6,3 \mathrm{~kb}, \mathrm{Kan}^{\mathrm{R}} \text {, from SM045) }\right.\end{array}$} \\
\hline FP907 & ATAATATGCGGACGCTGAGG & \\
\hline FP914 & TCTCGCGGAAGATAAAGTCG & \multirow{2}{*}{$\begin{array}{l}\text { Streptococcus mitis: aRJ20a } \\
\left(6,9 \text { kb, Ery }{ }^{\mathrm{R}} \text {, from MI009) }\right.\end{array}$} \\
\hline FP915 & GGGTTAGCAGCAACAAGGAA & \\
\hline FP1175 & TCTGGTTGTCGCAAGAGAAA & \multirow{2}{*}{$\begin{array}{l}\text { S. pneumoniae: aKSO1 } \\
\text { (6,0 kb, Kan }{ }^{R} \text {, from SP045) }\end{array}$} \\
\hline FP1176 & TGGAACCTCATATCCCTCCA & \\
\hline Primers for mutant construction & Sequence $\left(5^{\prime}\right.$ to $\left.3^{\prime}\right)$ & Restriction site \\
\hline \multicolumn{3}{|l|}{ SP045 } \\
\hline FP952 & AAAATTTCACGAGAATGCCTTA & \\
\hline FP953 & aggcgcgccTTGTTGGGAAAATGGGAAAA & - \\
\hline FP954 & aggccggccCGTAGAAAGTTTAACATACGATGA & Ascl \\
\hline FP955 & TCCCTCAGCATAGGTAACTCC & Fsel \\
\hline FP001 & aggcgcgccGTTTGATTTTTAATG & - \\
\hline FP068 & aggccggecTAGGTACTAAAACAATTCATCCAGTA & Ascl (kanamycin cassette) \\
\hline FP037 & TCATTTTCTCCCACCAGCTT & Fsel (kanamycin cassette) \\
\hline FP109 & CAAGCCTGATTGGGAGAAAA & - \\
\hline \multicolumn{3}{|l|}{ SP020 } \\
\hline FP423 & aaagtcgacGGCCAGTGAATCAGAAAATCA & Sall \\
\hline FP424 & aggatccAATCCTCATCTCCCCACCTT & BamHI \\
\hline \multicolumn{3}{|l|}{ SP032 } \\
\hline FP516 & agctagcTCCATGACCAACTTCACTGC & Nhel \\
\hline FP517 & aggatccCACCATCACCGACAAGGATA & $\mathrm{BamHI}$ \\
\hline Competence stimulating peptide (CSP) & Sequence & Source of reference \\
\hline CSP-1 (S. pneumoniae D39) & EMRLSKFFRDFILQRKK & Håvarstein et al. ${ }^{d}$ \\
\hline CSP-S. mitis (CCUG 31611) & EIRQTHNIFFNFFKRR & Håvarstein et al. ${ }^{\mathrm{e}}$ \\
\hline
\end{tabular}

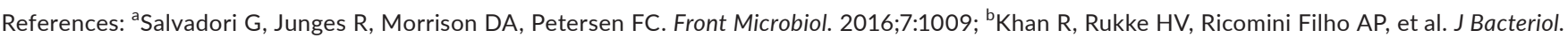
2012;194:3781-3788; ' Morrison DA, Khan R, Junges R, Amdal HA, Petersen FC. J Microbiol Methods. 2015;119:134-141; 'Håvarstein LS, Coomaraswamy G, Morrison DA. Proc Natl Acad Sci U S A. 1995;92:11140-11144; ' Håvarstein LS, Hakenbeck R, Gaustad P. J Bacteriol. 1997;179:6589-6594.

(Fermentas, St.Leon, Germany). Confirmation of the insertion was performed by phenotypic characterization (kanamycin resistance) and genotyping using primer pairs FP952/FP037 and FP955/FP109. For the reporter strain SP047, the $\mathrm{p}_{\text {sigX }}$-luc locus was transformed into S. pneumoniae D39 (NCTC 7466) with DNA from SP039. This strain (SP039) was constructed using transforming DNA from the previously reported S. mitis strain MI055 into the TIGR4 strain ATCC BAA334 by natural transformation. 


\section{4 | Donor DNA amplicons}

Bacterial DNA (from strains SP045, MI009 and SM045) and the PCR primers to construct the 6-kb, $\mathrm{Kan}^{\mathrm{R}}$-amplicon used as donor in the transformation assays are listed in Table 1 . The DNA fragment was amplified by PCR using Q5 DNA polymerase (New England Biolabs) following the manufacturer's instructions. Optimal annealing temperature was calculated using the NEB Tm Calculator (online software provided by New England BioLabs).

\section{5 | Luciferase reporter assays}

Antibiotics were diluted to different concentrations and divided into aliquots $(100 \mu \mathrm{L}$ per well) in a white 96 -well plate with clear bottom (Nunc ${ }^{\mathrm{TM}}$ MicroWell ${ }^{\mathrm{TM}}$ 96-Well Optical-Bottom Plate). All experiments contained a control without antibiotics in addition to a blank medium control. Bacterial cultures were prepared by inoculating fresh colonies grown overnight in fresh medium until an optical density at $600 \mathrm{~nm}\left(\mathrm{OD}_{600}\right)$ of $0.08(2 \times)$. Cultures were incubated for 15 minutes at $37^{\circ} \mathrm{C}, 5 \% \mathrm{CO}_{2}$ before addition of CSP and/or luciferin (100 $\mathrm{ng} \mathrm{mL}^{-1}$ ) (Synchem, Felsberg-Altenberg, Germany). Next, $100 \mu \mathrm{L}$ aliquots of the culture were added to wells containing the antibiotic solutions (2x). The final concentration of CSP-1 was $50 \mathrm{~nm}$, and for CSP S. mitis the final concentration was $300 \mathrm{~nm} . \mathrm{OD}_{600}$ and luciferase activity were measured every 30 minutes for 9 hours in a spectrophotometer plate reader (Synergy HT; BioTek, Winooski, VT). The 96 -well-plate was incubated at $37^{\circ} \mathrm{C}, 5 \% \mathrm{CO}_{2}$ in between readings.

\section{Ciprofloxacin}

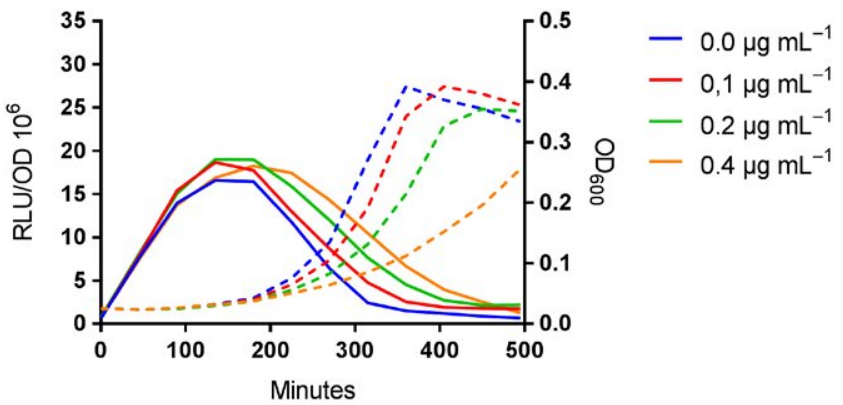

Erythromycin

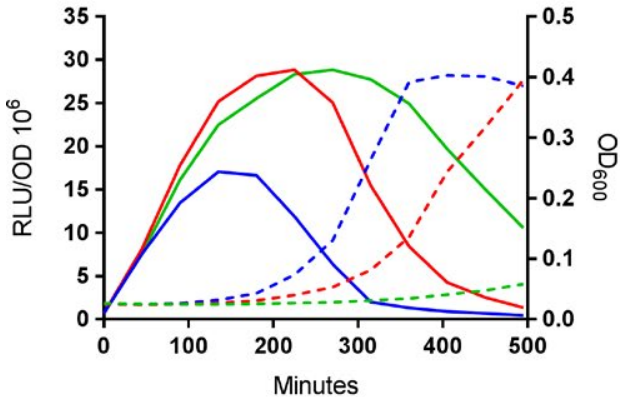

Ampicillin

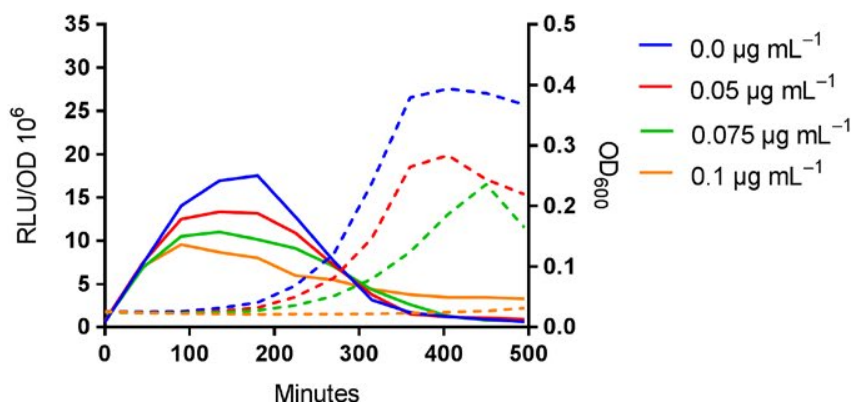

Novobiocin

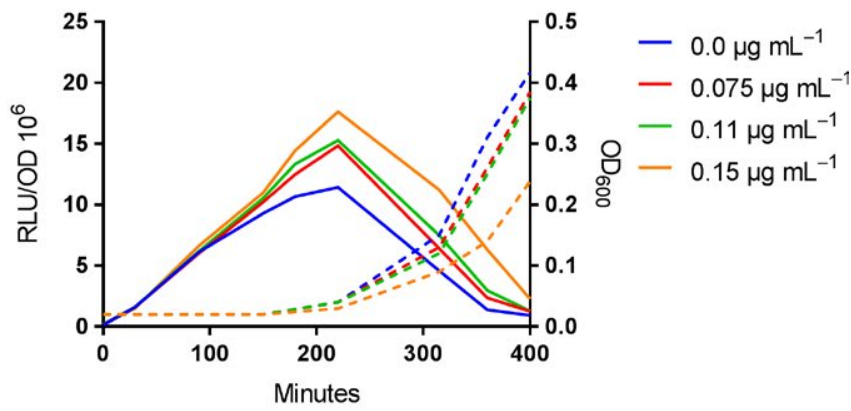

Tetracycline

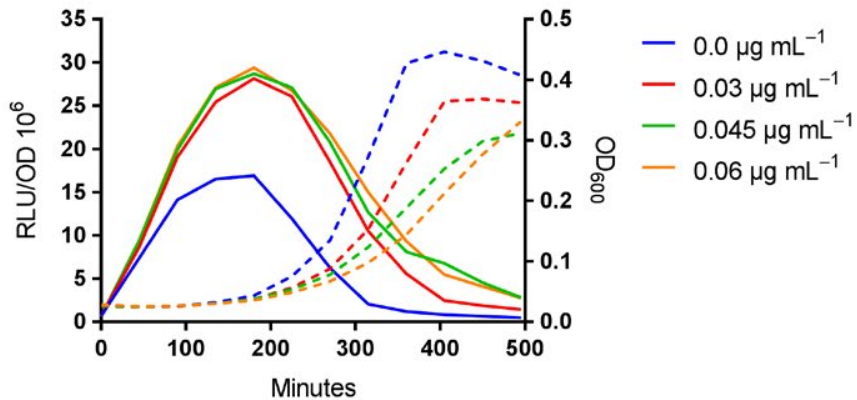

Streptomycin

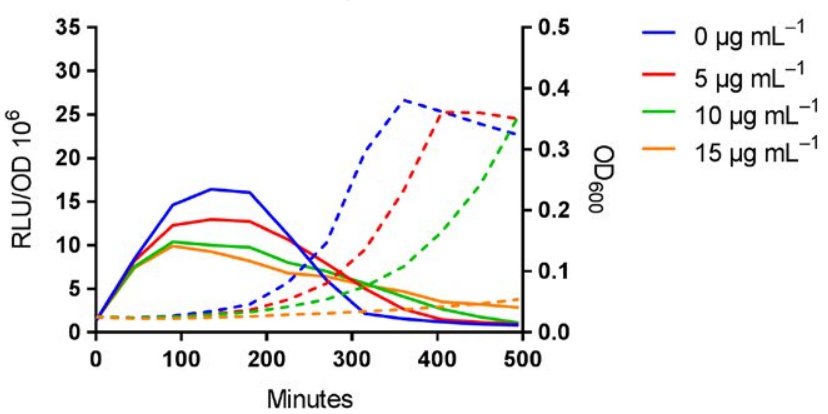

FIG URE 1 Effect of antibiotic agents on sigX expression in Streptococcus pneumoniae D39. Fresh colonies of the sigX reporter strain (SP047 $\mathrm{p}_{\text {sigx }}$ luc) were grown in $\mathrm{C}+\mathrm{Y}_{\mathrm{YB}}$ supplemented with CSP-1 to a working concentration of $50 \mathrm{nmol} \mathrm{L}^{-1}$ and aliquots were placed into a 96-well plate with different concentrations of antibiotics. Expression of sigX was measured every 30 minute during growth at $37^{\circ} \mathrm{C}$ in $5 \%$ $\mathrm{CO}_{2}$. The results are presented as relative luminescence units per culture optical density at $600 \mathrm{~nm}$ (RLU/OD, solid line) on the left $y$-axis and growth curves $\left(\mathrm{OD}_{600}\right.$, dashed line) are presented on the right $y$-axis. The results are averages from three replicates and representative of three independent experiments 


\section{6 | Transformation assays}

The antibiotics and bacterial cultures were prepared as described for the luciferase reporter assay. Transformation rates were assessed at different time-points during growth. At each time-point, DNA was added into the wells at a concentration of $100 \mathrm{ng} \mathrm{mL}^{-1}$. After 30 minutes, DNase (DNase I recombinant grade I; Roche, Basel, Switzerland) was added at a final concentration of $100 \mathrm{U} \mathrm{mL}^{-1}$. This was followed by another period of 30 minutes of incubation, after which $25 \mu \mathrm{L}$ of culture from each well was diluted and plated on selective and nonselective agar plates. Two parallels were included at each time-point and plates were incubated at $37^{\circ} \mathrm{C}, 5 \% \mathrm{CO}_{2}$. After 24 hours, colony-forming units were counted and transformation efficiency was calculated. Fold change was measured by dividing the transformation efficiency of the treated samples by the transformation efficiency of the nontreated controls.

\section{7 | Statistical analysis}

Statistical comparison of the transformation data was performed with unpaired $t$-test. $P$-value $<0.05$ was considered statistically significant.

\section{3 | RESULTS}

\section{1 | Effect of subinhibitory concentrations of different antibiotics on sigX expression}

Antibiotics are known to induce the expression of competence genes in S. pneumoniae under suppressive conditions for spontaneous competence. ${ }^{6,25,26}$ To investigate whether an effect is observed under nonsuppressive conditions of competence, a D39-sigX luciferase reporter was grown with CSP and various
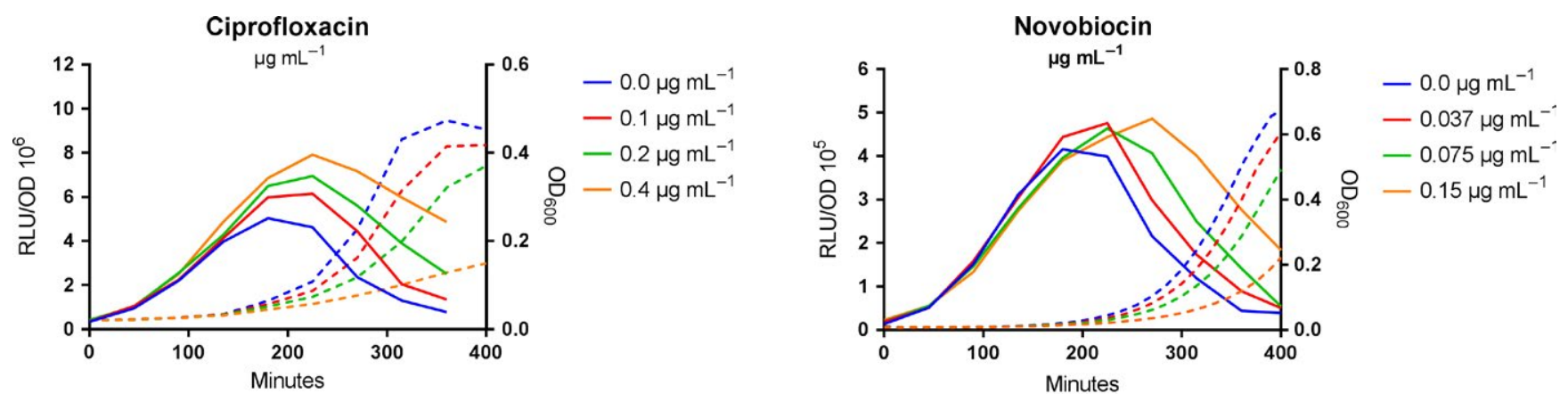

\section{Erythromycin}
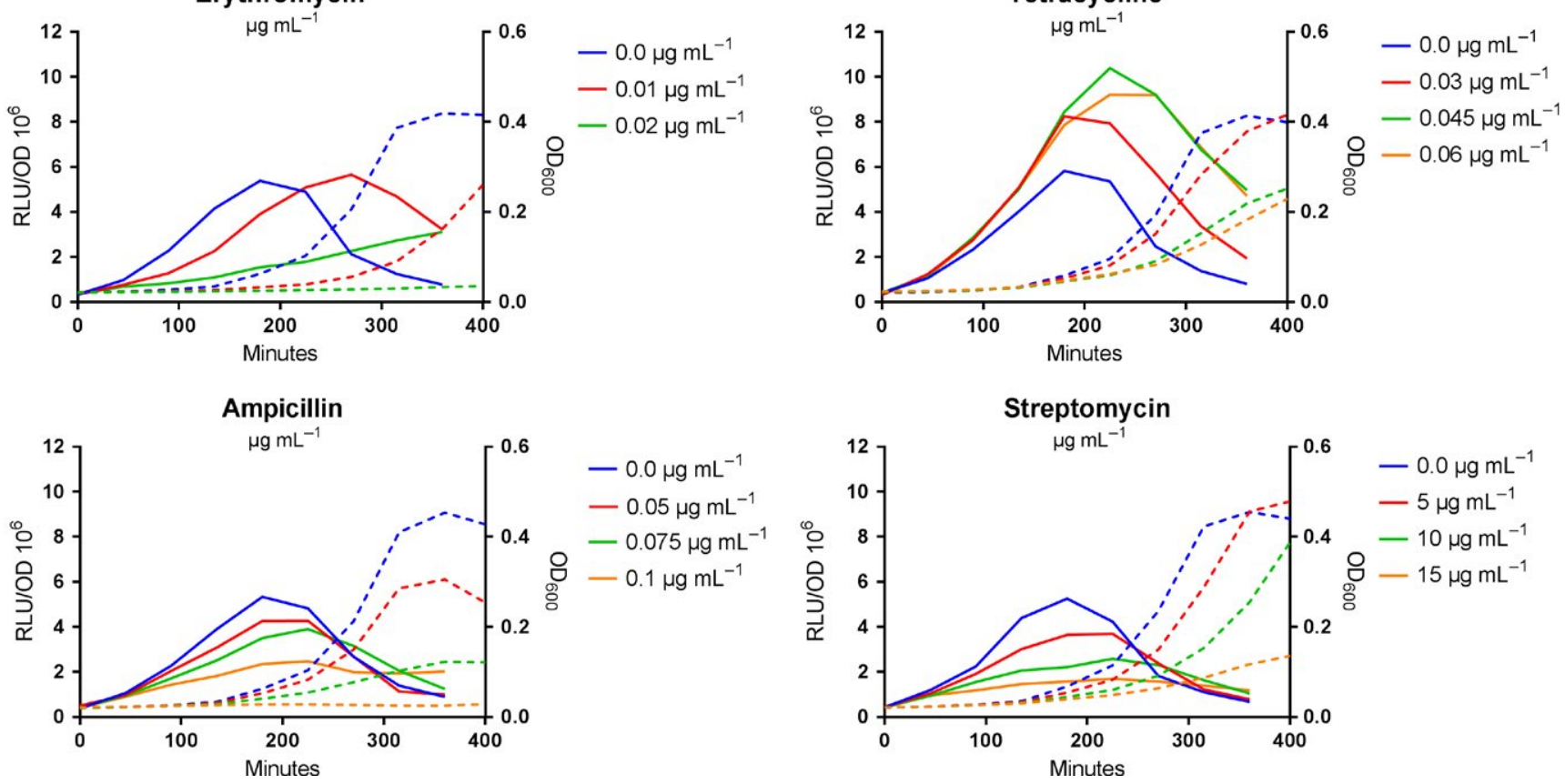

FIGURE 2 Effect of different antibiotics on sigX expression in Streptococcus pneumoniae D39 grown without exogenous competencestimulating peptide (CSP). Fresh colonies of the sigX reporter strain (SP047 $\mathrm{p}_{\text {sigX }}$ luc) were grown in $\mathrm{C}+\mathrm{Y}_{\mathrm{YB}}$ and aliquots were placed on a 96-well plate with different concentrations of antibiotics. Expression of sigX was measured every 30 minute during growth at $37^{\circ} \mathrm{C}$ in $5 \%$ $\mathrm{CO}_{2}$. The results are presented as relative luminescence units per culture optical density at $600 \mathrm{~nm}$ (RLU/OD, solid line) on the left $y$-axis and growth curves $\left(\mathrm{OD}_{600}\right.$, dashed line) are presented on the right $y$-axis. The results are averages from three replicates and representative of three independent experiments 
antibiotics in a semidefined medium. Expression of sigX reached maximal levels by 160 to 200 minutes. Cultures treated with ciprofloxacin, novobiocin, erythromycin, or tetracycline enhanced the level of sigX expression compared with the nontreated samples and also prolonged the time during which expression of $\operatorname{sig} X$ occurred. Contrastingly, in cultures treated with ampicillin or streptomycin, sigX expression was decreased for most of the period (Figure 1; and see Supplementary material, Figure S1). Under conditions relying exclusively on endogenous CSP, similar effects to those observed in the presence of synthetic CSP were observed, although the expression level of sigX was lower (Figure 2; and see Supplementary material, Figure S2).
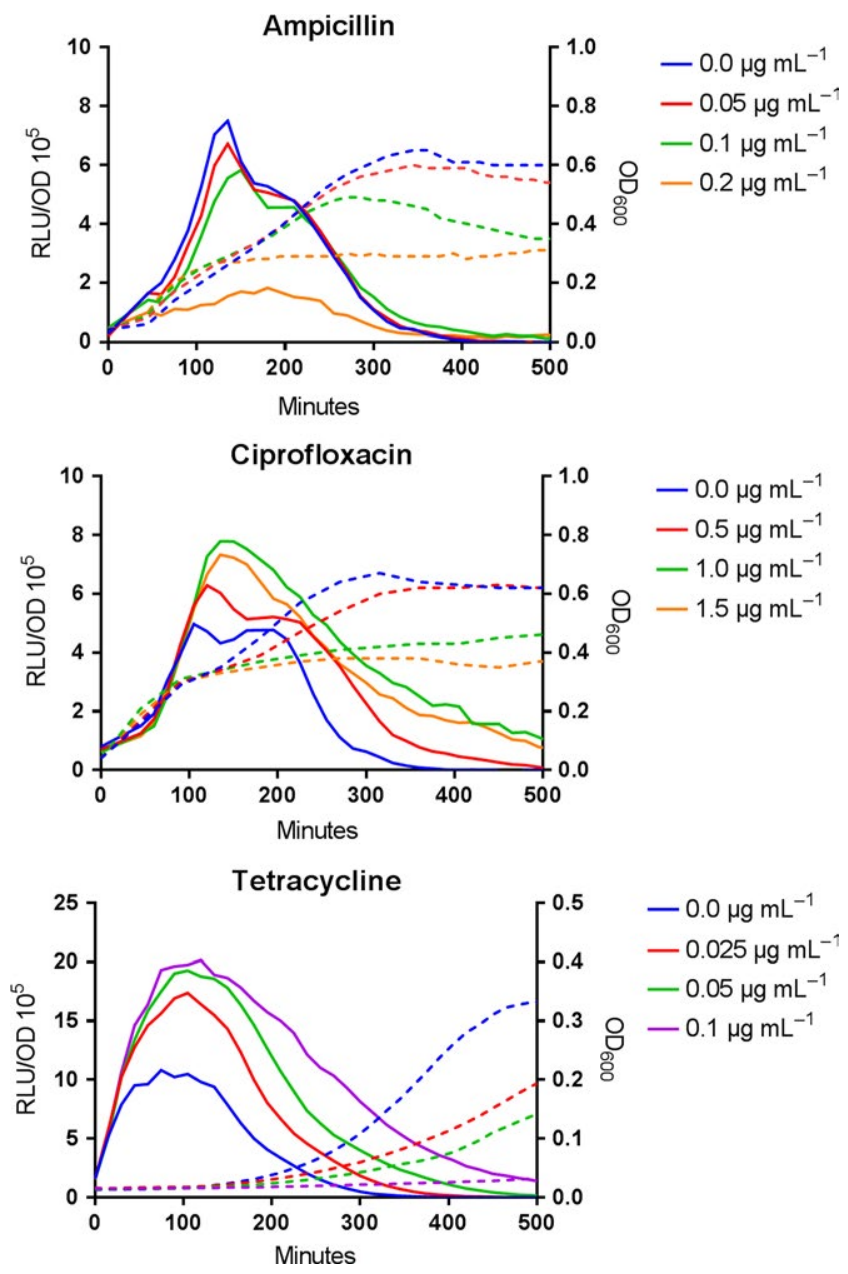

FIGURE 3 Effect of different antibiotics on comC-expression in Streptococcus. pneumoniae TIGR4 grown without exogenous competence-stimulating peptide (CSP). Fresh colonies of the TIGR4 comC reporter strain (SP020 $\mathrm{p}_{\text {comc }}$ luc) were grown in $\mathrm{C}+\mathrm{Y}_{\mathrm{YB}}$ and aliquots were placed on a 96-well plate with different concentrations of antibiotics. Expression of comC was measured every 15 minutes during growth at $37^{\circ} \mathrm{C}$ in $5 \% \mathrm{CO}_{2}$. The results are presented as relative luminescence units per culture optical density at $600 \mathrm{~nm}$ (RLU/OD, solid line) on the left $y$-axis and growth curves $\left(\mathrm{OD}_{600}\right.$, dashed line) are presented on the right $y$-axis. The results are averages from three replicates and representative of two independent experiments
We also examined the effect of different antibiotics in the S. pneumoniae TIGR4 strain, using a different reporter for early competence gene expression. Similar to D39, S. pneumoniae TIGR4 showed both increased and prolonged expression of early competence when stressed with ciprofloxacin and tetracycline, and reduced expression when stressed with ampicillin (Figure 3; and see Supplementary material, Figure S3). To rule out a general effect of antibiotics on translation and activity of the luciferase enzyme, a luciferase reporter for the constitutive gene Idh in TIGR4 was included. The results showed that antibiotics had no observable effect on expression of Idh (see Supplementary material, Figure S4).

\subsection{Antibiotic effects on sigX expression do not always correlate with transformability outcomes}

To gain insight into the kinetics of transformation in the presence of antibiotics, we measured the ability of D39 to take up and incorporate exogenous DNA in cultures treated with and without antibiotics, using six different time-points. A protocol for high efficiency of transformation was used. ${ }^{33}$ Here we hypothesized that enhanced sigX expression would lead to increased transformation efficiency. As expected due to similar sigX expression levels, transformation efficiency at the initial time-point in cultures grown with most antibiotics did not differ significantly from the control (Figure 4). The exception was bacteria treated with erythromycin, which had a decrease in transformation efficiency in the first time-point compared with the nontreated control. Cultures grown with ciprofloxacin and novobiocin showed a higher transformation efficiency than the nontreated control after 150 minutes (Figure 4), which corresponds with the appearance of difference in sig $X$ expression observed in Figure 1.

Tetracycline and erythromycin had inhibitory and no significant effects on S. pneumoniae transformability, respectively, despite being the antibiotic agents that induced the highest expression of sigX (Figures 1 and 4). Hence, the results indicate that subinhibitory concentrations of antibiotics that increase and prolong sigX expression do not always lead to an increase in transformability. Cultures grown with ampicillin and streptomycin had an overall decreased transformability compared with the control, which correlated with a decrease in sigX expression (Figure 4).

Furthermore, we also tested the effect of ciprofloxacin on sigX expression and transformation in S. mitis, a close relative of S. pneumoniae and Streptococcus mutans an oral streptococcus with an early competence-stimulating machinery that is different from those of S. pneumoniae and S. mitis. Interestingly, in S. mitis, as for S. pneumoniae, ciprofloxacin enhanced and prolonged sigX expression. Transformation in S. mitis correlated with an enhanced effect showing increased transformation at $240 \mathrm{~min}$ utes. (Figure 5). A prolonged effect on sigX expression was also observed in ciprofloxacin-treated S. mutans, with an increased transformability at 730 minutes (Figure 5; and see Supplementary material, Figure S5). ${ }^{34}$ 
Ciprofloxacin

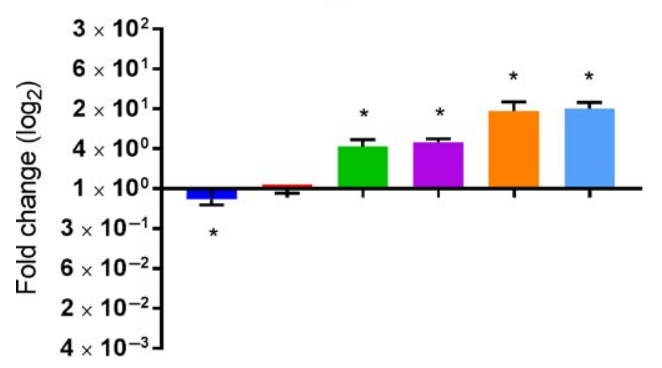

Erythromycin
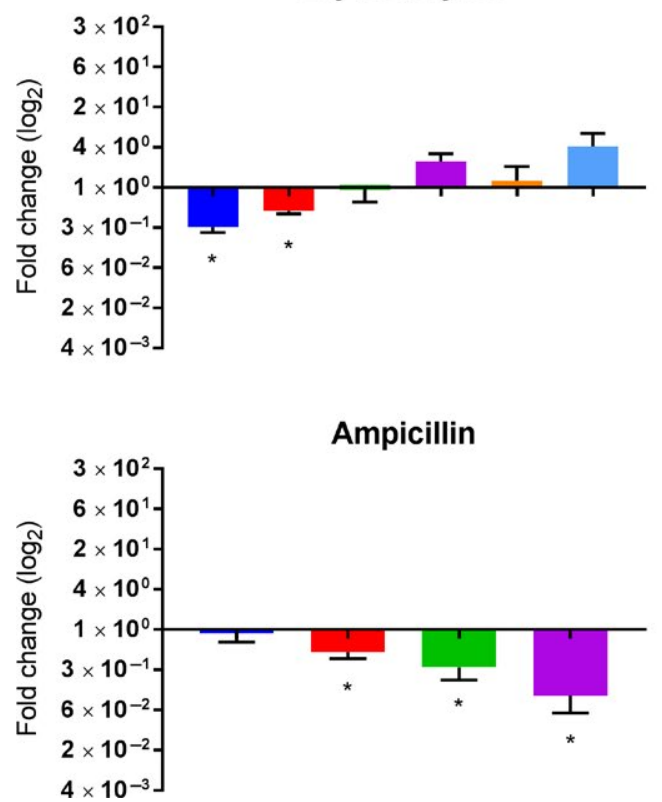
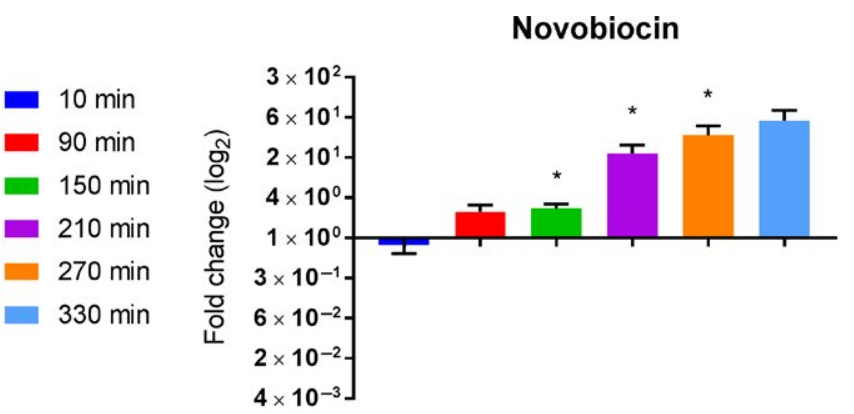

Tetracycline

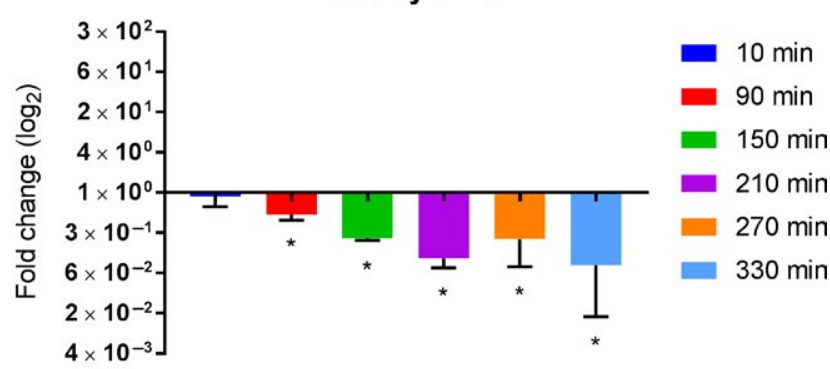

Streptomycin

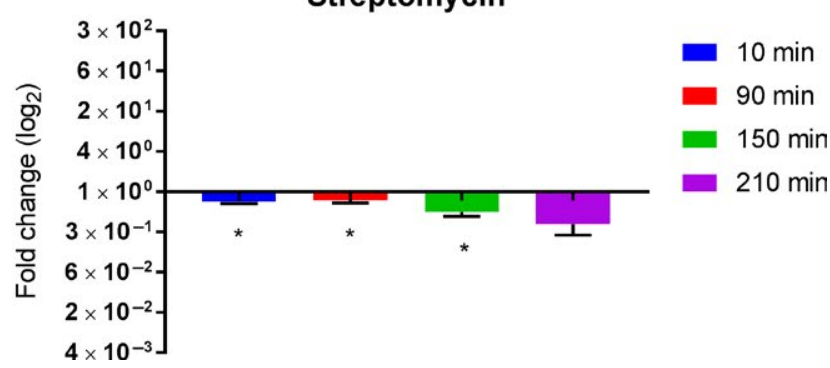

FIGURE 4 Fold changes in transformation efficiency between Streptococcus pneumoniae D39 grown with and without antibiotics. Fresh colonies of the sigX-reporter strain (SP047 $\mathrm{p}_{\text {sigX }}$ luc) were transferred to liquid medium supplemented with competence-stimulating peptide 1 (CSP-1) to a final concentration of $50 \mathrm{nmol} \mathrm{L^{-1 }}$ and aliquots were placed in wells with and without antibiotics (ciprofloxacin $0.4 \mu \mathrm{g} \mathrm{mL} \mathrm{L}^{-1}$, novobiocin $0.15 \mu \mathrm{g} \mathrm{mL}^{-1}$, erythromycin $0.01 \mu \mathrm{g} \mathrm{mL}^{-1}$, tetracycline $0.04 \mu \mathrm{g} \mathrm{mL}^{-1}$, ampicillin $0.05 \mu \mathrm{g} \mathrm{mL}^{-1}$, streptomycin $5.0 \mu \mathrm{g} \mathrm{mL} L^{-1}$ ). Donor DNA (6 kb, Kan ${ }^{R}$ PCR-amplicon) was added at different time-points, followed by DNase supplementation after 30 minutes (symbols). One hour after DNA addition, bacterial culture from each replicate was diluted and plated on blood agar plates with and without supplemented kanamycin. Transformation efficiency was calculated by dividing the number of colonies growing on the selective agar plate by the total number of colonies growing on the nonselective agar plate multiplying it by 100 . Fold change was calculated by dividing transformation efficiency of the treated sample on the transformation efficiency of the control. Bars represent fold change $\left(\log _{2}\right)$ between the treated sample and the control at each time-point and results are averages of a minimum of two to three individual experiments with two replicates in each experiment. $\left({ }^{*} P<0.05\right)$

\section{4 | DISCUSSION}

Antibiotics represent one of the most important discoveries in human history. However, overuse and misuse of antibiotics have led to widespread resistance. Of particular importance is the accumulated evidence that low concentrations of antibiotics have a non-negligible effect on bacterial behaviours associated with emergence and spread of resistance. ${ }^{35}$ Such behaviours include induction of cell-to-cell communication, biofilm formation and horizontal gene transfer, all of them inter-related, and induced by a range of antibiotic classes in S. pneumoniae. ${ }^{6,10}$ Horizontal gene transfer by natural transformation in S. pneumoniae can indeed be pervasive under crowded conditions and high antibiotic exposure, as recently suggested in a large scale study of humans living in a refugee camp. ${ }^{36}$

Although several studies have shown that antibiotics induce competence in S. pneumoniae, either by microarray, RNA sequencing, or luciferase reporter assays, only a few have directly accessed their effects on phenotypic transformation. ${ }^{6,25}$ For those studies in which transformation data are present, the results are limited to a single time-point during growth (Table 2). ${ }^{6,25}$ Here we investigated transformability during growth and showed that the effect of antibiotics on competence and transformation do not always correlate, and that different antibiotic agents may either increase or decrease the ability of S. pneumoniae to transform. 
Aminoglycosides, as well as quinolones that target topoisomerases, and mitomycin have all been shown to induce competence in S. pneumoniae. ${ }^{6,25,26}$ Common to them is their ability to damage
DNA. One of the mechanisms of DNA damage by aminoglycosides and quinolones is related to their effects in promoting bacterial production of hydroxyl radicals, ${ }^{37,38}$ whereas mitomycin acts mainly by
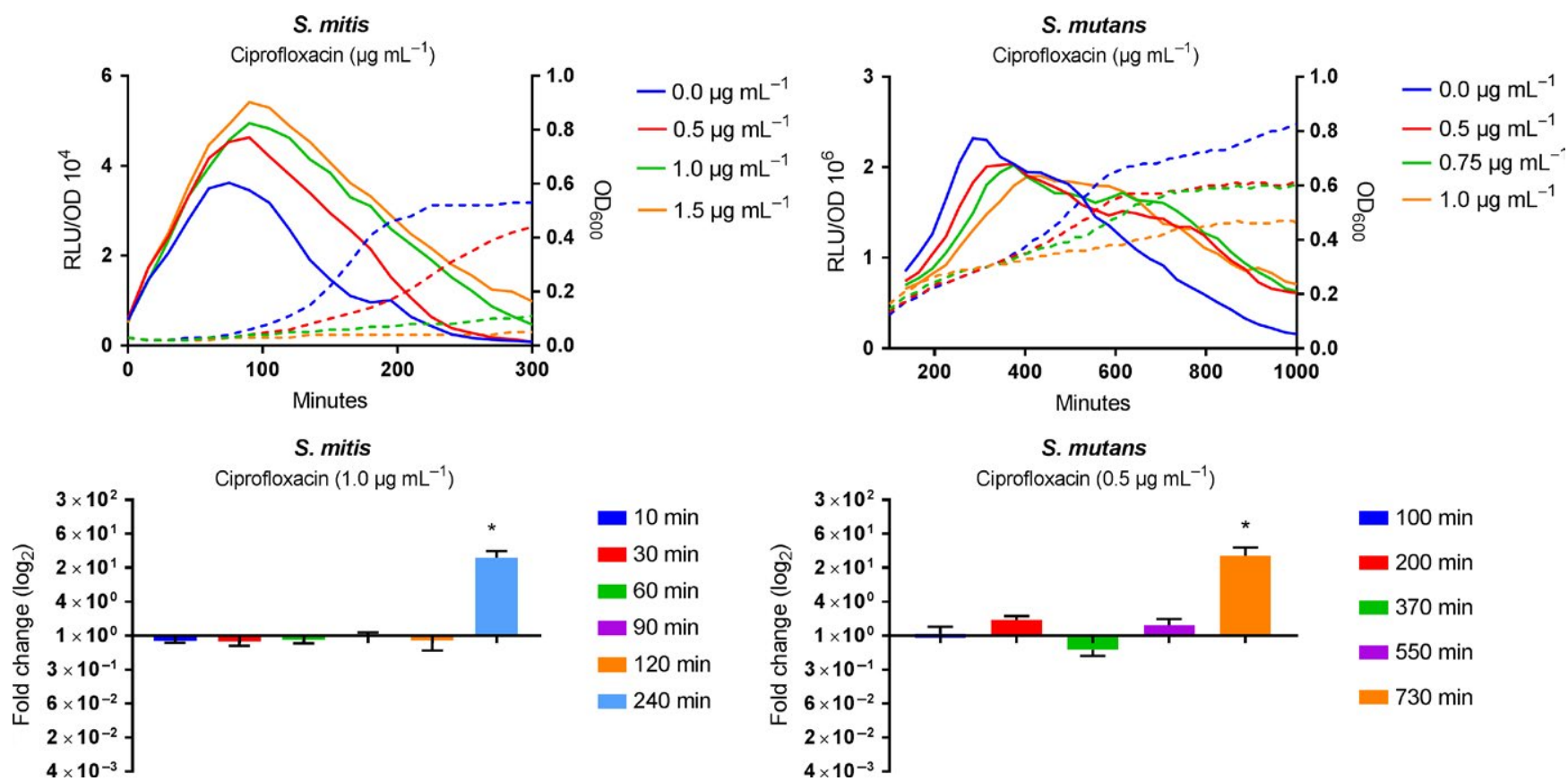

FIG URE 5 Effect of ciprofloxacin on sigX expression and transformability in Streptococcus. mutans and Streptococcus mitis. (A, C) Fresh colonies of the $S$. mitis sigX reporter strain (MI055) were grown in $\mathrm{C}+\mathrm{Y}_{\mathrm{YB}}$ supplemented with CSP-S. mitis at a final concentration of $300 \mathrm{nM}$. (B, D) Fresh colonies of the $S$. mutans sigX reporter strain (SM068) were grown in chemically defined medium (CDM) without exogenous competence-inducing peptide. (A, B) The strains were divided into aliquots in a 96-well plate with different concentrations of ciprofloxacin. Expression of sigX, presented on the left $y$-axis as relative luminescence units (RLU/OD, solid line) and optical density at $600 \mathrm{~nm}\left(O D_{600}\right)$, presented on the right $y$-axis (dashed line), were measured periodically during growth at $37^{\circ} \mathrm{C}$ in $5 \% \mathrm{CO}_{2}$. (C, D) Samples were grown with and without ciprofloxacin (S. mitis: $1.0 \mu \mathrm{g} \mathrm{mL}^{-1}$ and S. mutans: $0.5 \mu \mathrm{g} \mathrm{mL}^{-1}$ ). Donor DNA was added at different time-points, followed by DNase supplementation after 30 minutes. One hour after DNA addition, aliquots of each replicate were diluted and plated on blood agar plates with and without selective antibiotics. Transformation efficiency was calculated by dividing the number of colonies growing on the selective agar plate by the total number of colonies growing on the nonselective agar plate multiplying it by 100 . Bars represent fold change $\left(\log _{2}\right)$ at the each time-point. Fold change was calculated by dividing the transformation efficiency of the sample grown with antibiotics by the transformation efficiency of the control sample. Results are averages of a minimum of two independent experiments with two replicates in each experiment

TABLE 2 Antibiotic effects on competence and transformation in this study compared with previous studies

\begin{tabular}{|c|c|c|c|c|c|c|c|c|c|}
\hline \multirow{2}{*}{$\begin{array}{l}\text { Antibiotic } \\
\text { Ciprofloxacin }\end{array}$} & \multirow{2}{*}{$\begin{array}{l}\text { Classification } \\
\text { Fluoroquinolone }\end{array}$} & \multicolumn{2}{|c|}{$\begin{array}{l}\text { This } \\
\text { study }\end{array}$} & \multicolumn{2}{|c|}{$\begin{array}{l}\text { Prudhomme } \\
\text { et al. (6) }\end{array}$} & \multicolumn{2}{|c|}{$\begin{array}{l}\text { Slager } \\
\text { et al. }(25)^{b}\end{array}$} & \multicolumn{2}{|c|}{$\begin{array}{l}\text { Stevens } \\
\text { et al. (26) }\end{array}$} \\
\hline & & + & + & nt & $\mathrm{nt}$ & + & $\mathrm{nt}$ & $\mathrm{nt}$ & $\mathrm{nt}$ \\
\hline Novobiocin & Aminocoumarin & + & + & $x$ & $\mathrm{nt}$ & $x$ & nt & nt & $\mathrm{tt}$ \\
\hline Erythromycin & Macrolide & + & ns & $x$ & nt & nt & $\mathrm{nt}$ & nt & $\mathrm{nt}$ \\
\hline Tetracycline & Tetracycline & + & - & $x$ & nt & nt & $\mathrm{nt}$ & - & $\mathrm{nt}$ \\
\hline Ampicillin & $\beta$-lactam & - & - & $x$ & $\mathrm{nt}$ & nt & nt & nt & nt \\
\hline Streptomycin & Aminoglycoside & - & ns & + & + & + & nt & $+/-c$ & $\mathrm{nt}$ \\
\hline
\end{tabular}

White columns show increased $(+)$ or reduced $(-)$ expression of a competence luciferase reporter gene. Grey columns show increased (+) or reduced (-) transformation rates. ns, not significant; $n t$, not tested; $x$, not induced (suppressed conditions).

${ }^{a}$ Culture treated with norfloxacin and mitomycin $\mathrm{C}$ induced transformation; one-time-point experiment.

${ }^{\mathrm{b} C}$ Culture treated with 6-(p-hydrophenylazo)-uracil (HPUra) induced transformation; one-time-point experiment.

'Streptomycin induced competence under nonpermissive conditions for competence development, but not under permissive conditions. 
creating DNA cross-links. ${ }^{39}$ Induction of S. pneumoniae competence by such agents has been used to support the hypothesis that competence in S. pneumoniae, which lacks a classical SOS-system, has evolved as a mechanism to repair DNA damage. ${ }^{40}$ More recently, target-specific mechanisms by which different antibiotics induce competence have been proposed. Aminoglycosides such as kanamycin and streptomycin, for instance, may promote decoding errors during protein synthesis, ${ }^{26}$ which in turn can lead to the production of misfolded proteins that are targeted to degradation by the HtrA protease, so protecting CSP from HtrA cleavage. Notably, the effect of aminoglycosides in inducing competence was observed under nonpermissive conditions for development of competence, but not under permissive conditions. Such findings were confirmed by our results showing that streptomycin under permissive conditions had a slightly reducing effect on the expression of sigX.

In the case of antibiotics that target DNA replication, including ciprofloxacin, the effect on competence induction has been attributed to stalling of the replication fork close to the origin of replication. ${ }^{25}$ This leads to increased transcription dosage of the regulatory genes in the competence cascade, which are located close to the origin of replication. Our results confirmed the effects on the expression of competence genes, and showed a positive effect of ciprofloxacin on transformability. Furthermore, novobiocin, an antibiotic that targets the gyrB subunit of DNA gyrase, had also an increasing effect on both competence and transformability in our study. This effect on competence was associated with a delay in the decline of transformation efficiency observed during competence, as differences between antibiotic-treated and nontreated cultures were more pronounced close to the exit phase of the competence period.

Two antibiotics targeting ribosomes, erythromycin and tetracycline, induced competence gene expression in this study. Both agents were among the six tested antibiotics that had the strongest inducing effect on sigX expression. Notably, both antibiotics failed in a previous study to show any inducing effect on competence. ${ }^{6}$ Here, erythromycin led to a reduced transformability in the first time-points compared with the control, and at the latest time-points we observed no significant difference from the control. For tetracycline, however, despite a strong inducing effect on sigX expression, reduced transformation rates were observed in all time-points compared with the nontreated control. From a mechanistic perspective, induction of sig $X$ by tetracycline was unexpected, since tetracycline has been shown to reduce decoding errors in translation, in contrast to antibiotics that seem to induce competence by the increase in decoding errors. It is possible, however, that the effect of tetracycline in inducing competence gene expression may be related to other stress mechanisms. The effect of aminoglycosides in enhancing production of free radicals, as described above, is in fact a common feature to several antibiotics belonging to other classes, including tetracycline and $\beta$-lactams. ${ }^{41}$ Hence, although the current findings cannot exclude a more general mechanism of free-radical-induced stress or growth-rate reduction as mechanisms behind the triggering of competence by antibiotics, the results indicate that mechanisms specific to the different antibiotic agents are important. Of note, our results show that the $\beta$-lactam ampicillin decreases transformability, and supports previous findings that $\beta$-lactams have an inhibitory effect on expression of competence gene expression. ${ }^{1,27,42}$ This is of particular relevance, as $\beta$-lactams are one of the most important therapeutic resources against pneumococcal infections.

In conclusion, specific antibiotic agents affect competence and transformability in different ways, and antibiotics that stimulate competence gene expression may either increase or reduce S. pneumoniae transformability, depending on antibiotic type. Antibiotics that increase or decrease transformability are of particular clinical relevance, as they may confer survival advantages to $S$. pneumoniae, such as those resulting in capsule exchange or antimicrobial resistance, allowing vaccine and/or antibiotic escape.

\section{ACKNOWLEDGEMENTS}

This work was supported by the Faculty of Dentistry, University of Oslo and by the Norwegian surveillance system for antibiotic resistance in microbes (NORM).

\section{CONFLICTS OF INTEREST}

The authors declare no conflict of interest.

\section{ORCID}

\section{F. Petersen (iD http://orcid.org/0000-0003-4649-247X}

\section{REFERENCES}

1. Aminov RI. A brief history of the antibiotic era: lessons learned and challenges for the future. Front Microbiol. 2010;1:134.

2. WHO. Antimicrobial resistance. http://www.who.int/mediacentre/ factsheets/fs194/en/. Accessed March 26, 2018.

3. Davies J, Davies D. Origins and evolution of antibiotic resistance. Microbiol Mol Biol Rev. 2010;74:417-433.

4. Shun-Mei E, Zeng JM, Yuan H, Lu Y, Cai RX, Chen C. Sub-inhibitory concentrations of fluoroquinolones increase conjugation frequency. Microb Pathog. 2018;114:57-62.

5. Nagel M, Reuter T, Jansen A, Szekat C, Bierbaum G. Influence of ciprofloxacin and vancomycin on mutation rate and transposition of IS256 in Staphylococcus aureus. Int J Med Microbiol. 2011;301:229-236.

6. Prudhomme M, Attaiech L, Sanchez G, Martin B, Claverys JP. Antibiotic stress induces genetic transformability in the human pathogen Streptococcus pneumoniae. Science. 2006;313(5783):89-92.

7. Kelly JA, Moews PC, Knox JR, Frere JM, Ghuysen JM. Penicillin target enzyme and the antibiotic binding site. Science. 1982;218(4571):479-481.

8. Beaber JW, Hochhut B, Waldor MK. SOS response promotes horizontal dissemination of antibiotic resistance genes. Nature. 2004;427(6969):72-74.

9. Cortes PR, Pinas GE, Albarracin Orio AG, Echenique JR. Subinhibitory concentrations of penicillin increase the mutation rate to optochin resistance in Streptococcus pneumoniae. J Antimicrob Chemother. 2008;62:973-977. 
10. Henderson-Begg SK, Livermore DM, Hall LM. Effect of subinhibitory concentrations of antibiotics on mutation frequency in Streptococcus pneumoniae. J Antimicrob Chemother. 2006;57:849-854

11. Hoffman LR, D'Argenio DA, MacCoss MJ, Zhang Z, Jones RA, Miller SI. Aminoglycoside antibiotics induce bacterial biofilm formation. Nature. 2005;436:1171-1175.

12. Zhang X, McDaniel AD, Wolf LE, Keusch GT, Waldor MK, Acheson DW. Quinolone antibiotics induce Shiga toxin-encoding bacteriophages, toxin production, and death in mice. J Infect Dis. 2000;181:664-670.

13. Liang J, Tang X, Guo N, et al. Genome-wide expression profiling of the response to linezolid in Mycobacterium tuberculosis. Curr Microbiol. 2012;64:530-538.

14. WHO. Pneumococcal disease. http://www.who.int/ith/diseases/ pneumococcal/en/. Accessed April 25, 2016.

15. Kilian M, Poulsen K, Blomqvist T, et al. Evolution of Streptococcus pneumoniae and its close commensal relatives. PLOS ONE. 2008;3:e2683.

16. Bogaert D, De Groot R, Hermans PW. Streptococcus pneumoniae colonisation: the key to pneumococcal disease. Lancet Infect Dis. 2004:4:144-154.

17. Blokesch M. Natural competence for transformation. Curr Biol. 2016;26:R1126-R1130.

18. Straume D, Stamsas GA, Håvarstein LS. Natural transformation and genome evolution in Streptococcus pneumoniae. Infect Genet Evol. 2015;33:371-380.

19. Claverys JP, Martin B, Håvarstein LS. Competence-induced fratricide in streptococci. Mol Microbiol. 2007;64:1423-1433.

20. Håvarstein LS, Hakenbeck R, Gaustad P. Natural competence in the genus Streptococcus: evidence that streptococci can change pherotype by interspecies recombinational exchanges. J Bacteriol. 1997;179:6589-6594.

21. Pestova EV, Håvarstein LS, Morrison DA. Regulation of competence for genetic transformation in Streptococcus pneumoniae by an auto-induced peptide pheromone and a two-component regulatory system. Mol Microbiol. 1996;21:853-862.

22. Håvarstein LS, Gaustad P, Nes IF, Morrison DA. Identification of the streptococcal competence-pheromone receptor. Mol Microbiol. 1996;21:863-869.

23. Martin B, Soulet AL, Mirouze N, et al. ComE/ComE P interplay dictates activation or extinction status of pneumococcal X-state (competence). Mol Microbiol. 2013;87:394-411.

24. Goossens H, Ferech M, Vander Stichele R, Elseviers M. Outpatient antibiotic use in Europe and association with resistance: a crossnational database study. Lancet. 2005;365(9459):579-587.

25. Slager J, Kjos M, Attaiech L, Veening JW. Antibiotic-induced replication stress triggers bacterial competence by increasing gene dosage near the origin. Cell. 2014;157:395-406.

26. Stevens KE, Chang D, Zwack EE, Sebert ME. Competence in Streptococcus pneumoniae is regulated by the rate of ribosomal decoding errors. MBio. 2011;2(5):e00071-11.

27. Rogers PD, Liu TT, Barker KS, et al. Gene expression profiling of the response of Streptococcus pneumoniae to penicillin. J Antimicrob Chemother. 2007;59:616-626.

28. Jensen PA, Zhu Z, van Opijnen T. Antibiotics disrupt coordination between transcriptional and phenotypic stress responses in pathogenic bacteria. Cell Rep. 2017;20:1705-1716.
29. Claverys JP, Martin B, Polard P. The genetic transformation machinery: composition, localization, and mechanism. FEMS Microbiol Rev. 2009;33:643-656.

30. Khan R, Rukke HV, Ricomini Filho AP, et al. Extracellular identification of a processed type II ComR/ComS pheromone of Streptococcus mutans. J Bacteriol. 2012;194:3781-3788.

31. Junges R, Salvadori G, Shekhar S, et al. A quorum-sensing system that regulates Streptococcus pneumoniae biofilm formation and surface polysaccharide production. mSphere. 2017;2(5):e00324-17.

32. Lau PC, Sung CK, Lee JH, Morrison DA, Cvitkovitch DG. PCR ligation mutagenesis in transformable streptococci: application and efficiency. J Microbiol Methods. 2002;49:193-205.

33. Junges R, Khan R, Tovpeko Y, Amdal HA, Petersen FC, Morrison DA. Markerless genome editing in competent streptococci. Methods $\mathrm{Mo}$ Biol. 2017b;1537:233-247.

34. Son M, Shields RC, Ahn SJ, Burne RA, Hagen SJ. Bidirectional signaling in the competence regulatory pathway of Streptococcus mutans. FEMS Microbiol Lett. 2015;362:465-468.

35. Andersson DI, Hughes D. Microbiological effects of sublethal levels of antibiotics. Nat Rev Microbiol. 2014;12:465-478.

36. Chewapreecha C, Harris SR, Croucher NJ, et al. Dense genomic sampling identifies highways of pneumococcal recombination. Nat Genet. 2014;46:305-309.

37. Dwyer DJ, Belenky PA, Yang JH, et al. Antibiotics induce redoxrelated physiological alterations as part of their lethality. Proc Natl Acad Sci U S A. 2014;111:E2100-E2109.

38. Kohanski MA, Dwyer DJ, Hayete B, Lawrence CA, Collins JJ. A common mechanism of cellular death induced by bactericidal antibiotics. Cell. 2007;130:797-810.

39. Tomasz M. Mitomycin C: small, fast and deadly (but very selective). Chem Biol. 1995;2:575-579.

40. Claverys JP, Prudhomme M, Martin B. Induction of competence regulons as a general response to stress in gram-positive bacteria. Annu Rev Microbiol. 2006;60:451-475.

41. Fani F, Leprohon P, Legare D, Ouellette M. Whole genome sequencing of penicillin-resistant Streptococcus pneumoniae reveals mutations in penicillin-binding proteins and in a putative iron permease. Genome Biol. 2011;12:R115.

42. El Khoury JY, Boucher N, Bergeron MG, Leprohon P, Ouellette $M$. Penicillin induces alterations in glutamine metabolism in Streptococcus pneumoniae. Sci Rep. 2017;7:14587.

\section{SUPPORTING INFORMATION}

Additional supporting information may be found online in the Supporting Information section at the end of the article.

How to cite this article: Sturød K, Salvadori G, Junges R, Petersen FC. Antibiotics alter the window of competence for natural transformation in streptococci. Mol Oral Microbiol. 2018;33:378-387. https://doi.org/10.1111/omi.12240 


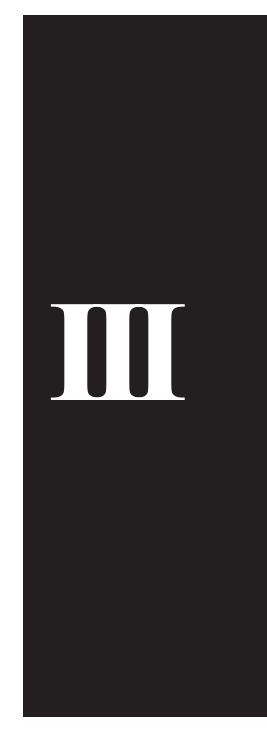





\title{
Impact of narrow-spectrum penicillin $\mathrm{V}$ on the oral and faecal resistome in a young child treated for otitis media
}

\author{
Kjersti Sturød ${ }^{\mathrm{a}}$, Achal Dhariwal ${ }^{\mathrm{a}}$, Ulf R. Dahle ${ }^{\mathrm{b}}$, Didrik F. Vestrheim ${ }^{\mathrm{b}}$, \\ Fernanda C. Petersen ${ }^{\mathrm{a}, *}$ \\ a Institute of Oral Biology, Faculty of Dentistry, University of Oslo, Oslo, Norway \\ ${ }^{\mathrm{b}}$ Centre for Antimicrobial Resistance, Norwegian Institute of Public Health, Oslo, Norway
}

\section{A R T I C L E I N F O}

\section{Article history:}

Received 16 May 2019

Received in revised form 2 August 2019

Accepted 6 August 2019

Available online 12 August 2019

\section{Keywords}

Resistome

Microbiome

Antibiotic

Narrow spectrum

Otitis media

Antimicrobial resistance gene

\begin{abstract}
A B S T R A C T
Objectives: Antibiotic overuse has led to the global emergence of antimicrobial-resistant bacteria, and children are among the most frequent users of antibiotics. Most studies with broad-spectrum antibiotics show a severe impact on resistome development in patients. Although narrow-spectrum antibiotics are believed to have fewer side effects, their impact on the microbiome and resistome is mostly unknown. The aim of this study was to investigate the impact of the narrow-spectrum antibiotic phenoxymethylpenicillin (penicillin V) on the microbiome and resistome of a child treated for acute otitis media. Methods: Oral and faecal samples were collected from a 1-year-old child before (Day 0) and after (Days 5 and 30 ) receiving penicillin $V$ for otitis media. Metagenomic sequencing data were analysed to determine taxonomic profiling using Kraken and Bracken software, and resistance profiling using KMA in combination with the ResFinder database.

Results: In the oral samples, antimicrobial resistance genes (ARGs) belonging to four classes were identified at baseline. At Day 5, the abundance of some ARGs was increased, whereas some remained unchanged and others could no longer be detected. At Day 30, most ARGs had returned to baseline levels or lower. In the faecal samples, seven ARGs were observed at baseline and five at Day 5. At Day 30, the number of ARGs had increased to 21.

Conclusions: Following penicillin V, we observed a remarkable enrichment of the aecal resistome, indicating that even narrow-spectrum antibiotics may have important consequences in selecting for a more resistant microbiome.

(C) 2019 International Society for Antimicrobial Chemotherapy. Published by Elsevier Ltd. This is an open access article under the CC BY-NC-ND license (http://creativecommons.org/licenses/by-nc-nd/4.0/).
\end{abstract}

\section{Introduction}

The increasing prevalence of antimicrobial-resistant bacteria is now threatening what has been modern medicine's security blanket for over 70 years, namely effective antibiotics [1] Antibiotics are among the most essential and prescribed drugs in the world, but extensive antibiotic use has led to the global emergence of antimicrobial-resistant bacteria, making bacterial infections once again difficult to treat. Antibiotic use is particularly high in children aged $<4$ years $[2,3]$. The leading reason for antibiotic prescription in these children is upper airway infection, including otitis media [3,4]. In Scandinavia, the treatment guidelines for otitis media are much more restrictive than they were some years ago [3,5] and doctors are encouraged to use as few antibiotics as possible in these cases. However, when

\footnotetext{
* Corresponding author.

E-mail address: f.c.petersen@odont.uio.no (F.C. Petersen).
}

recommended, the first-line antibiotic is phenoxymethylpenicillin, also known as penicillin $\mathrm{V}[6,7]$. Penicillin $\mathrm{V}$ has activity against Gram-positive bacteria but is less active against Gramnegative bacteria. This drug is among the narrowest-spectrum antibiotics in use.

Use of broad-spectrum antibiotics is associated with a reduction in gut microbiome diversity, as demonstrated in several studies [8,9]. The impact on the microbiota in other body sites is less known, but the microbiome in saliva appears to be more resilient to antibiotics than the gut microbiome, at least in healthy volunteers exposed to broad-spectrum antibiotics [10]. In children, loss of diversity is of particular importance given the relevance of the microbiome on immune system maturation [11]. Whilst such antibiotic effects on microbial composition have been the focus of several investigations, less is known about the effects on the overall antimicrobial resistance gene (ARG) load in the human microbiome, known as the resistome [12]. The resistome constitutes an important reservoir of ARGs that can be transferred to pathogens [13]. Emerging data indicate that broad-spectrum 
antibiotics can lead not only to a general increase in resistance genes related to the antibiotic target, but also to other groups of antibiotics [14]. Such resistance genes can in some cases persist for long periods and increase upon cumulative exposure to antibiotics [15]. For narrow-spectrum antibiotics such as penicillin $\mathrm{V}$, the impact on the resistome remains largely unknown.

In the present study, the effect of the narrow-spectrum antibiotic penicillin $\mathrm{V}$ on the oral and gut resistome of a young child treated for otitis media was followed. Deep metagenomic sequencing was used to investigate its possible relevance in promoting enrichment of pathogens and ARGs. The results indicate that penicillin $\mathrm{V}$ may affect both the taxonomic and resistome profiles of the microbiome, as observed at 25 days after therapy termination.

\section{Materials and methods}

\subsection{Ethics}

This study was approved by the Regional Committee for Medical and Health Research Ethics-South East ('REK sør-øst'). Written informed consent was obtained from the child's parents. The participants received no compensation.

\subsection{Sample collection}

Faecal and oral samples from a 1-year-old child presenting with otitis media at the Accident and Emergency Department, Municipal Hospital, South Norway, were collected for shotgun metagenomic sequencing. The child was of Caucasian origin, had no history of travel outside the Nordic Countries, and had previously received antibiotic treatment on one occasion ( $>1$ month ago). Samples were collected at three time points: (i) the same day as the visit to the emergency department (baseline); (ii) immediately after the antibiotic treatment course was completed (Day 5); and (iii) after 25 days post-antibiotic treatment (Day 30). Oral samples were collected using FLOQSwab ${ }^{\circledR}$ (Copan Diagnostics, Murrieta, CA, USA). The swab was stored in $2 \mathrm{~mL}$ of TE buffer, was placed directly on ice and DNA was extracted within $2 \mathrm{~h}$ of sample collection. Faecal samples were collected in sterile containers and were placed directly in a $-20^{\circ} \mathrm{C}$ freezer. Faecal DNA was extracted after all samples had been collected.

\subsection{DNA extraction and sequencing}

DNA from oral samples was extracted using the MasterPure ${ }^{\mathrm{TM}}$ Gram Positive DNA Purification Kit (Epicentre, Madison, WI, USA). Sample material in TE buffer was pelleted by centrifugation (10 000 $\mathrm{rpm}$ for $10 \mathrm{~min}$ ) and was extracted following the manufacturer's protocol. Faecal DNA extraction was performed using a PowerLyzer ${ }^{\mathrm{TM}}$ PowerSoil ${ }^{\circledR}$ DNA Isolation Kit(MoBio Laboratories, Carlsbad, CA, USA). Minor adjustments to the protocol were implemented according to the Human Microbiome Project (Core Microbiome Sampling Protocol A, HMP Protocol \#07-001) [16]. The amount of extracted DNA was measured using a NanoDrop ${ }^{\mathrm{TM}} 2000$ c spectrophotometer (Thermo Fisher Scientific, Waltham, MA, USA). DNA quality was evaluated by agarose gel electrophoresis. Metagenomic shotgun sequencing was conducted at the Norwegian Sequencing Centre (Oslo, Norway) on an Illumina HiSeq 2500 platform (Illumina Inc., San Diego, CA, USA) using a paired-end sequencing approach with a targeted read length of $125 \mathrm{bp}$ in high-output mode.

\subsection{Quality control and pre-processing of metagenomic data}

The quality of raw sequencing reads was assessed using the FastQC tool [17], with all samples passing commonly applied quality criteria including base quality, GC content, nucleotide distribution and duplication rate (mean Phred score $>20$; read length $>100 \mathrm{bp}$; nucleotide distribution $\% \mathrm{~A}=\% \mathrm{~T}$ and $\% \mathrm{G}=\% \mathrm{C}$ with a constant proportion over the length of the read; duplicated sequences should make up $<50 \%$ of the total reads). Low-quality reads and adapter sequences were trimmed out using Trimmomatic [18], followed by removal of human DNA sequences by extracting all reads mapping to an assembly of the human genome (version GRch38, downloaded from NCBI GenBank) using BowTie2 [19]. The remaining reads were subsequently used to characterise the microbiome and resistome in oral and faecal samples.

\subsection{Taxonomic profiling}

Paired non-host reads were classified and assigned taxonomic labels using Kraken v.1 software [20]. Reads (k-mers) were aligned against the prebuilt MiniKraken DB_8GB database, which encompasses complete archaeal, bacterial and viral genomes in NCBI's RefSeq (18 October 2017). Kraken assigns the most specific taxonomic label to each read in a given set of metagenomic reads for classification. However, certain times the label assignment is not at the species level. Especially in the case of nearly identical reads that are found in more than one species, Kraken will assign it to the lowest common ancestor, which could be genus level or higher. Therefore, the number of species-specific reads would be underestimated in samples containing one or few highly similar species. To overcome this issue, the species abundance after classification with KrakEN was re-estimated using Bracken (Bayesian Reestimation of Abundance after Classification with KrakEN) [21]. Furthermore, Shannon and Chao1 diversity indexes were calculated at species level for oral and faecal samples. The samples were rarefied to even sequencing depth (per million reads) for comparative analysis. Only reads that were taxonomically classified were used in downstream analyses.

\subsection{Identification and quantification of antimicrobial resistance genes}

The KMA program [22] was used in combination with the ResFinder 2.1 database [23] to identify ARGs in the metagenomic data set. The ResFinder database consists of $\sim 2200$ resistance genes and is curated from existing databases and published literature. Resistant phenotypes attributed to mutations within an antibiotic target gene [target resistance alleles (TRAs)] were not included in the analysis since read-based approaches using short reads are still limited in providing reliable identifications of TRAs [24]. KMA was selected over other alignment tools (SRST2, MGmapper etc.) because of its accuracy in aligning short reads against redundant databases. In addition, this method is able to resolve the issue of multiple read matches by evaluating and statistically testing the global alignment scores. Quality-controlled reads were mapped against the ResFinder database using KMA, with $80 \%$ identity threshold for resistance gene identification (see Supplementary Table S1 for detailed information). To reduce the number of false positives, only genes present at significant levels $(P<0.05)$ with a coverage $>50 \%$ were used for further analysis. For co-occurrence analyses, the source (organism) of genes (identified template) was manually searched through their accession ID in NCBI and the Comprehensive Antibiotic Resistance Database (CARD). On the background of this search, genes described in multiple bacterial species or defined by CARD as present in mobile elements were not included in the cooccurrence analysis.

Furthermore, the given depth/abundance of each resistance gene and the classes they belong to were normalised using RPKM (reads per kilobase million mapped reads) for comparison across samples. The abundance profiles are represented in the form of a 
heatmap both for oral and faecal samples. Heatmaps were generated using 'pheatmap' package in R. Likewise, all of the cooccurrence or correlation line plots between the ARGs and potential microbial taxa were created in $\mathrm{R}$.

\section{Results}

\subsection{Sequencing results}

A total of six samples were sequenced and analysed. The samples were collected from two body sites $(\mathrm{O}=$ oral and $\mathrm{F}=$ faecal $)$ and from three different time points (Day $0=\mathrm{d} 0$, Day $5=\mathrm{d} 5$ and Day $30=\mathrm{d} 30$ ). For all six samples, a total of 260 million pairedreads were generated from shotgun metagenomic sequencing. The mean Phred quality score of raw reads across all samples was 37.3. Host DNA contamination was higher in oral compared with faecal samples. On average, $66 \%(28 \mathrm{M})$ and $8 \%(3 \mathrm{M})$ reads were identified as human DNA in oral and faecal samples, respectively. Human DNA was filtered from the sequencing data during analysis as described in Section 2.4.

\subsection{Oral microbiome composition}

On average, $48 \%$ reads in oral samples remained unclassified. The abundance of the remaining taxonomically classified reads are illustrated as a stacked bar chart in Fig. 1. The results suggest that the taxonomic composition of the oral metagenomes following antibiotic treatment varied slightly with respect to genus and species, but less with respect to phylum. All of the oral samples were dominated by Gram-positive bacteria, most of them belonging to the phylum Firmicutes. The baseline (O-d0) sample contained around $67 \%$ Firmicutes, with strong dominance of the genus Streptococcus (64\%). The majority of reads were assigned to Streptococcus mitis (24\%) at species level. In addition, $15 \%, 12 \%$ and $5 \%$ of the reads were also assigned to bacteria from the phyla Proteobacteria, Actinobacteria and Bacteroidetes, respectively. The second most abundant species in the baseline sample was Rothia mucilaginosa (11\%), belonging to the phylum Actinobacteria. The sample taken at Day 5 (O-d5), corresponding to the day of therapy termination, shows a pattern that was slightly different from O-d0. Firmicutes was still the dominating phylum. However, the relative proportion of Proteobacteria was doubled compared with O-d0. Actinobacteria and Bacteroidetes were both reduced in their relative abundance compared with baseline (O-d0). The most abundant species was still S. mitis, but the proportion of some of the Gram-negative species such as Haemophilus parainfluenzae increased from $5 \%$ in O-d0 to $12 \%$ in the 0 -d5-sample. The sample collected 25 days after the end of antibiotic exposure (O-d30) revealed a taxonomic composition that was more similar to O-d0 than O-d5. Whilst the fraction of reads belonging to Proteobacteria was still high as in $\mathrm{O}-\mathrm{d} 5$, the relative proportion of Bacteroidetes was restored to the level shown in O-d0. Within the Proteobacteria, the highest proportion of reads were assigned to the Neisseria and Haemophilus genera. Also, the relative abundance of Neisseria was found to be highest at O-d30 (12\%). Furthermore, the Chao1 (richness) and Shannon (evenness) species diversity measurements decreased drastically at O-d5 compared with O-d0 and increased again at O-d30 (Fig. 2). The statistical significance of such changes could not be measured due to only one child (case) in the study.

\subsection{Faecal microbiome composition}

Large differences in microbiota composition were observed in the faecal samples before antibiotic treatment (F-d0), at the termination of antibiotic treatment (F-d5) and 25 days after antibiotic termination (F-d30) (Fig. 1). The faecal baseline sample (F-d0) was strongly dominated by the phyla Actinobacteria (62\%) and Firmicutes (36\%). However, after 5 days of antibiotic treatment the taxonomic profile showed a shift towards the phylum Proteobacteria completely dominating the sample with a contribution of $>76 \%$ in total reads compared with $<1 \%$ at baseline. A massive increase in abundance of Escherichia coli (49\%) contributed particularly to the high proportion of Proteobacteria. In the F-d0 sample, species belonging to the Firmicutes were mainly from the genus Streptococcus or Anaerostipes. Enterococcus (especially Enterococcus faecalis) was the leading genus in the Firmicutes in the F-d5 sample. In the follow-up sample from Day 30 (F-d30), the relative abundance of Proteobacteria decreased to levels that approached those at baseline, with Actinobacteria again dominating the sample. The Firmicutes showed also a tendency of returning to baseline values, except for Streptococcus thermophilus, whilst the phylum Bacteroidetes, with its most abundant species Bacteroides fragilis (17\%), became a substantial part of the gut microbiome. Interestingly, B. fragilis was not detected in F-d0 or Fd5 samples. Furthermore, a considerably larger portion of unmapped reads was observed for F-d30 than for F-d0 and Fd05. For F-d05, only $10 \%$ of the reads were not mapped to a known reference compared with $58 \%$ for F-d 30 and $40 \%$ for F-d0. Similar to the oral samples, the species richness and evenness in the faecal samples were reduced at F-d5 compared with F-d0 (Fig. 2). Both oral and faecal samples had the highest species diversity at d30.

\subsection{Oral resistome}

For oral metagenomes, seven ARGs were found that were present at all time points, i.e. O-d0, O-d05 and O-d30 (Fig. 3B). At baseline, a total of 11 annotated ARGs were identified. These genes encoded resistance to antibiotics belonging to four different classes, representing three different mechanisms of resistance. The largest group of ARGs at baseline were those conferring resistance to $\beta$-lactams. In total, five different genes belonging to the $\beta$ lactamase group ( bla $_{\mathrm{TEM}-1 \mathrm{~B}}, c f x A 3$, bla $_{\mathrm{OXA}-85}$, bla $_{\mathrm{SPU}-1}$ and penA) were detected before antibiotic treatment started. The TEM-1 enzyme was described already in the early 1960s [25] and is one of the most prevalent $\beta$-lactamase enzymes in Gram-negative bacteria. It is found on transferable genetic elements and is able to inactivate penicillins and narrow-spectrum cephalosporins [26]. In addition to the $\beta$-lactamases, the efflux pump mef(A) conferring resistance to macrolides was detected at $\mathrm{O}-\mathrm{d} 0$, together with $\operatorname{msr}(D)$, which is a macrolide efflux protein expressed on the same operon as mef(A) [27]. The $l s a(C)$ gene confers resistance to lincosamides, streptogramins and pleuromutilins, whilst erm $(F)$ confers resistance to the macrolide-lincosamide-streptogramin $\mathrm{B}\left(\mathrm{MLS}_{\mathrm{B}}\right)$ group. Two genes conferring tetracycline resistance $[\operatorname{tet}(M)$ and tet $(Q)]$ were also detected at O-d0. Most ARGs discovered at O-d0 were also identified at O-d5. Levels of $b l a_{\mathrm{OXA}-85}, \operatorname{ls} a(C)$ and tet( $(\mathrm{Q})$ were similar to $\mathrm{O}-\mathrm{d} 0$, whereas the abundance of $b l a_{\mathrm{TEM}-1 \mathrm{~B}}, c f \times A 3, \operatorname{mef}(\mathrm{A})$ and $m s r$ $(D)$ were increased at $\mathrm{O}-\mathrm{d} 5$. Of the four genes with an increased abundance after 5 days, different responses were observed at Od30: $\operatorname{mef}(A)$ and $\operatorname{msr}(D)$ both decreased in abundance below their baseline level, whilst $c f x A 3$ increased even more at O-d30. bla $a_{\mathrm{TEM}-1 \mathrm{~B}}$ decreased from the high abundance at O-d5, but not to the low levels observed at Day 0. Thus, in oral samples most of the observed changes at O-d5 showed a tendency to return to baseline levels at O-d30 (Fig. 3B).

\subsection{Faecal resistome}

In the faecal samples, in total 25 different ARGs were detected. At baseline, seven different ARGs were identified, conferring resistance to four different antibiotic classes (Fig. 3A). ant(6)-Ia 
A Phylum Composition

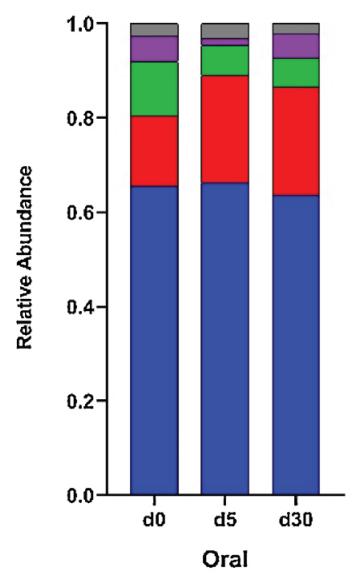

C

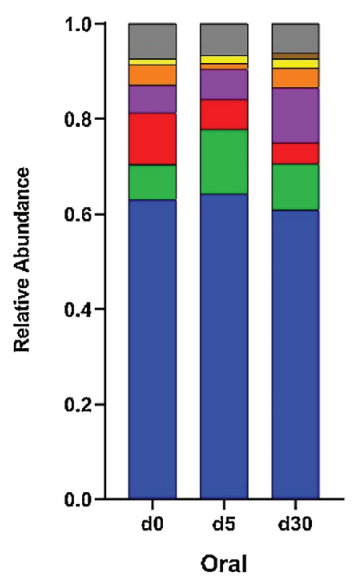

E

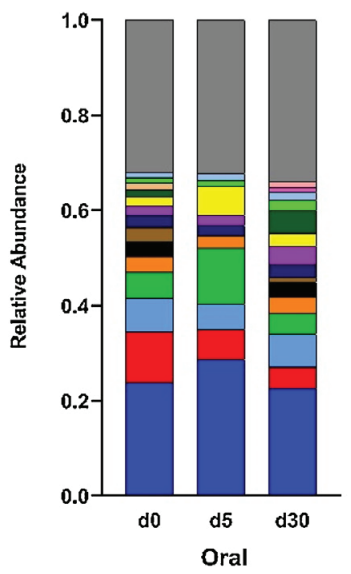

B

$$
\begin{aligned}
& \square \text { Firmicutes } \\
& \square \text { Proteobacteria } \\
& \square \text { Actinobacteria } \\
& \square \text { Bacteroidetes } \\
& \square \text { Others }
\end{aligned}
$$

Streptococcus

$\square$ Rothia

$\square$ Haemophilus

- Neisseria

$\square$ Prevotella

$\square$ Veillonella

$\square$ Actinomyces

$\square$ Others

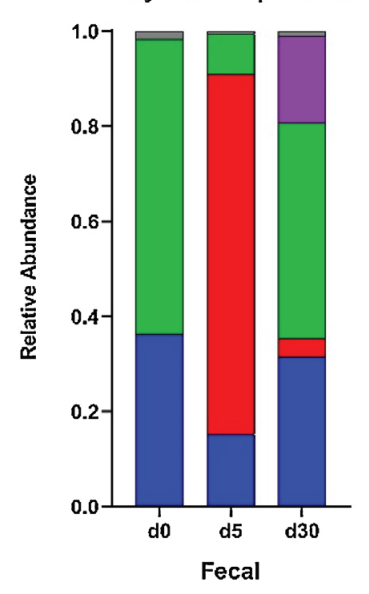

D Genus Composition

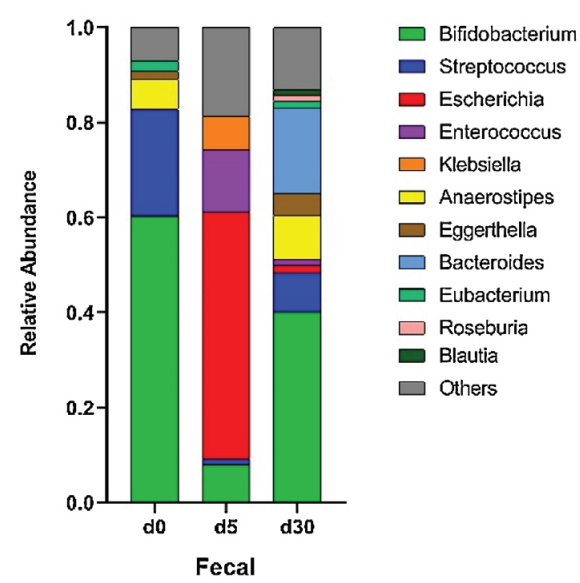

F

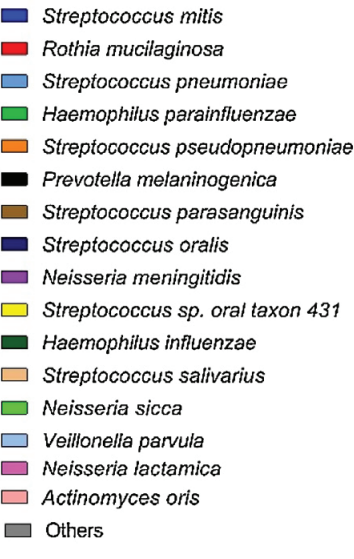

\section{Species Composition}

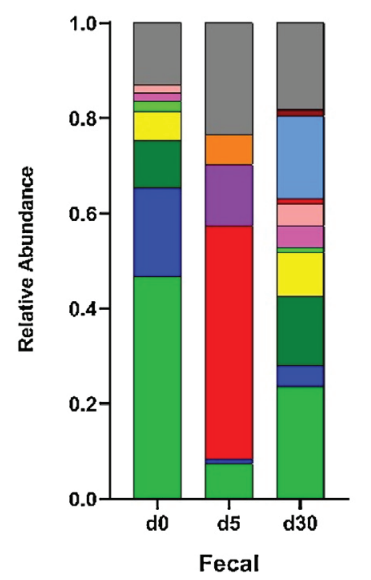

$$
\begin{aligned}
& \square \text { Firmicutes } \\
& \square \text { Proteobacteria } \\
& \square \text { Actinobacteria } \\
& \square \text { Bacteroidetes } \\
& \square \text { Others }
\end{aligned}
$$

$$
\begin{aligned}
& \square \text { Bifidobacterium longum } \\
& \square \text { Streptococcus thermophitus } \\
& \square \text { Bifidobacterium bifidum } \\
& \square \text { Anaerostipes hadrus } \\
& \square \text { Eubacterium halii } \\
& \square \text { Streptococcus salivarius } \\
& \square \text { Eggerthella lenta } \\
& \square \text { Escherichia coli } \\
& \square \text { Enterococcus faecalis } \\
& \square \text { Klebsiella oxytoca } \\
& \square \text { Bacteroides fragilis } \\
& \square \text { Roseburia hominis } \\
& \square \text { Others }
\end{aligned}
$$

Fig. 1. Taxonomic profile of the oral (left) and faecal (right) metagenomes. Relative abundance of taxa from three time points, namely baseline (d0), immediately after treatment completion at Day 5 (d5) and 25 days post-antibiotic treatment (d30), presented at phylum (top), genus (middle) and species (bottom) levels. Those found at $<1 \%$ are grouped as 'Others'. 

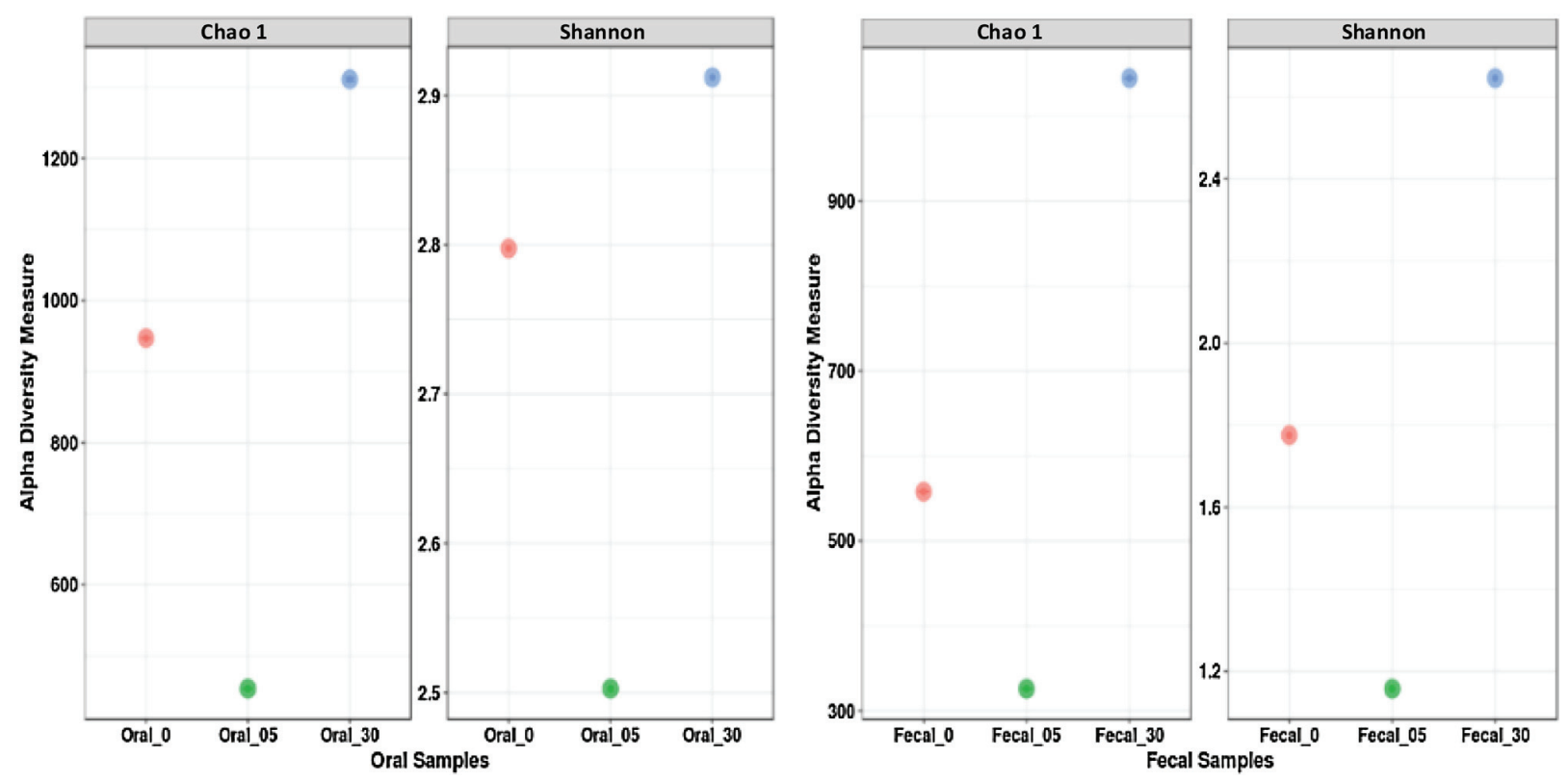

Fig. 2. Alpha diversity measured by Chao1 (richness) and Shannon (evenness) diversity indexes plotted for oral and faecal samples at three time points, namely baseline (0), immediately after treatment completion at Day 5 (05) and 25 days post-antibiotic treatment (30). Both oral and faecal samples have been rarefied to even sequencing depth for diversity estimation.

confers aminoglycoside resistance, mef(A) encodes a macrolide efflux pump, $\operatorname{msr}(D)$ is associated with resistance to the $\mathrm{MLS}_{\mathrm{B}}$ group, and $\operatorname{tet}(M)$, tet $(W)$, tet $(O)$ and tet(32) encode ribosomal protection proteins preventing damage from tetracyclines. Only one of these genes $[$ tet $(M)]$ was identified again after 5 days (F-d5), thus showing a shift in the faecal resistome at Day 5 . The abundance of tet $(M)$ was increased at F-d5 compared with the baseline sample. In addition to tet(M), four ARGs not present at baseline were identified at F-d5. One $\beta$-lactamase $\left(\right.$ bla $\left._{\mathrm{OXY}-2}\right)$, a fosfomycin resistance gene (fos $A$ ), and two efflux pumps [ $l s a(A)$ and oq $x B$ ] conferring resistance to macrolides and fluoroquinolones, respectively. In the last sample, 21 ARGs were identified in total, showing a considerably increase from the first two faecal samples. At F-d30, ARGs from seven different antibiotic classes were identified, including genes encoding resistance to vancomycin that were not detected at F-d0 or F-d5. tet( $M$ ) was the only gene detected at all timepoints, with its highest abundance at F-d5. Interestingly, 14 ARGs were solely identified at F-d30, 25 days after the last antibiotic exposure. Hence, the faecal resistome showed an extensive shift in composition and increase in diversity following antibiotic treatment (Fig. 3A).

\subsection{Relationship between the resistome and microbiome}

Some of the observed ARGs, such as $b l a_{\mathrm{BRO}-1}, b l a_{\mathrm{OXA}-85}$ and penA in oral samples, and $b l a_{\mathrm{OXY}-2-7}$ and the van genes in faecal samples, are found intrinsically in specific species. Others, such as bla $a_{\mathrm{TEM}-1}$, tet genes and most erm genes, are found either intrinsically in several bacteria or on mobile DNA elements. A correlation analysis was performed between intrinsic resistance genes and the bacterial species in which the resistance genes have been identified. For this, their abundances (co-occurrence) were plotted across the three different time points in oral and faecal samples (Fig. 4). In the oral samples, the rise in abundance of bla $a_{\mathrm{BRO}-1}$, a resistance gene found in the chromosome of Moraxella catarrhalis, correlated with the increase in M. catarrhalis abundance on Day 5. The same is true for $b l a_{\mathrm{OXY}-2-7}$ and the van genes that are intrinsic to Klebsiella oxytoca and Enterococcus casseliflavus, respectively.
Enterococcus casseliflavus is known to harbour intrinsic, nontransferable resistance to vancomycin owing to a chromosomally encoded vanC gene cluster $[28,29]$. All five vancomycin resistance genes found in this study are gene variants found in this cluster. Enterococcus casseliflavus is not as well described as E. faecalis and Enterococcus faecium, however it can cause serious infections and, due to its high level of intrinsic resistance to several antibiotics, it is a difficult bacteria to treat [30].

Not all genes followed the expected source of origin. The resistance genes penA and $b l a_{\mathrm{OXA}-85}$ (also named $b l a_{\mathrm{FUS}-1}$ ), which usually are found in Neisseria meningitidis and Fusobacterium nucleatum, respectively, did not follow the abundance profile of their expected host, suggesting that these genes may also be intrinsic in other bacteria or that the genes can be found on mobile elements. For genes that are found intrinsically in several bacteria or on mobile DNA elements, it is not possible to correlate them with bacterial species with the methods applied in this study.

\section{Discussion}

Young children are frequent users of antibiotics. Antibiotic use in Scandinavian countries is still lower than in many other European countries and the low usage most likely contributes to the low prevalence of antibiotic resistance that is observed [31]. Penicillin V is recommended in Norwegian treatment guidelines as a first-line drug for empirical treatment of otitis media [6].

In this study, a sequence-based metagenomic approach was used to elucidate the impact of penicillin $\mathrm{V}$ on the oral and faecal microbiome and resistome of a child living in Norway. Supporting previous findings [10], the results of the current study showed that the oral microbiota was more resilient to the effects of antibiotics than the faecal microbiota. However, previous observations have generally been done with broader-spectrum antibiotics, in healthy adults, and not in young children with an infection such as in the present study.

Microbial diversity both in oral and faecal samples decreased after 5 days of treatment. After 30 days there was a tendency for higher diversity than at baseline. This is an observation that is in line with recent results showing that in children the faecal 
A

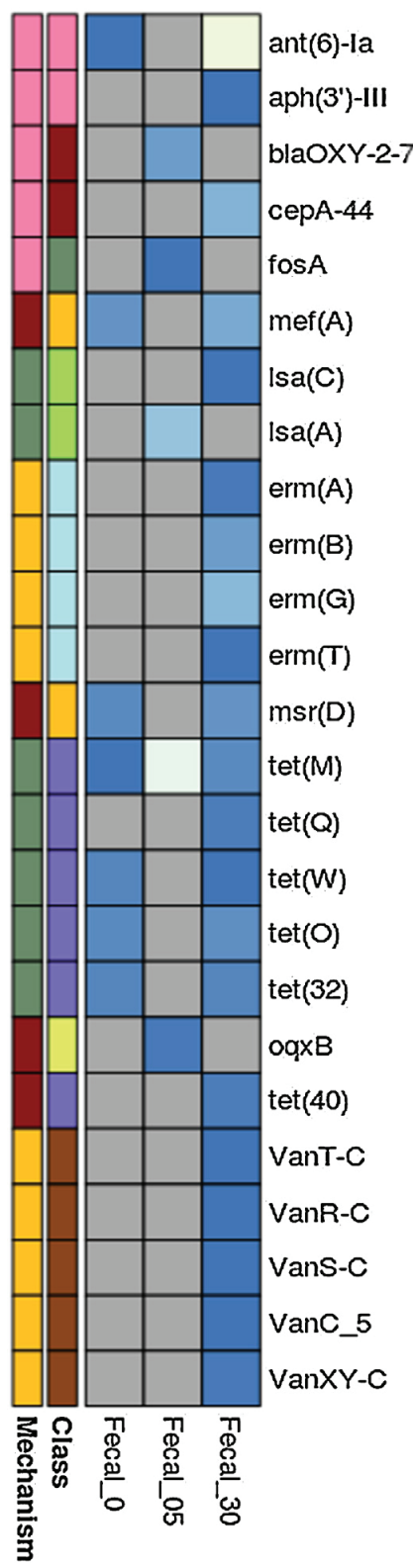

B

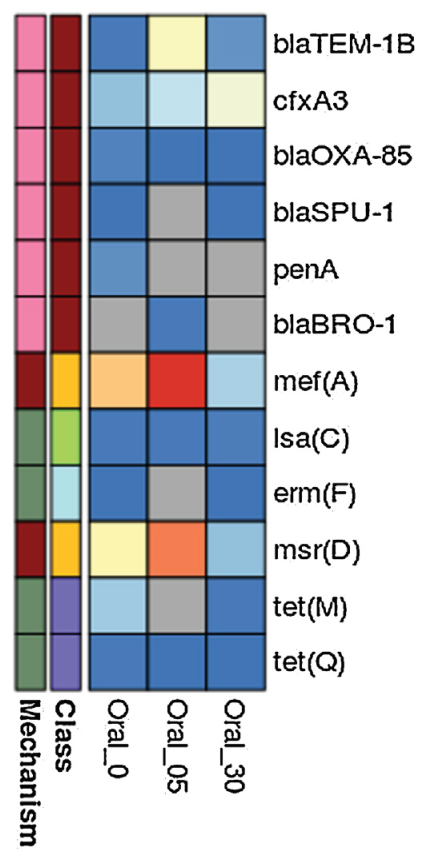

7 Mechanism

6

5

Antibiotic inactivation

Antibiotic efflux

Antibiotic target protection

4

Antibiotic target alteration

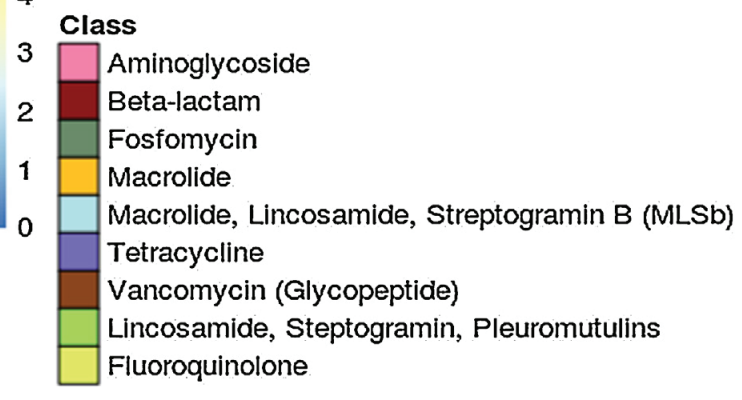

Fig. 3. Antimicrobial resistance genes (ARGs) identified in (A) faecal and (B) oral samples. Heatmap showing distribution of ARGs detected within the metagenomic samples at three time points, namely baseline (0), immediately after treatment completion at Day $5(05)$ and 25 days post-antibiotic treatment (30). Genes are grouped by antibiotic class and mechanism of action. Colours shown in the legend (right) indicated the abundance of ARGs scaled from 'blue' (minimum) to 'red' (maximum). The scale $0-7$ are normalised levels for the abundance of genes based on sequencing depth and gene length as determined by RPKM (reads per kilobase million mapped reads). Genes that have not been detected or have been excluded based on cut-off criteria are coloured grey.

microbial diversity continues to increase until it stabilises at around 3 years of age independent of antibiotic use [32]. Hence, the increase in diversity at Day 30 compared with baseline is not necessarily a result of antibiotic exposure.

The taxonomic profile of the oral microbiota at the three different time points was relatively stable despite the fact that penicillin $\mathrm{V}$ has antimicrobial activity against Gram-positive bacteria, which predominate in the oral cavity. In contrast, the taxonomic alterations observed in the faecal samples were prominent, especially at Day 5 . In the faecal baseline sample, Bifidobacterium spp. predominated. After 5 days of treatment the potentially pathogenic Enterobacteriaceae were the dominating family and the abundance of Bifidobacterium spp. was reduced. This is likely an undesirable outcome, since high levels of Bifidobacterium are associated with several health benefits [33], including reduced levels of antimicrobial resistance in early life [34]. Conversely, the Enterobacteriaceae are a group of bacteria known to harbour high levels of ARGs and they have been assigned the highest priority by the World Health Organization (WHO) in the fight against antibiotic-resistant bacteria [35]. The observed reduction of Bifidobacteriaceae and the increase in Enterobacteriaceae during penicillin $\mathrm{V}$ treatment supports previous studies investigating the effect of other $\beta$-lactams of broader spectrum on the faecal microbiome [36,37]. 

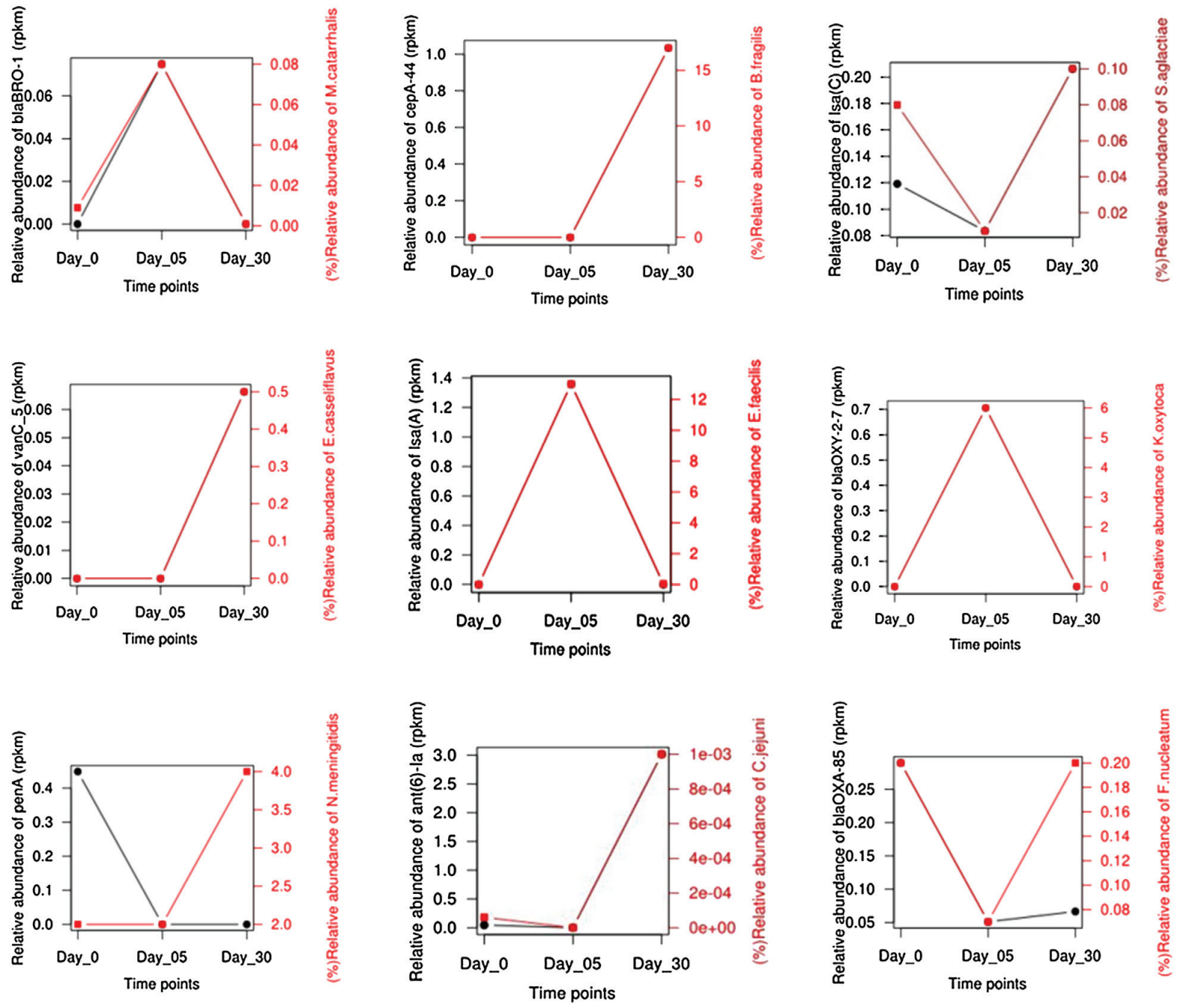

Fig. 4. Line plots showing the abundance of antimicrobial resistance genes (ARGs) (reads per kilobase million mapped reads) in the oral and faecal metagenome samples (black), together with the relative abundance of selected species potentially carrying the ARGs (based on annotation by KMA) (red).

Five ARGs [mef(A), lsa(C), $\operatorname{msr}(D)$, tetM and tet(Q)] were observed both in the oral and faecal microbiome. Four of these $[m e f(A), \operatorname{msr}(D)$, tetM and tet( $Q)]$ can be found in several bacteria on mobile elements and are therefore of particular significance for spreading via horizontal gene transfer [38]. The impact of penicillin $\mathrm{V}$ on the resistome was greater in faecal samples than in oral samples. Whilst in the oral samples the 10 ARGs detected at O-d30 were also observed at baseline (Fig. 3B), in the faecalsamples 14 genes were observed that were exclusive to $\mathrm{d} 30$ samples (Fig. 3A). Interestingly, only one of the faecal ARGs identified at Day 30 conferred resistance to $\beta$-lactam antibiotics, which was used to treat the patient. ARGs conferring resistance to $\beta$ lactam antibiotics were also observed in oral samples, but these were not enriched following antibiotic therapy. The extensive impact on the faecal resistome at Day 30 compared with the modest effects on the oral sample might be explained by a larger taxonomic shift in the faecal samples. Newly appeared taxa or taxa with higher abundance at the last time point, such as Clostridium spp., B. fragilis and E. casseliflavus (Supplementary Table S2), may be contributing to new genes such as ant(6)-la and aph $\left(3^{\prime}\right)-I I I$, cepA-44 and the van genes, respectively, in the resistome. Also, some of the enriched ARGs are known to cluster together, such as $m e f(A)$ and $m \operatorname{sr}(D)$, and will consequently be co- selected. However, the large difference in the resistome of the faecal samples may also be a result of higher antibiotic selection pressure and horizontal gene transfer within the already existing microbiota [39].

Although definitive conclusions require a larger and ideally randomised study, this case report indicates that even narrow-spectrum antibiotics may have a significant effect on the faecal microbiome and resistome, thus warranting further investigations. Overall, acute and recurrent otitis media is among the most predominant conditions associated with antibiotic prescription and thus studies on these patients should be encouraged.

\section{Data availability}

The metagenome sequences generated in this work were deposited in the European Nucleotide Archive (ENA) (https:// www.ebi.ac.uk/ena) under accession no. PRJEB31957.

\section{Funding}

This work was partly funded by the Dental Faculty, University of Oslo (Oslo, Norway) and theNorwegian Institute of Public Health 
(Oslo, Norway). AD is supported by a PhD grant from the Research Council of Norway [grant no. 421258].

\section{Competing interests}

None declared.

\section{Ethical approval}

This study was approved by the Regional Committee for Medical and Health Research Ethics [2014/1946/REK sør-øst C]. Written informed consent was obtained from the participating child's parents.

\section{Acknowledgments}

The authors thank the Accident \& Emergency Department at Bærum Hospital (Gjettum, Norway) for contributions in sample collection. The sequencing service was provided by the Norwegian Sequencing Centre (Oslo, Norway) (www.sequencing.uio.no).

\section{Appendix A. Supplementary data}

Supplementary material related to this article can be found, in the online version, at doi:https://doi.org/10.1016/j.jgar.2019.08.004.

\section{References}

[1] Davies SC. Annual report of the Chief Medical Officer. Volume 2, 2011. Infections and the rise of antimicrobial resistance. London, UK: Department of Health; 2013

[2] Holstiege J, Schink T, Molokhia M, Mazzaglia G, Innocenti F, Oteri A, et al. Systemic antibiotic prescribing to paediatric outpatients in 5 European countries: a population-based cohort study. BMC Pediatr 2014;14:174.

[3] Størdal K, Mårild K, Blix HS. Use of antibiotics in children during the period 2005-16. Tidsskr Nor Laegeforen 2017;137:, doi:http://dx.doi.org/10.4045/ tidsskr.17.0272 [in Norwegian].

[4] Hersh AL, Shapiro DJ, Pavia AT, Shah SS. Antibiotic prescribing in ambulatory pediatrics in the United States. Pediatrics 2011;128:1053-61.

[5] Treatment for acute inflammation of the middle ear in children. Stockholm, Sweden: Swedish Medical Research Council; 2000. . . [Accessed 15 March 2019] http://strama.se/wp-content/uploads/2016/04/Konsensut_ora_eng.pdf.

[6] Akutt otitis media. Nasjonal faglig retningslinje for antibiotikabruk i primærhelsetjenesten [Acute otitis media. National academic guideline for antibiotic use in primary health care]. http://www.antibiotikaiallmennpraksis. no/index.php?action=showtopic\&topic=VMpmsqDE. [Accessed 14 March 2019].

[7] Solen MG, Hermansson A. Otitis media-from self-healing to life-threatening. New therapeutic guidelines. Lakartidningen 2011;108:1049-52 [in Swedish].

[8] Dethlefsen L, Huse S, Sogin ML, Relman DA. The pervasive effects of an antibiotic on the human gut microbiota, as revealed by deep 16S rRNA sequencing. PLoS Biol 2008:6:e280.

[9] Panda S, El Khader I, Casellas F, López Vivancos J, García Cors M, Santiago A, et al. Short-term effect of antibiotics on human gut microbiota. PLoS One 2014;9:e95476

[10] Zaura E, Brandt BW, Teixeira de Mattos MJ, Buijs MJ, Caspers MP, Rashid MU, et al. Same exposure but two radically different responses to antibiotics: resilience of the salivary microbiome versus long-term microbial shifts in feces. mBio 2015;6: e01693-01615.

[11] Round JL, Mazmanian SK. The gut microbiota shapes intestinal immune responses during health and disease. Nat Rev Immunol 2009;9:313-23.

[12] Wright GD. The antibiotic resistome: the nexus of chemical and genetic diversity. Nat Rev Microbiol 2007:5:175-86.

[13] Penders J, Stobberingh EE, Savelkoul PH, Wolffs PF. The human microbiome as a reservoir of antimicrobial resistance. Front Microbiol 2013;4:87.
[14] Willmann M, El-Hadidi M, Huson DH, Schütz M, Weidenmaier C, Autenrieth IB, et al. Antibiotic selection pressure determination through sequence-based metagenomics. Antimicrob Agents Chemother 2015;59:7335-45.

[15] Jernberg C, Löfmark S, Edlund C, Jansson JK. Long-term ecological impacts of antibiotic administration on the human intestinal microbiota. ISME J 2007:1:56-66.

[16] Manual of procedures for Human Microbiome Project. Core microbiome sampling protocol A. HMP Protocol \# 07-001. 2010 Version number: 12.0. https://hmpdacc.org/hmp/doc/HMP_MOP_Version12_0_072910.pdf. [Accessed 15 March 2019].

[17] Andrews S. FastQC: a quality control tool for high throughput sequence data. Babraham Bioinformatics; 2010. http://www.bioinformatics.babraham.ac.uk/ projects/fastqc.

[18] Bolger AM, Lohse M, Usadel B. Trimmomatic: a flexible trimmer for Illumina sequence data. Bioinformatics 2014;30:2114-20.

[19] Langmead B, Salzberg SL. Fast gapped-read alignment with Bowtie 2. Nat Methods 2012;9:357-9.

[20] Wood DE, Salzberg SL. Kraken: ultrafast metagenomic sequence classification using exact alignments. Genome Biol 2014;15:R46.

[21] Lu J, Breitwieser FP, Thielen P, Salzberg SL. Bracken: estimating species abundance in metagenomics data. PeerJ Comput Sci 2017;3:e104.

[22] Clausen PT, Aarestrup FM, Lund O. Rapid and precise alignment of raw reads against redundant databases with KMA. BMC Bioinformatics 2018;19:307.

[23] Zankari E, Hasman H, Cosentino S, Vestergaard M, Rasmussen S, Lund O, et al. Identification of acquired antimicrobial resistance genes. J Antimicrob Chemother 2012;67:2640-4.

[24] Willmann M, Peter S. Translational metagenomics and the human resistome: confronting the menace of the new millennium.J Mol Med (Berl) 2017;95:41-51.

[25] Datta N, Kontomichalou P. Penicillinase synthesis controlled by infectious R factors in Enterobacteriaceae. Nature 1965;208:239-41.

[26] Salverda ML, De Visser JA, Barlow M. Natural evolution of TEM-1 $\beta$-lactamase: experimental reconstruction and clinical relevance. FEMS Microbiol Rev 2010;34:1015-36.

[27] Ambrose KD, Nisbet R, Stephens DS. Macrolide efflux in Streptococcus pneumoniae is mediated by a dual efflux pump (mel and mef) and is erythromycin inducible. Antimicrob Agents Chemother 2005;49:4203-9.

[28] Hegstad K, Mikalsen T, Coque TM, Werner G, Sundsfjord A. Mobile genetic elements and their contribution to the emergence of antimicrobial resistant Enterococcus faecalis and Enterococcus faecium. Clin Microbiol Infect 2010; 16:541-54.

[29] Vincent S, Minkler P, Bincziewski B, Etter L, Shlaes DM. Vancomycin resistance in Enterococcus gallinarum. Antimicrob Agents Chemother 1992:36:1392-9.

[30] Monticelli J, Knezevich A, Luzzati R, Di Bella S. Clinical management of nonfaecium non-faecalis vancomycin-resistant enterococci infection. Focus on Enterococcus gallinarum and Enterococcus casseliflavus/flavescens. J Infect Chemother 2018;24:237-46.

[31] Goossens H, Ferech M, Vander Stichele R, Elseviers M, ESAC Project Group. Outpatient antibiotic use in Europe and association with resistance: a crossnational database study. Lancet 2005;365:579-87.

[32] Yassour M, Vatanen T, Siljander H, Hämäläinen AM, Härkönen T, Ryhänen SJ, et al. Natural history of the infant gut microbiome and impact of antibiotic treatment on bacterial strain diversity and stability. Sci Transl Med 2016;8:343ra381.

[33] Hidalgo-Cantabrana C, Delgado S, Ruiz L, Ruas-Madiedo P, Sanchez B, Margolles A. Bifidobacteria and their health-promoting effects. Microbiol Spectr 2017;5:, doi:http://dx.doi.org/10.1128/microbiolspec.BAD-0010-2016.

[34] Taft DH, Liu J, Maldonado-Gomez MX, Akre S, Huda MN, Ahmad SM, et al. Bifidobacterial dominance of the gut in early life and acquisition of antimicrobial resistance. mSphere 2018;3: pii: e00441-18.

[35] World Health Organization (WHO). Global priority list of antibiotic-resistant bacteria to guide research, discovery, and development of new antibiotics. Geneva, Switzerland: WHO; 2017.

[36] Tanaka S, Kobayashi T, Songjinda P, Tateyama A, Tsubouchi M, Kiyohara C, et al. Influence of antibiotic exposure in the early postnatal period on the development of intestinal microbiota. FEMS Immunol Med Microbiol 2009;56:80-7.

[37] Arboleya S, Sánchez B, Milani C, Duranti S, Solís G, Fernández N, et al. Intestinal microbiota development in preterm neonates and effect of perinatal antibiotics. J Pediatr 2015; 166:538-44.

[38] Partridge SR, Kwong SM, Firth N, Jensen SO. Mobile genetic elements associated with antimicrobial resistance. Clin Microbiol Rev 2018;31: pii: e00088-17.

[39] Davies J, Davies D. Origins and evolution of antibiotic resistance. Microbiol Mol Biol Rev 2010;74:417-33. 